AVICELM

Instituto de Astronomia, Geofísica e Ciências Atmosféricas Universidade de São Paulo

\title{
ESTUDO DE ANOMALIAS GRAVIMÉTRICAS E AEROMAGNÉTICAS DAS ALCALINAS MORRO DE ENGENHO E A2, SUDOESTE DE GOIÁS.
}

ALANNA COSTA DUTRA

Orientadora: Dra. Yára Regina Marangoni

SÃO PAULO - SP 
Estudo das Anomalias gravimétricas e magnéticas das alcalinas Morro de Engenho e A2, sudoeste de Goiás.

\author{
por \\ Alanna Costa Dutra
}

Orientadora: Dra. Yára Regina Marangoni

DISSERTAÇÃO DE MESTRADO

MESTRE EM CIÊNCIAS

EM

GEOFÍSICA

Instituto de Astronomia, Geofísica e Ciências Atmosféricas - IAG Universidade DE SÃo PAUlo - USP 
Dutra, Alanna Costa,

Estudo das Anomalias gravimétricas e magnéticas das alcalinas Morro de Engenho e A2, sudoeste de Goiás. / Alanna Costa Dutra. - São Paulo, .

73 p. il.

Dissertação (Mestrado) - Pós-Graduação em Geofísica. Instituto de Astronomia, Geofísica e Ciências Atmosféricas da Universidade de São Paulo, .

Gravimetria, Magnetometria, Modelamento Conjunto e Inversão. 
Para Isis, Ítalo e Wanderson. 


\section{Agradecimentos}

Ao corpo docente, técnico e administrativo do Programa de Pós-Graduação em Geofísica do IAG/USP, pela oportunidade da realização deste trabalho.

À Fapesp pela concessão da bolsa de mestrado n. 04/01662-8 e auxílio pesquisa a Y.R.M., n. 03/05088-1.

À minha orientadora, Yára Regina Marangoni pela orientação responsável e pela atenção durante a condução dessa pesquisa.

Aos professores do Departamento de Geofísica (IAG/USP) Carlos Alberto Mendonça e Ricardo I. F. de Trindade pelas sugestões propostas no decorrer do trabalho.

À empresa Teckcominco e aos seus geólogos Guilherme S. Canha e Paulo I. Brito pela coleta de amostras.

Ao técnico Clarino do Divino Vieira pelo apoio nos trabalhos de campo.

Aos colegas da Pós-Graduação em Geofísica do IAG, especialmente ao Dionísio U. Carlos e Marcelo B. Bianchi pelas informações sugeridas.

Aos colegas Manuelle G. S. Paixão, Ana Nicolaça, Lucieth C. Vieira, Selma Rodrigues, Deborah V. de Souza, Elizete M. A. da Silva, Sarah Freitas, Soraya I. L. Tuma, Danillo S. de Oliveira, Eduardo R. V. Rocha Jr., Marcelo S. T. Santos e Everton P. Bomfim pela 
companhia e amizade.

À minha família, em especial aos meus filhos Isis e Ítalo, pela cumplicidade, compreensão e incentivo constante.

Ao meu companheiro, Wanderson Muniz Santana, pelo carinho e dedicação. 


\section{Resumo}

A Província Alcalina Rio Verde - Iporá, na borda norte da Bacia do Paraná é caracterizada pela presença de intrusões alcalinas com forte assinatura aeromagnética e gravimétrica, apresentando-se como anomalias quase circulares. O trabalho refinou o levantamento gravimétrico na região sudoeste de Goiás, incluindo um levantamento de detalhe sobre as intrusões de Morro do Engenho (ME) e uma intrusão a poucos quilômetros a NE de Morro de Engenho (A2), com informações gravimétricas e aeromagnéticas, e sobre a anomalia gravimétrica próxima à cidade de Britânia, sem informação de anomalia aeromagnética. As anomalias gravimétricas variam de 15 a 30 mGal com relação ao campo gravimétrico regional, enquanto que as anomalias aeromagnéticas são da ordem de \pm 3000 nT. Foram feitas também medidas das propriedades petrofísicas de amostras da área. Os resultados da inversão 2D e 3D dos dados gravimétricos e 3D dos dados magnéticos indicam que os corpos alongam-se dentro da crosta superior até a profundidade máxima de $10 \mathrm{~km}$ e diâmetro da ordem de $8 \mathrm{~km}$, com geometria aproximadamente cilíndrica. Os dados gravimétricos e aeromagnéticos de ME foram tratados de forma conjunta por modelamento direto $(2,5 \mathrm{D})$ onde foi incluída a magnetização remanescente, os resultados obtidos indicam que o volume do corpo anômalo é da ordem de 980 km³. 


\section{Abstract}

The Alkaline Province Rio Verde - Iporá, in the north border of the Paraná Basin is characterized by the presence of alkaline intrusions with strong gravity and magnetic signature. This project implemented a gravity survey in the Southwest of Goiás, including a detail one on Morro do Engenho Complex (ME), and one a few kilometers towards NE from ME over an aeromagnetic anomaly known as A2, and over a gravity anomaly close to Britânia city. ME and A2 have magnetic anomaly. The gravity anomalies vary from 15 to $30 \mathrm{mGal}$ in relation to the regional gravity field, while the magnetic anomalies are of the order \pm 3000 nT. Measurements of petrophysical properties of samples from the area were also done. The results present the inversion of the gravity and magnetic data, suggesting that the bodies are inside of the superior crust until the maximum depth of $10 \mathrm{~km}$, in a cylindrical form with 8 to $10 \mathrm{~km}$ in diameter. 2.5D direct modeling was also done for $\mathrm{ME}$ including remanent magnetization and was performed at the two data sets together, the obtained results indicate that the close volume of the anomalous body it's $980 \mathrm{~km}^{3}$. 


\section{Índice}

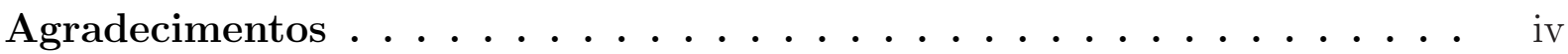

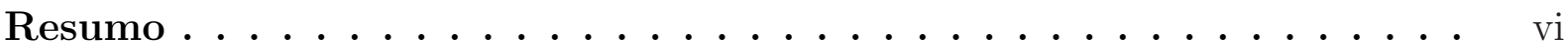

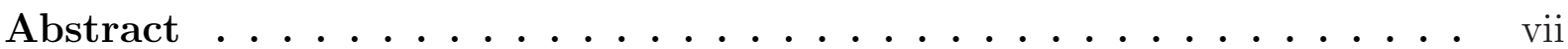

Índice ......................... $\ldots \ldots$ viii

Índice de Tabelas $\ldots \ldots \ldots \ldots \ldots$

Índice de Figuras .................... xi

Introdução . . . . . . . . . . . . . . . . . . . 1

1 GEOLOGIA DA ÁREA DE ESTUDO . . . . . . . . . . 4

2 INFORMAÇÕES GEOFÍSICAS E PETROFÍSICAS . . . . . . . . 10

2.1 Dados gravimétricos . . . . . . . . . . . . . . . . . . . . . 11

2.1.1 Mapa de anomalia Bouguer . . . . . . . . . . . . . . . . . . . . 14

2.1.2 Separação regional-residual . . . . . . . . . . . . . . . . 16

2.2 Dados magnéticos . . . . . . . . . . . . . . . . . . . . . . 21

2.2.1 Tratamento dos dados . . . . . . . . . . . . . . . 23

2.2.2 Estimativa da profundidade . . . . . . . . . . . . . . 27

2.3 Propriedades físicas das amostras . . . . . . . . . . . . . . . . . 30 
2.3.1 Magnetização remanescente . . . . . . . . . . . . . . . . . . . 33

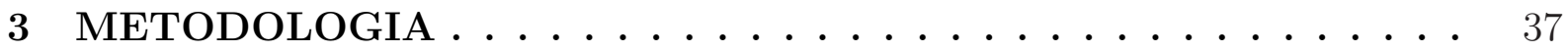

3.1 Modelamento direto $2,5 \mathrm{D} \ldots \ldots \ldots \ldots$

3.2 Inversão dos dados gravimétricos e magnéticos . . . . . . . . . . . . . . . . 42

3.2.1 Aplicação da teoria de inversão 2D aos dados gravimétricos . . . . . 44

3.2.2 Aplicação da teoria de inversão 3D aos dados gravimétricos e magnéticos 45

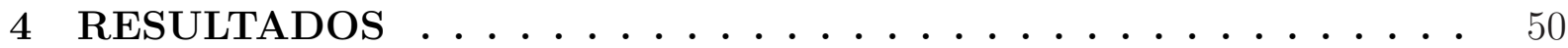

4.1 Modelamento direto 2,5D para dados gravimétricos e magnéticos . . . . . . 51

4.2 Inversão dos dados gravimétricos e magnéticos . . . . . . . . . . . 53

4.2.1 Inversão 2D: dados gravimétricos das alcalinas ME e A2 . . . . . . 54

4.2.2 Inversão 3D: dados gravimétricos e magnéticos das alcalinas ME e $\mathrm{A} 2 \ldots \ldots \ldots \ldots \ldots \ldots \ldots \ldots \ldots$

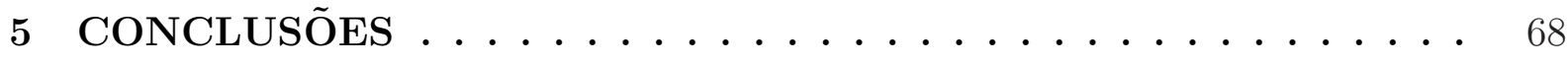

6 REFERÊNCIAS BIBLIOGRÁFICAS . . . . . . . . . 70 


\section{Índice de Tabelas}

1.1 Principais depósitos de níquel no oeste do Estado de Goiás* . . . . . . . . . 9

2.1 Localização das amostras e descrição litológica. . . . . . . . . . . . . . . 30

2.2 Medidas de magnetização remanescente e razão de Konigsberger. . . . . . . 35 


\section{Índice de Figuras}

1.1 Mapa da Província Alcalina de Goiás (PAGO) (modificado de JunqueiraBrod et al., 2002). . . . . . . . . . . . . . 5

1.2 Foto do Complexo Morro de Engenho $(\mathrm{ME}) \ldots \ldots \ldots$

1.3 Esboço geológico regional, modificado de Radaelli (2000). . . . . . . . . . . 7

2.1 Mapa da altitude com localização das estações gravimétricas obtidas em 2004,2005 e anteriores. . . . . . . . . . . . . . . . . 12

2.2 Mapa de anomalia Bouguer com as estações gravimétricas e perfis AA', BB' e PP' para separação regional-residual. Os símbolos em azul representam as cidades. . . . . . . . . . . . . . . . . . . . 15

2.3 Mapa de anomalia Bouguer residual (imagem colorida) e mapa regional (isolinhas tracejada vermelhas). Os residuais obtidos por: (a) remoção do polinômio de grau 1; (b) remoção do polinômio de grau 2; (c) remoção do

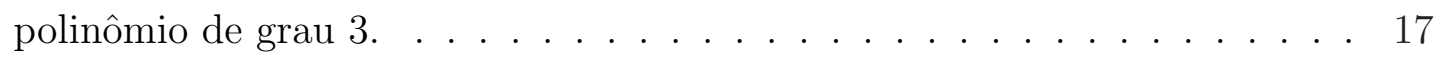

2.4 Perfil AA' para escolha do campo regional analisando os resultados obtidos pela regressão polinômial de grau 1,2 e $3 . \quad \ldots \ldots$. . . . . . . . . 18

2.5 Perfil BB' para escolha do campo regional analisando os resultados obtidos

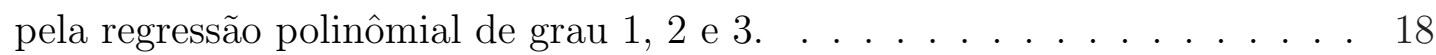

2.6 Perfil PP' para escolha do campo regional analisando os resultados obtidos pela regressão polinômial de grau 1,2 e $3 . \quad$. . . . . . . . . . . . . . . 19 
2.7 Mapa de anomlia Bouguer residual obtido pela remoção de um polinômio de grau 1. . . . . . . . . . . . . . . . . . . . . 20

2.8 Mapa de campo magnético total. . . . . . . . . . . . . . . . . . 21

2.9 Mapa de campo magnético residual. . . . . . . . . . . . . . . . . 22

2.10 Mapa de amplitude do sinal analítico dos dados aeromagnético. O símbolo $\triangle$ representa o local onde ME aflora e + a localização inferida para A2. . . 25

2.11 Mapa aeromagnético de amplitude do sinal analítico continuado a $2000 \mathrm{~m}$. O símbolo $\triangle$ representa o local onde $\mathrm{ME}$ aflora e + a localização inferida

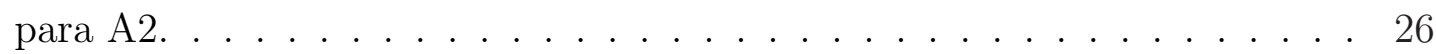

2.12 Curva de amplitude do sinal analítico para A2 . . . . . . . . . . 27

2.13 Histograma das soluções de profundidade para toda a região de Iporá. . 29

2.14 Histograma das soluções de profundidade para região de ME e A2 . . . . . 29

2.15 Densidade média * e desvio padrão (barra vertical) de cada amostra. . . . 32

2.16 Susceptibilidade média * e desvio padrão (barra vertical) de cada amostra. 33

3.1 Perfis do campo magnético total e anomalia magnética residual: (a) Perfil magnético $D^{\prime} D$ e (b) Perfil magnético E'E. . . . . . . . . . . . . 39

3.2 Elemento geométrico envolvido na atração gravitacional de um polígono de $n$ lados (modificado de Talwani et al., 1959). . . . . . . . . . . . . . . . 40

3.3 Elemento geométrico representando a aproximação de um corpo bi-dimensional por um polígono de $n$ lados (modificado de Blakely, 1996). . . . . . . . . . 41

4.1 Esquema do modelo geológico para ME. . . . . . . . . . . . . . . 52

4.2 Modelo dos sinais gravimétricos e magnéticos para o perfil E’E do complexo

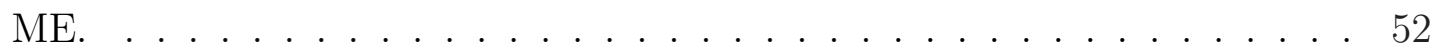


4.3 Perfil AA' da figura 2.2. Inversão com vínculo de compacidade e informação geológica do corpo. Limites do contraste de densidade em cada prisma: $\Delta \rho_{\min }=0,0 \mathrm{~g} / \mathrm{cm}^{3}$ e $\Delta \rho_{\max }=0,27 \mathrm{~g} / \mathrm{cm}^{3}$. A legenda indica o valor percentual do limite máximo que foi atingido em cada célula. . . . . . . . . . 55

4.4 Perfil AA' da figura 2.2. Inversão com vínculo de compacidade e informação geológica do corpo. Limites do contraste de densidade (\%) em cada prisma: $\Delta \rho_{\min }=0,0 \mathrm{~g} / \mathrm{cm}^{3}$ e $\Delta \rho_{\max }=0,31 \mathrm{~g} / \mathrm{cm}^{3}$. A legenda indica o valor percentual do limite máximo que foi atingido em cada célula. . . . . . . . . . 56

4.5 Perfil BB' da figura 2.2. Inversão com vínculo de compacidade e informação geológica do corpo. Limites do contraste de densidade (\%) em cada prisma: $\Delta \rho_{\min }=0,0 \mathrm{~g} / \mathrm{cm}^{3}$ e $\Delta \rho_{\max }=0,26 \mathrm{~g} / \mathrm{cm}^{3}$ para ME; $\Delta \rho_{\max }=0,2 \mathrm{~g} / \mathrm{cm}^{3}$ para A2 e $\Delta \rho_{\max }=0,1 \mathrm{~g} / \mathrm{cm}^{3}$ em Britânia. A legenda indica o valor percentual do limite máximo que foi atingido em cada célula. . . . . . . . . 57

4.6 Perfil BB' da figura 2.2. Inversão com vínculo de compacidade e informação geológica do corpo. Limites do contraste de densidade (\%) em cada prisma: $\Delta \rho_{\min }=0,0 \mathrm{~g} / \mathrm{cm}^{3}$ e $\Delta \rho_{\max }=0,31 \mathrm{~g} / \mathrm{cm}^{3}$ para ME; $\Delta \rho_{\max }=0,2 \mathrm{~g} / \mathrm{cm}^{3}$ para A2 e $\Delta \rho_{\max }=0,1 \mathrm{~g} / \mathrm{cm}^{3}$ em Britânia. A legenda indica o valor percentual do limite máximo que foi atingido em cada célula. . . . . . . . . 58

4.7 Modelo da distribuição de contraste de densidade em subsuperfície obtido pela inversão de dados gravimétricos com $\Delta \rho_{\min }=0,0 \mathrm{~g} / \mathrm{cm}^{3}$ e $\Delta \rho_{\max }=$ $0,3 \mathrm{~g} / \mathrm{cm}^{3}$. O corte feito em (a) serve para mostrar como os dois corpos estão disposto em profundidade, melhor apresentado em (b) . . . . . . . . . 61

4.8 Modelo de contraste de densidade obtido pela inversão de dados gravimétricos, com a profundidade de cada seção. 
4.9 Valores do (a) campo gravimétrico anômalo observado comparados aos (b) dados calculdados de forma direta a partir do modelo de distribuição de contraste de densidade obtido. . . . . . . . . . . . . . . . . . 63

4.10 Campo magnético residual observado. . . . . . . . . . . . . . . . . . 64

4.11 Susceptibilidade recuperada pela inversão da anomalia magnética de campo total: (a) adotando apenas a magnetização induzida e (b) magnetização induzida mais remanescente . . . . . . . . . . . . . . . . 65

4.12 Modelo de susceptibilidade obtido pela inversão de dados magnéticos considerando a magnetização remanescente mais induzida, com a profundidade de cada seção . . . . . . . . . . . . . . . . . . . . . . . . . 66

4.13 Campo magnético calculado para o modelo de distribuição de susceptibilidade obtido pela inversão dos dados magnéticos: (a) adotando apenas a magnetização induzida e (b) magnetização induzida mais remanescente. . 67 


\section{Introdução}

A província Rio Verde - Iporá está situada ao longo da margem norte da Bacia do Paraná, na região do sudoeste de Goiás. Estas feições tectônicas foram especialmente ativas durante o Cretáceo Superior tendo então possibilitado o acesso e a instalação do magmatismo alcalino nesta área. Tais alcalinas encontram-se em arranjos lineares dispostos paralelamente à costa da borda erosiva da bacia ou fazendo ângulos variados em relação a essa borda (Almeida, 1983). Esta província possui vários complexos alcalinos, numerosos diques e produtos vulcânicos locais.

O termo 'rochas alcalinas' é utilizado para designar rochas que contenham minerais feldspáticos ou rochas que não necessariamente contenham um feldspatóide, mas com baixo conteúdo de $\mathrm{SiO}_{2}$ e alto conteúdo de álcalis (Fitton and Upton, 1987).

As intrusões da Provínicia Ígnea de Rio Verde - Iporá apresentam tamanho e composição variada. Três principais formas de intrusão são comumente encontradas na área estudada: diques, plugs e sills (Danni, 1994). Os plugs constituem intrusões cilíndricas, com diâmetros que podem ultrapassar 200 m, como bem exemplificam as ocorrências no extremo noroeste da província, próximo a Araguaiana, onde aflora o Complexo Morro do Engenho (ME). Uma breve discussão sobre a geologia da região em estudo está no capítulo 1 mostrando os aspectos a serem considerados na área estudada. 
A província alcalina de Rio Verde - Iporá tem assinatura geofísica gravimétrica e magnetométrica, portanto um estudo detalhado dessas intrusões pode proporcionar modelos para a estrutura desses corpos em profundidade e ajudar no entendimento de como os mesmos foram alojados na crosta continental. As informações geofísicas disponíveis na área de estudo são estações gravimétricas espaçadas cerca de $5 \mathrm{~km}$ e dados aeromagnéticos do Projeto Iporá, de 1972 e 1973 (Brasil, 1974).

Neste estudo, dados gravimétricos e aeromagnéticos são analisados visando obter informações sobre a extensão de alguns corpos da província em subsuperfície . Para isso, um método de modelagem de corpos e o processo de inversão foram empregados para alguns dos corpos da província Rio Verde - Iporá determinando a distribuição espacial das propriedades físicas em subsuperfície para os mesmos.

Uma das etapas da pesquisa realizada incorporou novos dados gravimétricos com melhor distribuição espacial, localizados de preferência ao longo dos corpos em malha regular mais fechada que a existente, e coleta de material para determinar as propriedades físicas das amostras.

Uma vez coletados os dados gravimétricos, foram realizados os procedimentos usuais de análise e interpretação, através da elaboração de mapas e perfis, realização da separação regional-residual, escolha de perfis para aplicação das técnicas de modelagem dos corpos e inversão dos dados geofísicos. De posse das amostras, determinou-se em laboratório a densidade e a susceptibilidade magnética dos tipos de rochas coletadas, sendo também realizadas as medidas de magnetização remanescente no laboratório de paleomagnetismo do Instituto de Astonomia, Geofísica e Ciências Atmosféricas da Universidade de São Paulo (IAG-USP). Estas informações são discutidas no capítulo 2. 
Os dados gravimétricos e aeromagnéticos foram tratados de forma conjunta por modelamento direto $(2,5 \mathrm{D})$ e separadamente por inversão (2D e 3D). A metologia utilizada está descrita no capítulo 3 e os resultados foram discutidos no capítulo 4 .

Ao final do projeto alguns corpos alcalinos da Província Ígnea Rio Verde - Iporá foram caracterizados, incluindo um levantamento de detalhe sobre as intrusivas ME e A2 e modelos destes corpos para distribuição de contraste de densidade e susceptibilidade magnética em subsuperfície. 


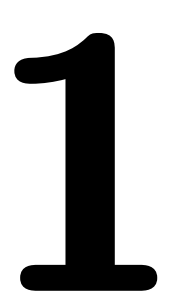

\section{GEOLOGIA DA ÁREA DE ESTUDO}

A província Rio Verde - Iporá, situada ao longo da margem norte da Bacia do Paraná, foi afetada por importantes eventos de magmatismo alcalino durante o Cretáceo Superior. Almeida (1983) classificou as ocorrências alcalinas em diversas províncias no Brasil, ressaltando a importância da tectônica regional como controle na colocação desses corpos, e agrupou as ocorrências de rochas alcalinas das margens da Bacia do Paraná em diferentes províncias, as que se encontram a oeste de Goiás foram designadas como Provínicia Ígnea de Rio Verde - Iporá.

As ocorrências de rochas alcalinas da província Rio Verde - Iporá apresentam idades entre 90 e 75 Ma obtidas por K/Ar (Morbidelli et al., 1995). Gibson et al. (1995) reavaliaram as datações na província Iporá, pelo mesmo método, e sugeriram o intervalo de 90-80 Ma.

Em Junqueira-Brod et al. (2002) as alcalinas ocorridas na região de Iporá e Rio Verde foram desiginadas como Província Alcalina de Goiás (PAGO), ocorrendo ao longo 
de uma faixa de dobramento de direção NW. Esta província tem cerca de 250 x $70 \mathrm{~km}$ e inclui desde os complexos máfico-ultramáficos alcalinos da porção norte, rochas alcalinas sub-vulcânicas predominantes na porção central a vulcânicas na porção sul (figura 1.1).

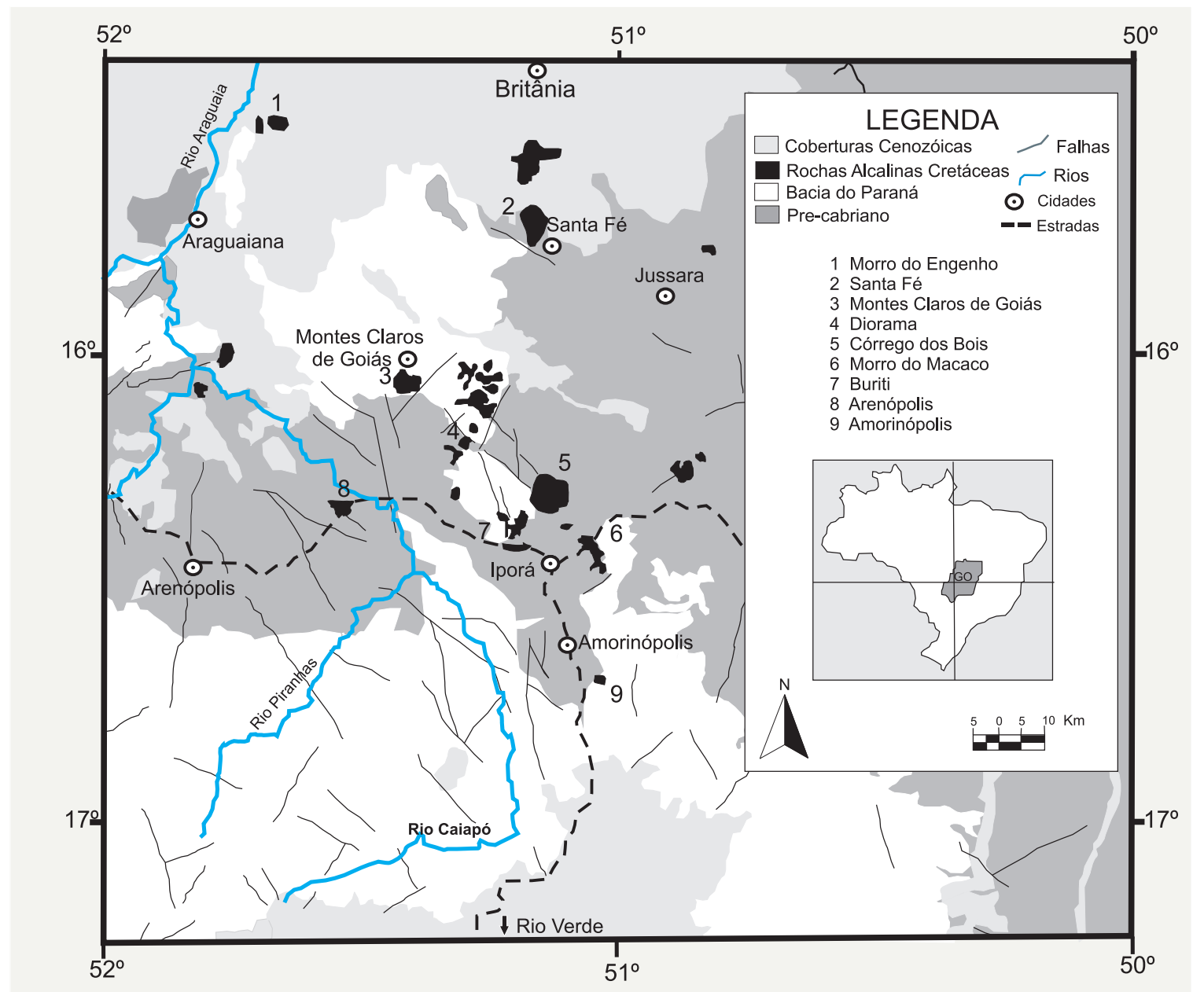

Figura 1.1: Mapa da Província Alcalina de Goiás (PAGO) (modificado de Junqueira-Brod et al., 2002).

A Província Rio Verde - Iporá possui vários complexos alcalinos, numerosos diques, plugs e produtos vulcânicos locais. A metade norte da Província, na qual se encontram as intrusivas alcalinas Morro do Engenho (ME) e uma intrusão poucos quilômetros a NE de Morro de Engenho possuem informações gravimétricas e aeromagnéticas. A intrusão a NE de Morro do Engenho foi denominada Anomalia 2 (A2) segundo o Mapa de Interpretação Magnética do Projeto Iporá escala 1:250.000 (Brasil, 1974). 


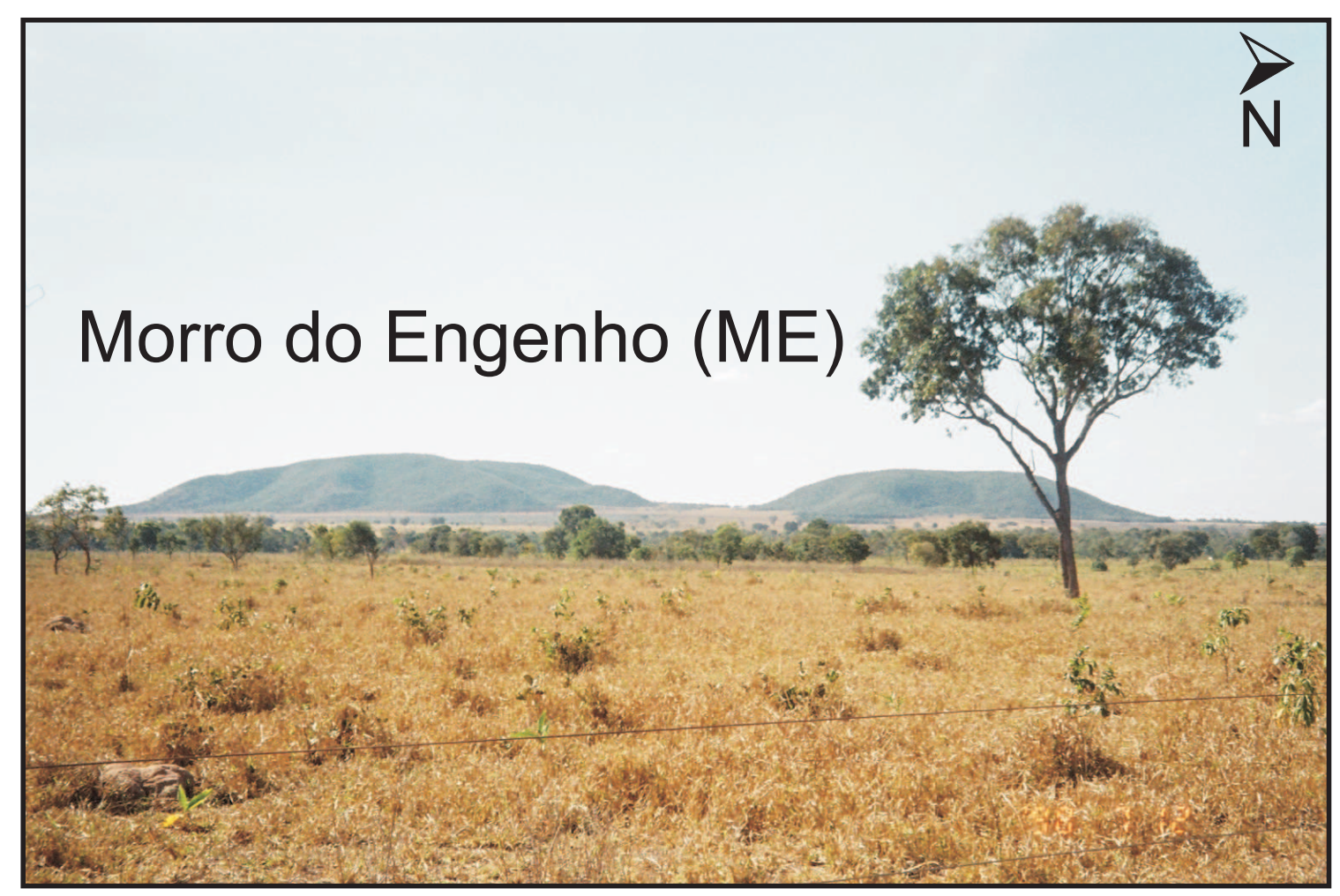

Figura 1.2: Foto do Complexo Morro de Engenho (ME).

Próxima à cidade de Britânia aparece uma anomalia gravimétrica sem informação de anomalia aeromagnética, mas com características que inicialmente apontavam para que a mesma fizesse parte do conjunto de intrusões alcalinas. Em julho de 2005 foi observado pela equipe da empresa Teckominco, através da análise de testemunhos de poços, que se trata de um corpo granítico com extensa cobertura sedimentar (Guilherme S. Canha, comunicação pessoal em 2005).

No extremo noroeste da PAGO, próximo à Araguaiana, aflora o Complexo do Morro do Engenho (15²'S; 5140'W) apresentado na figura 1.2. O complexo possui aproximadamente 5 km de diâmetro e intrude a Formação Furnas (Junqueira-Brod et al., 2002). A Formação Furnas é constituída de arenitos grosseiros e mal selecionados, sendo considerada de idade devoniana, esta unidade é cortada pelos maciços de Iporá. Rodrigues et al. (1999) descreve que as unidades geológicas pré-cambrianas expostas nas vizinhanças de 
Iporá (figura 1.3) são sequências vulcanossedimentares de Iporá, ortognaisses/granitos, intrusões gabro-dioríticas e graníticas pós-tectônicas. Os ortognaisses correspondem predominantemente a granitos e granodioritos cálcio-alcalinos de alto potássio, com fácies tonalíticas muito restritas.

A área de pesquisa localiza-se no extremo noroeste de Goiás, praticamente às margens do Rio Araguaia a cerca de $75 \mathrm{~km}$ a WNW de Jussara. O relevo da região pesquisada é caracterizado por uma superfície plana e por outra unidade morfologicamente distinta com morros isolados, representado por ultramáficas com cobertura de material silicificado. As altitudes nos locais estudados não são superiores à $500 \mathrm{~m}$ acima do nível do mar. A zona plana desenvolveu-se sobre gnaisses, dunitos, peridotitos, piroxenitos serpentinizados e rochas alcalinas associadas a litologias menores (Radaelli, 2000). A região estudada neste trabalho está indicada na figura 1.3.
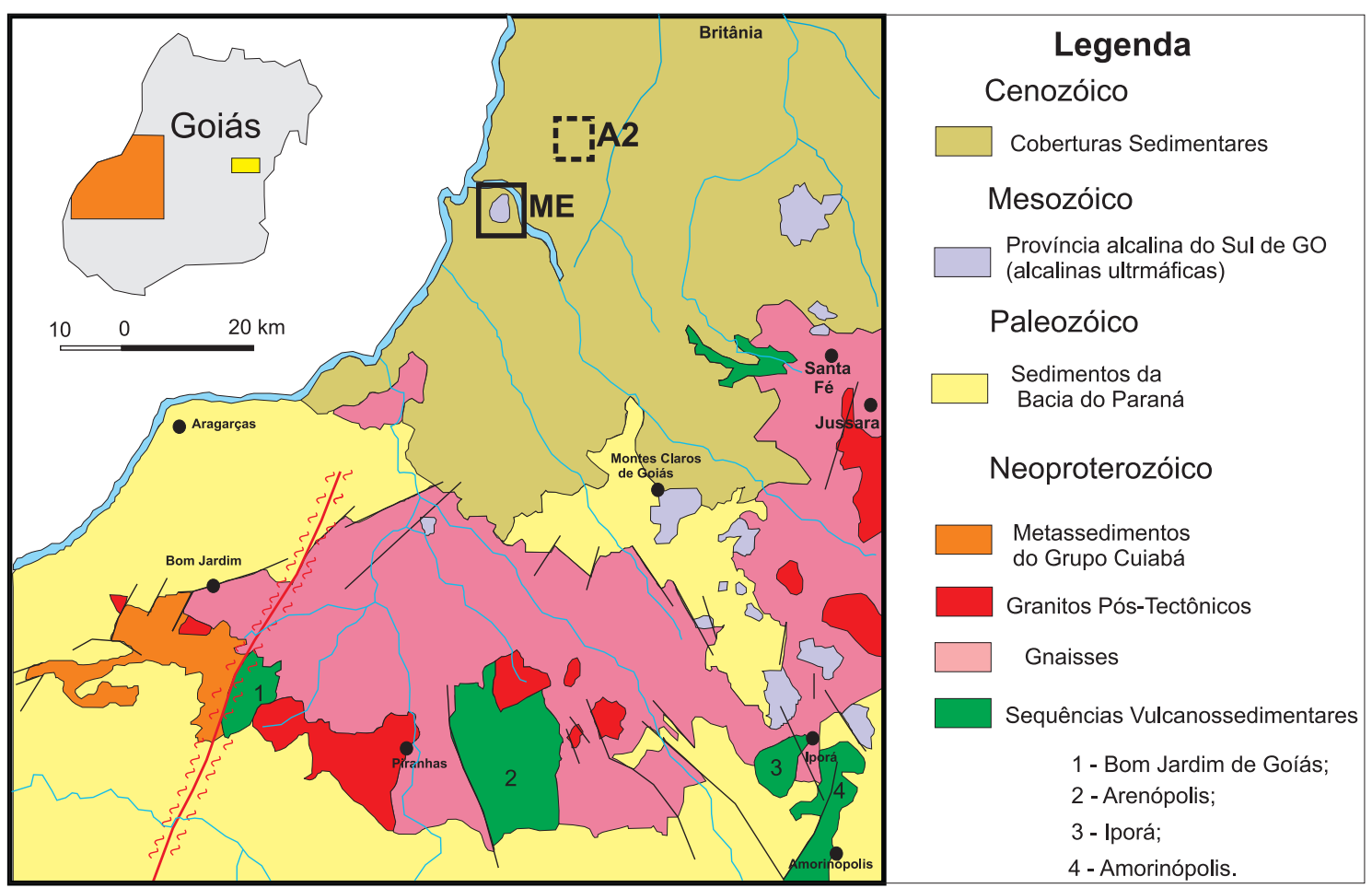

Figura 1.3: Esboço geológico regional, modificado de Radaelli (2000). 
Após a intrusão da ultramáfica, as rochas foram submetidas a um longo processo de aplainamento. Este ciclo foi seguido da formação de crosta de calcedônia e laterita. Após o rejuvenescimento, com erosão e degradação mecânica destas crostas, houve a remoção acelerada do serpentinito superficial enriquecido em Ni (Barbour, 1976).

O zoneamento metassomático relacionado às rochas ultramáficas é mais claramente observado quando elas estão em contato com rochas silicosas e foram conjuntamente submetidas a metamorfismo regional. A serpentinização pode ser considerada como um processo que envolve a transformação metamórfica dos minerais ígneos originais de uma rocha ultramáfica em minerais predominantemente do grupo das serpentinitas. Esta transformação pode ser obtida a partir de simples hidratação de uma rocha ultramáfica sob condições metamórficas (Strieder, 1992). Para região estudada considera-se o dunito como a rocha que deu origem aos serpentinitos.

Segundo Radaelli (2000) esta região é constituída por núcleos de dunitos circundados por peridotitos e piroxenitos alcalinos serpentinizados que sofrem mudança gradual para gabro alcalino e nefelina sienito. Os depósitos de níquel laterítico na região estão relacionados exclusivamente ao processo de enriquecimento supergênico em terrenos derivados de ultrabásicas alcalinas. É descrito pelo mesmo autor que tais depósitos silicatados são constituídos sobretudo por garnierita, concentrados principalmente em nível próximo ao serpentinito e em suas fraturas.

O dunito ocupa o centro do complexo, sua importância se dá pela representatividade geográfica e por ser a rocha original portadora de níquel, além de estar envolvido por peridotitos e piroxenitos. A passagem de dunito para peridotito na zona periférica é gradual. Os peridotitos formam um anel descontínuo e irregular distribuídos em torno dos 
dunitos e são constituídos essencialmente de olivina e piroxênios.

As reservas de níquel foram avaliadas pela Companhia de Pesquisa de Recursos Minerais (CPRM), que delimitou na região os depósitos de níquel presentes com o objetivo de viabilizar um aproveitamento comum para os depósitos (tabela 1.1).

Tabela 1.1: Principais depósitos de níquel no oeste do Estado de Goiás*.

\begin{tabular}{lccc}
\hline \multicolumn{1}{c}{ Local } & $\begin{array}{c}\text { Reserva Medida } \\
\left(10^{3} t\right)\end{array}$ & $\begin{array}{c}\text { Teor } \\
(\% N i)\end{array}$ & $\begin{array}{c}\text { Níquel Contido } \\
\left(10^{3} t\right)\end{array}$ \\
\hline Morro do Engenho & 11.956 & 1,34 & 160 \\
Santa Fé & 1.843 & 1,40 & 25 \\
Agua Branca & 4.531 & 1,40 & 63 \\
Montes Claros & 49.966 & 1,26 & 632 \\
Tira Pressa & 45.602 & 1,55 & 708 \\
Diorama & 11.104 & 1,33 & 147 \\
Iporá & 13.644 & 1,45 & 198 \\
\hline Total & 138.646 & 1,39 & 1.933 \\
\hline *depósitos localizados em raio de $60 \mathrm{~km}$ (modificado de Radaelli, 2000)
\end{tabular}

Pouco se conhece sobre o comportamento do Complexo ME em subsuperfície e o mapeamento geológico da superfície é prejudicado pelo profundo intemperismo das rochas máficas/ultramáficas e pela presença de coberturas aluviais.

No intuito recuperar com relativa eficiência a geometria dos corpos intrusivos ME e A2 foram empregadas, neste trabalho, técnicas de modelamento direto e inversão para estimativa sobre largura e profundidade do complexo em subsuperfície. Foram utilizados dados gravimétricos e aeromagnéticos tratados de forma conjunta por modelamento direto (2,5D) e separadamente por inversão. As informações sobre localização e caracterização dos litotipos encontrados na literatura disponível também foram utilizadas. 


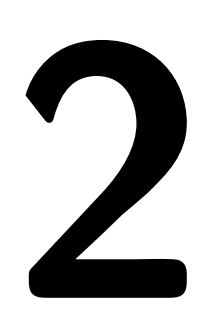

\section{INFORMAÇÕES GEOFÍSICAS E PETROFÍSICAS}

As informações geofísicas disponíveis na área de estudo, descritas neste capítulo, compõem-se de estações gravimétricas espaçadas cerca de $5 \mathrm{~km}$ e dos dados aeromagnéticos do Projeto Iporá de 1972 e 1973 (Brasil, 1974). Estas informações foram analisadas visando obter estimativas sobre a extensão dos corpos em subsuperfície.

No mês de maio de 2004 e julho/agosto de 2005 foram feitas viagens de campo à área que resultaram na incorporação de novos dados gravimétricos com melhor distribuição espacial. Também foi coletado material para determinar as propriedades físicas: densidade, susceptibilidade magnética e magnetização remanescente.

Os dados do levantamento aeromagnético utilizados foram obtidos a partir da digitalização de cartas magnéticas e encontram-se na forma de mapas de campo total na escala 1:50.000 (Brasil, 1974). 


\subsection{Dados gravimétricos}

Parte dos dados gravimétricos da figura 2.1 foram obtidos em várias campanhas anteriores a 1990. Esses dados cobrem a maior parte das alcalinas da Província Iporá, mas ainda existiam algumas lacunas, principalmente na região do ME e a nordeste de ME. Estas regiões foram preenchidas com dados levantados em maio de 2004 e julho/agosto de 2005 permitindo uma melhor definição da forma da anomalia. Nestes dois últimos levantamentos, o posicionamento horizontal e vertical foi realizado com um GPS de dupla freqüência. Este equipamento, em levantamentos geodésicos ou topográficos, proporciona as coordenadas retilíneas geocêntricas $(\mathrm{X}, \mathrm{Y}, \mathrm{Z})$ referenciadas ao World Geodetic System 1984 - WGS84, que podem ser transformadas em latitude, longitude e altitude geométrica. O posicionamento de todas estações disponíveis está apresentado na figura 2.1.

Após a aquisição de dados gravimétricos seguiu-se com a etapa de processamento, conhecida como redução, que transforma as leituras do equipamento em acelerações e anomalias de gravidade para que sejam interpretadas na forma de mapas e perfis.

A primeira etapa de redução consiste nas correções de variações temporais do campo de gravidade causadas pela atração luni-solar, resultando no valor da gravidade no ponto. Em seguida subtraem-se da aceleração da gravidade do ponto o valor da gravidade normal para estação, fornecida pela fórmula do Sistema Geodésico de Referência de 1967, e correção ar-livre obtendo-se o valor da anomalia ar-livre. Dando seguimento à redução, aplica-se sobre a anomalia ar-livre a correção de Bouguer, para então obter a anomalia Bouguer. Esse procedimento foi realizado através do programa REGRAV 02 (Sá, 2002). Para redução de Bouguer usou-se o valor de $2,67 \mathrm{~g} / \mathrm{cm}^{3}$ para a densidade. As equações envolvidas nesse procedimento são encontradas em diversos textos didáticos como Lowrie 


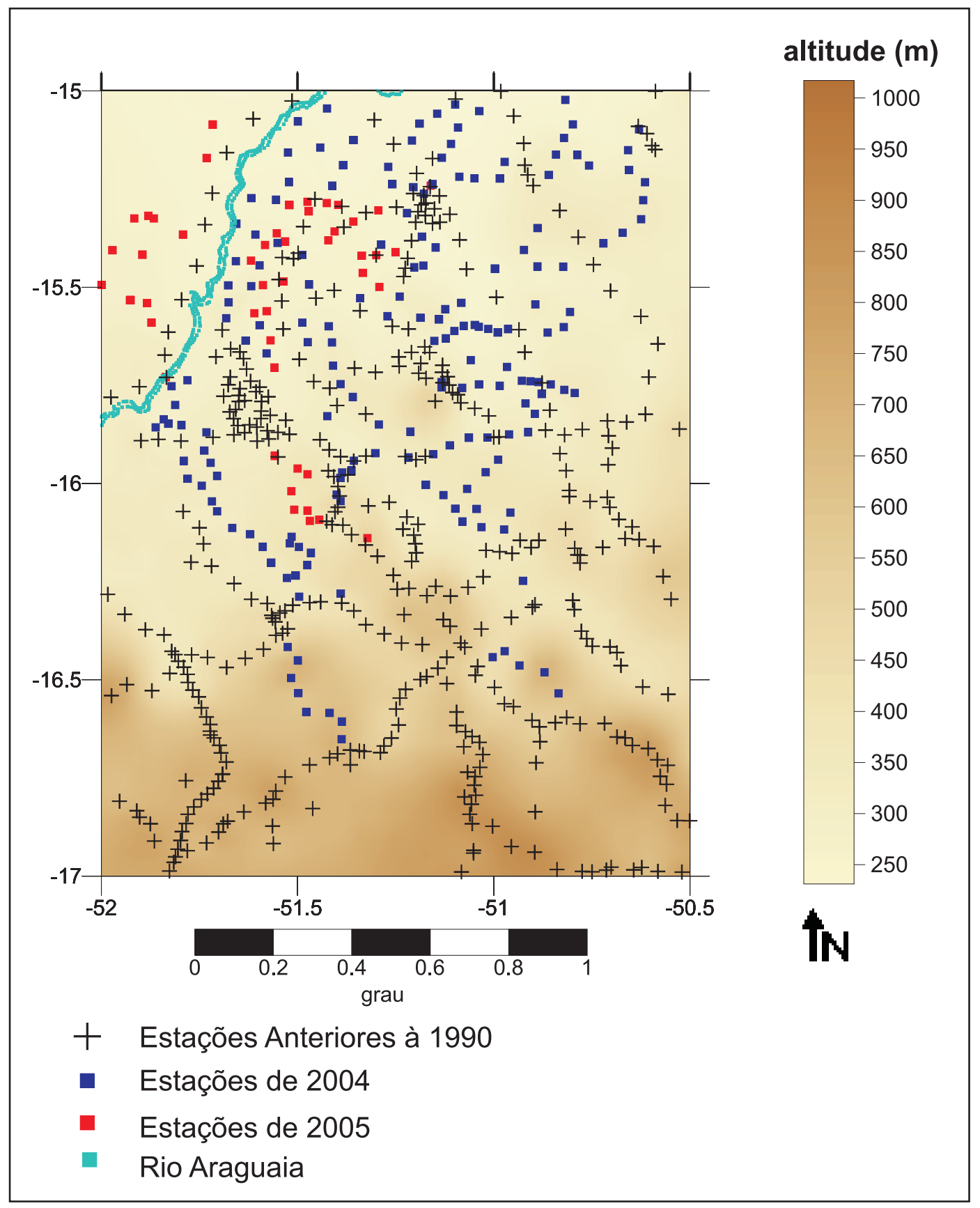

Figura 2.1: Mapa da altitude com localização das estações gravimétricas obtidas em 2004, 2005 e anteriores.

(1997); Telford et al. (1976) entre outros.

Nos dados anteriores a 1990 o posicionamento das estações foi realizado com mapas topográficos na escala de 1:100.000, o erro estimado é de +/- 100 m para o posicionamento horizontal das estações. A altitude, na maior parte das estações foi obtida usando 
barometria. O erro de fechamento nos vários circuitos não ultrapassou a 1,5 m. Para variações de altitude entre 1 e 2 metros, o erro estimado é de $0,3 \mathrm{mGal}$ e para variações no posicionamento horizontal entre 20 e 100 m, o erro é da ordem de 0,05 mGal. Esses erros foram calculados por Sá (2002). Usando a fórmula de propagação de erro: Erro Bouguer $=\left[(\text { erro de posicao })^{2}+(\text { erro da altitude })^{2}\right]^{1 / 2}$ obtém-se um erro da ordem de 0,3 mGal. Considerando os dados com GPS o erro de altitude é de $30 \mathrm{~cm}$, o que dá um erro da ordem de $0,1 \mathrm{mGal}$.

A partir dos dados espacialmente distribuídos de forma não regular, como mostrado na figura 2.1, foi feita a interpolação dos mesmos para gerar os mapas de anomalia. O valor de um ponto a ser predito $\left(S^{*}\right)$ é a somatória do produto entre o valor da variável de um ponto conhecido $\left(S_{i}\right)$ pelo peso calculado $\left(\zeta_{i}\right)$ para os pontos $i$ variando de 1 a $\mathrm{N}$, onde $\mathrm{N}$ representa o número total de pontos considerados:

$$
S^{*}=\sum_{i=1}^{N} S_{i} \zeta_{i}
$$

Os algoritmos de interpolação funcionam fornecendo pesos aos pontos amostrados na predição diferindo, entre eles, em como atribuir o peso às amostras.

Foi realizada interpolação baseada na krigagem. Este método permite a análise da dependência espacial a partir do ajuste de semivariogramas experimentais a uma função simples e a caracterização da variabilidade espacial por meio do mapeamento, a partir da estimativa sem tendenciosidade, de dados para locais não amostrados.

O processo de krigagem se diferencia dos outros métodos de interpolação pela forma de atribuição dos pesos. Neste método não se utiliza a distância euclidiana entre os pontos mas uma 'distância estatística' que expressa tanto a distância como a estrutura de variabilidade (semivariância ou covariância). Não apenas a distância dos vizinhos 
ao ponto que será estimado é considerada, mas também as distâncias entre os mesmos influenciam a distribuição dos pesos. Assim, os vizinhos agrupados têm importância individual relativamente menor do que aqueles isolados.

A krigagem ordinária utiliza um estimador linear com mínima variância para interpolação do atributo medido em posições não-amostradas (Isaaks and Srivastava, 1989). É linear porque suas estimativas são feitas por combinações lineares, o erro entre a estimativa e o esperado é nulo e seu objetivo é minimizar a variância destes erros de estimativa. O estimador é uma combinação linear que é uma média móvel e leva em conta a estrutura de variabilidade encontrada para aquela variável (medida), expressa pelo semivariograma (ou, equivalentemente, função de autocorrelação) e pela localização dos valores conhecidos (Camargo, 1997). Pontos próximos da posição a ser interpolada tem pesos maiores que os mais distantes.

\subsubsection{Mapa de anomalia Bouguer}

No mapa de anomalia Bouguer da Província Rio Verde - Iporá da figura 2.2 encontrase a localização dos dados. Este foi elaborado na forma digital usando o programa Surfer (1999) 7.0 através do método de krigagem com intervalo de 2,5’ para o grid.

As anomalias variam em intervalos diversificados, os valores mais negativos estão no sudoeste do mapa sobre a bacia do Paraná e na maior parte desta área as anomalias variam de -20 a -60 mGal. As anomalias positivas estam ligadas a alguns corpos alcalinos conhecidos, aflorante ou mapeados por métodos geofísicos. Seu intervalo de amplitude é de -10 a +40 mGal, são esboços de forma oval a circular no plano visto, como esperado para intrusões de núcleos massivos (plugs ou stock), como foi apontado por Gomes et al. (1990). 


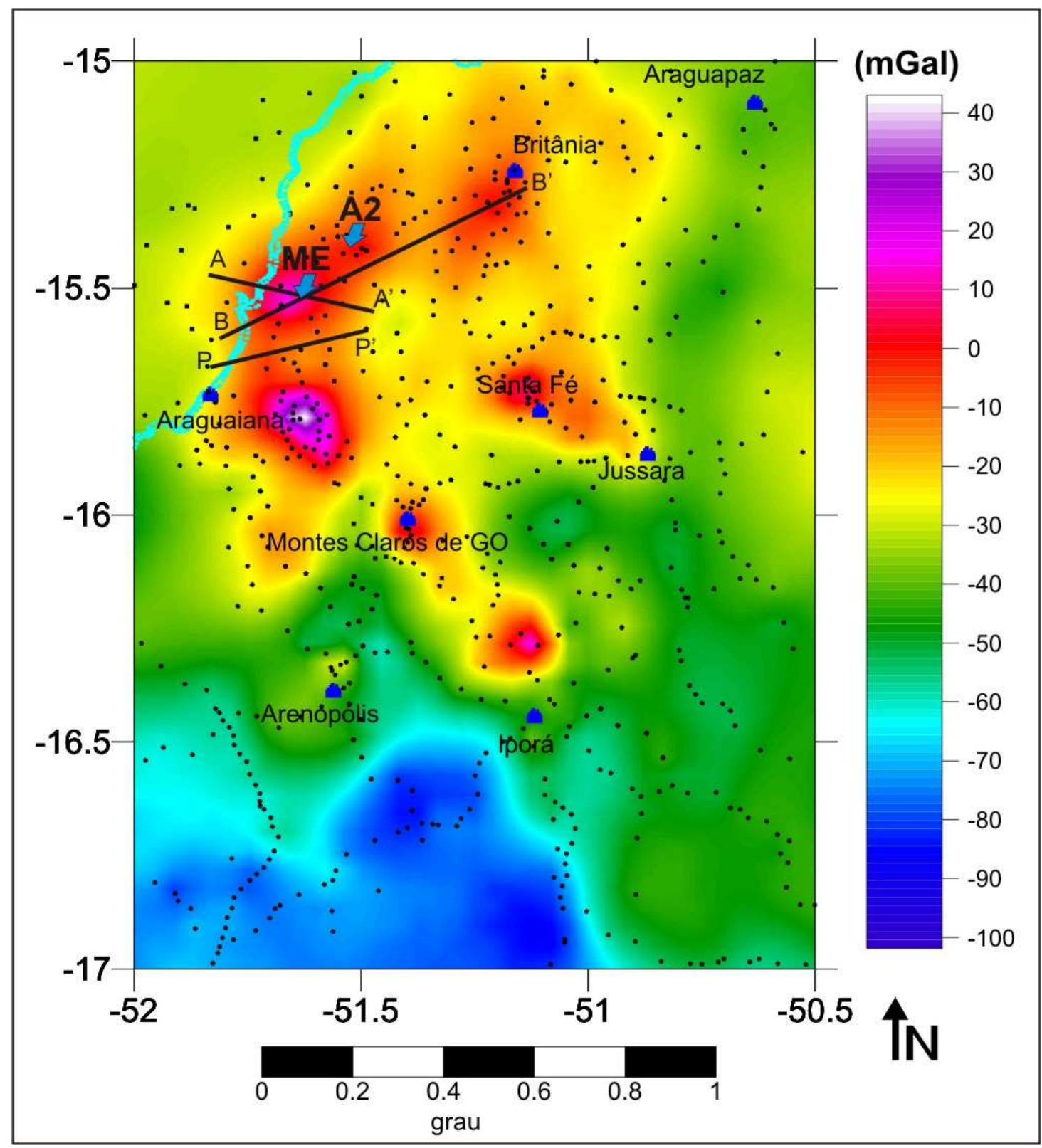

Figura 2.2: Mapa de anomalia Bouguer com as estações gravimétricas e perfis AA', BB' e PP' para separação regional-residual. Os símbolos em azul representam as cidades.

Os perfis gravimétricos $\mathrm{AA}^{\prime}, \mathrm{BB}^{\prime}$ e $\mathrm{PP}$ ' foram retirados dos dados interpolados do mapa de anomalia Bouguer e foram escolhidos de forma que cortassem as anomalias mais significativas próximas a ME. Esses perfis foram utilizados na separação regional-residual da anomalia Bouguer, e apenas os perfis AA' e BB' foram utilizados no processo de inversão 2D. 


\subsubsection{Separação regional-residual}

A separação regional-residual da anomalia Bouguer é importante para este problema, pois o programa para modelamento $2,5 \mathrm{D}$ e os programas de inversão usam os dados residuais. Podemos dizer que um experimento gravimétrico envolve a medida do componente vertical do campo gravimétrico produzido por massas anômalas (seu excesso ou deficiência) sob a superfície. A distribuição de massas anômalas, caracterizada por uma densidade $\rho(x, y, z)$, produz seu próprio campo gravimétrico que é superposto ao campo gravimétrico regional. Através da medida do campo resultante e remoção do campo regional das medidas por processamento numérico, obtém-se o campo devido à massa anômala.

Para estimativa do efeito gravimétrico regional e posterior separação foi aplicado o método de ajuste polinomial por mínimos quadrados onde é encontrado o polinômio de superfície que melhor represente o comportamento regional dos dados. Os resultados obtidos encontram-se na figura 2.3 .

A escolha do melhor regional foi feita através da análise dos mapas regionais e residuais, verificando-se qual grau melhor representa a anomalia circular em ME e A2, e como a superfície do regional se ajusta aos dados fora da área de concentração das anomalias.

Os perfis AA', BB' e PP' (figuras 2.4, 2.5, 2.6)foram usados para verificar como a superfície do regional se comporta longe do máximo da anomalia.

O mapa da figura 2.3a foi obtido pela remoção da superfície polinomial de grau 1 gerada a partir do arquivo com as estações gravimétricas. Apesar de não representar muito bem o campo regional, principalmente a tendência gravimétrica NE-SW, não contém 

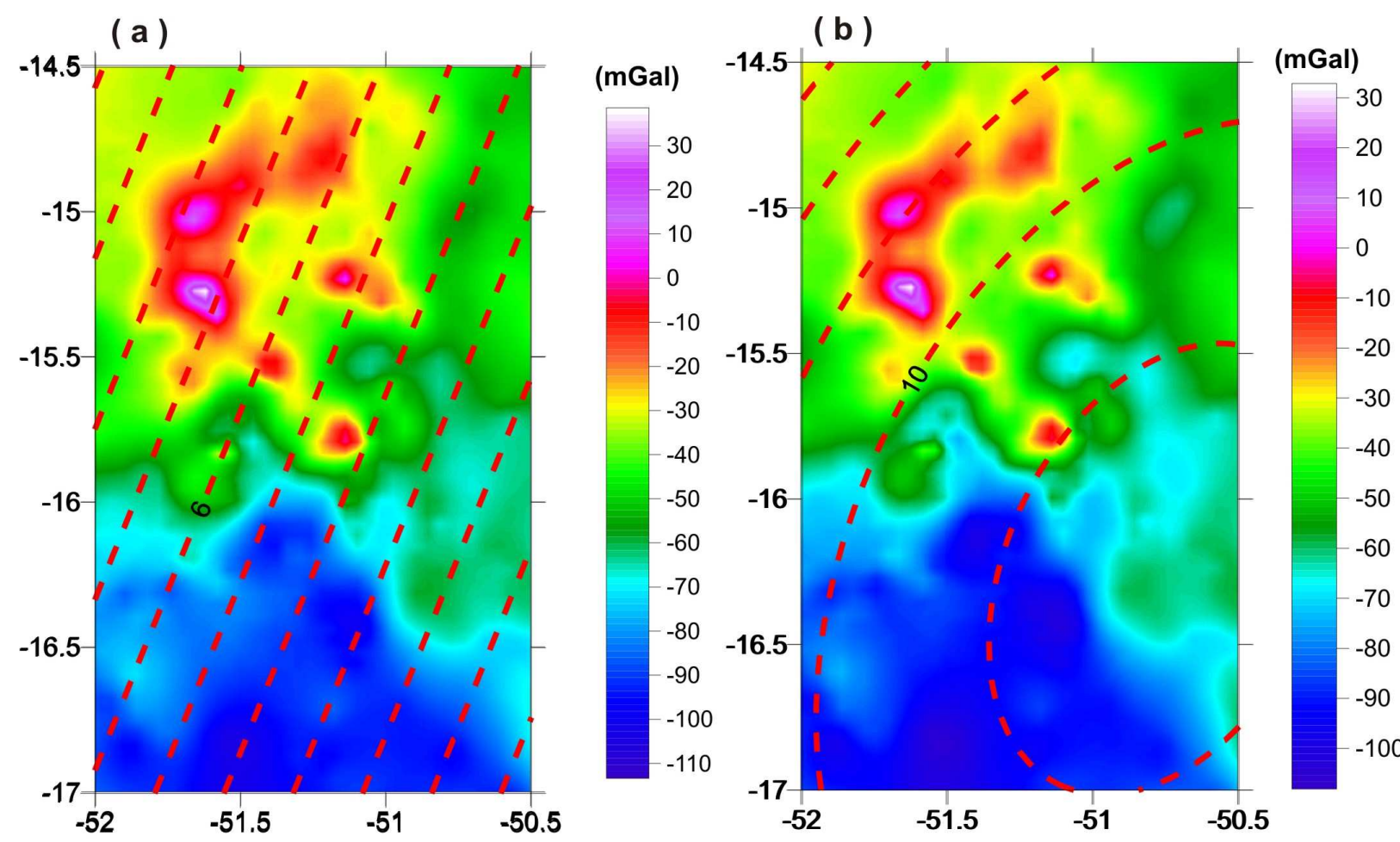

(c)

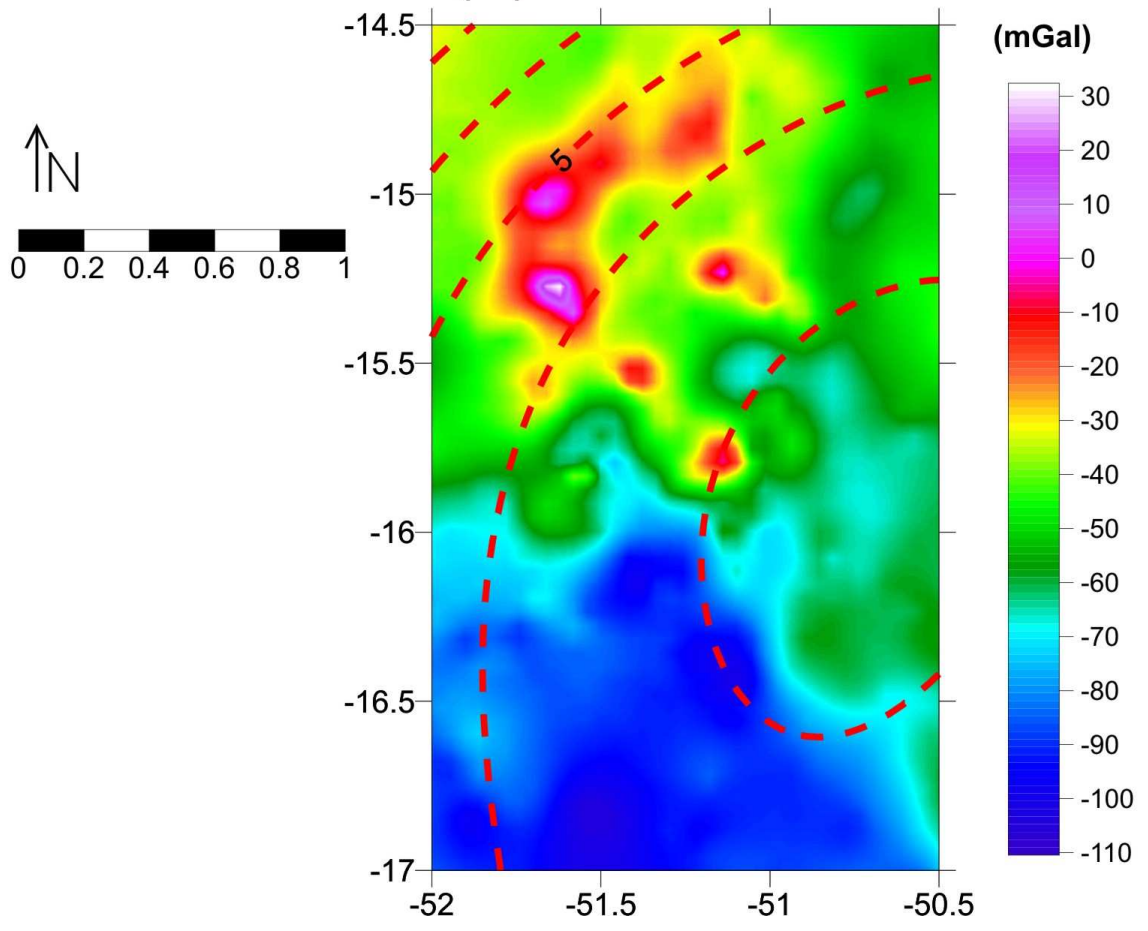

Figura 2.3: Mapa de anomalia Bouguer residual (imagem colorida) e mapa regional (isolinhas tracejada vermelhas). Os residuais obtidos por: (a) remoção do polinômio de grau 1; (b) remoção do polinômio de grau 2; (c) remoção do polinômio de grau 3. 


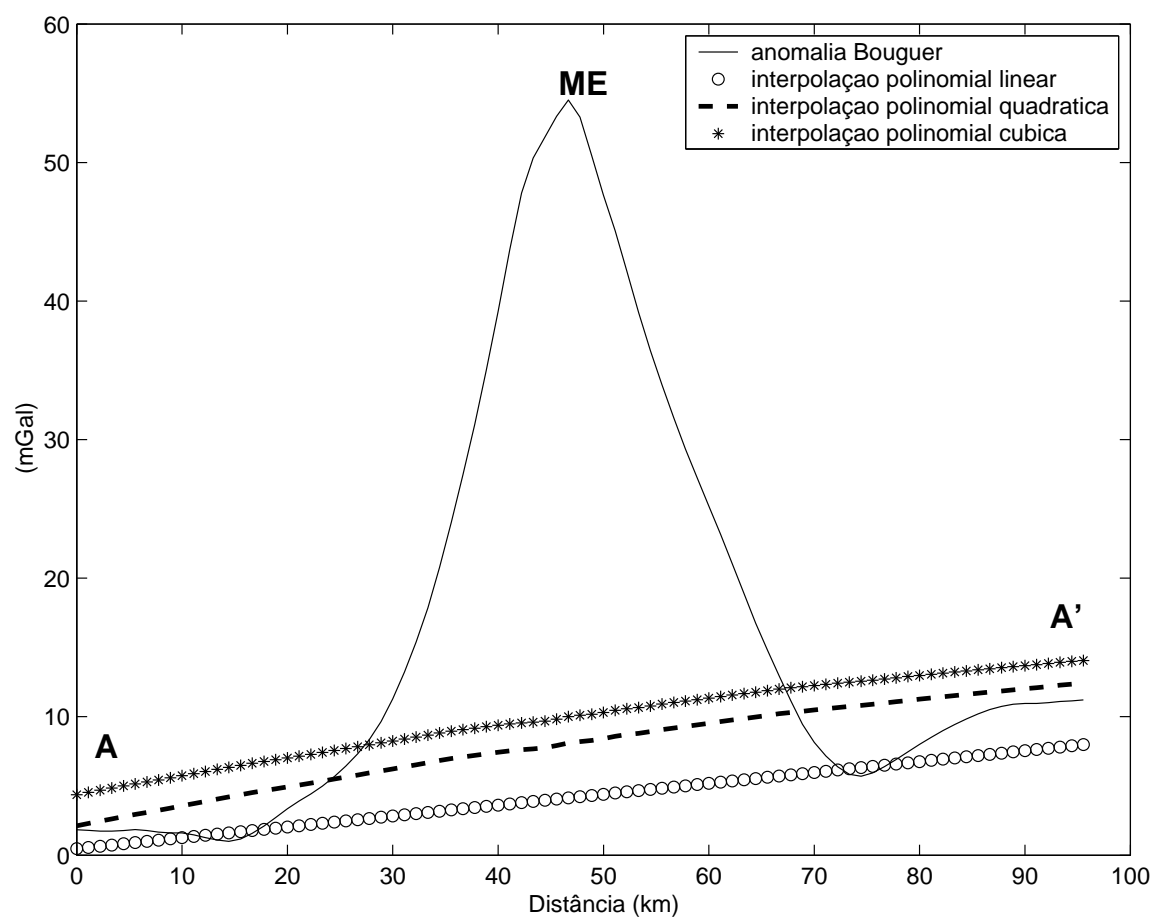

Figura 2.4: Perfil AA' para escolha do campo regional analisando os resultados obtidos pela regressão polinômial de grau 1, 2 e 3 .

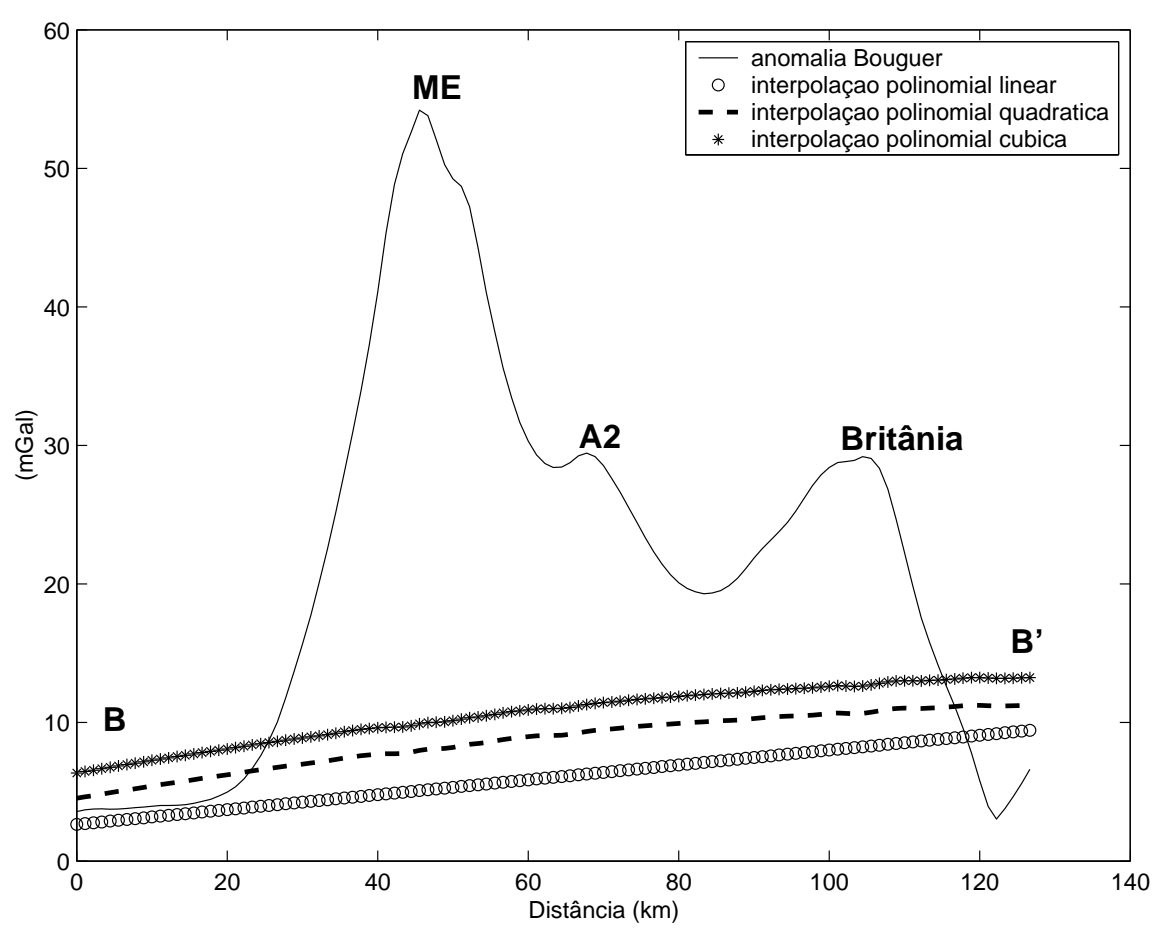

Figura 2.5: Perfil BB' para escolha do campo regional analisando os resultados obtidos pela regressão polinômial de grau 1, 2 e 3 . 


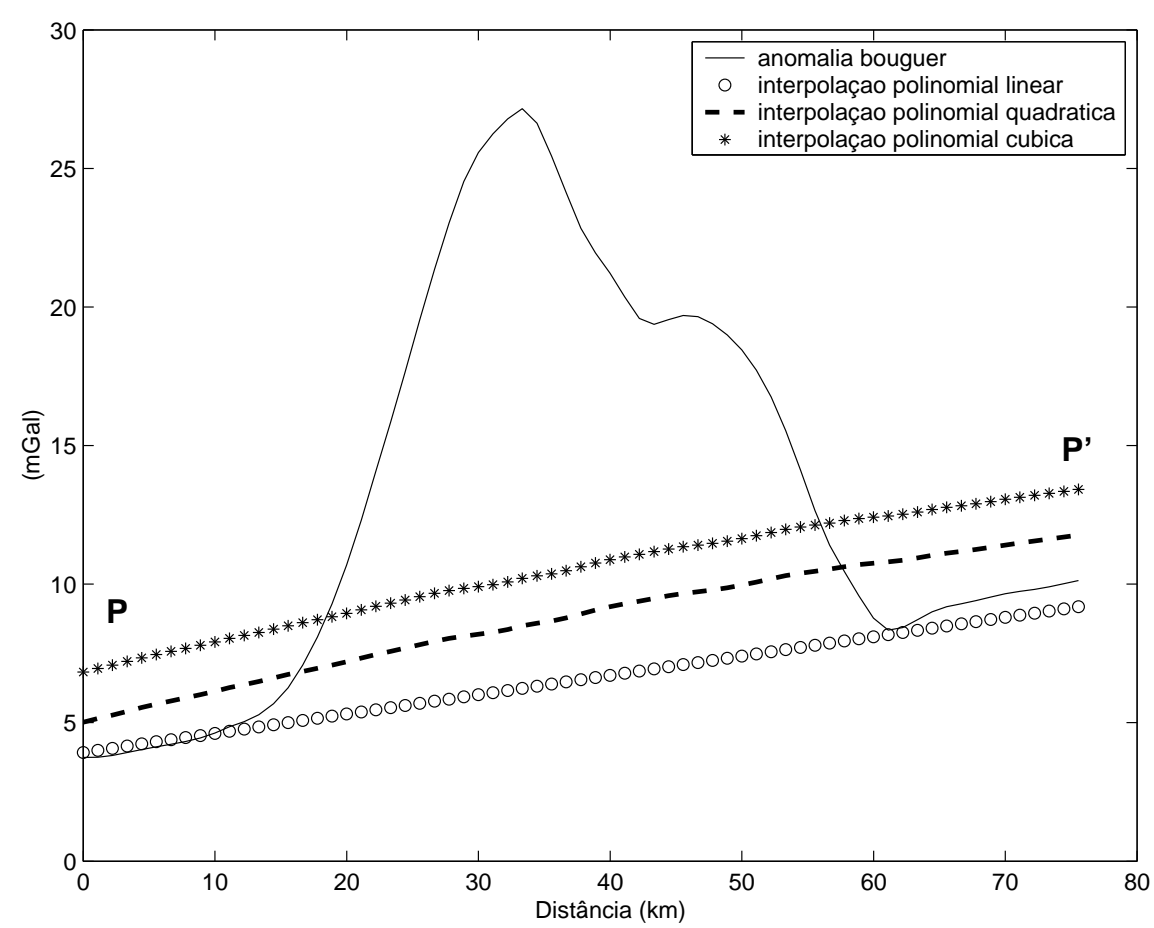

Figura 2.6: Perfil PP' para escolha do campo regional analisando os resultados obtidos pela regressão polinômial de grau 1, 2 e 3 .

valores negativos nas bordas da anomalia como observado nas figuras (2.4 a 2.6).

O polinômio de grau 2 começa a ajustar a tendência NE-SW (figura 2.3) e o polinômio de grau 3 ajusta melhor a tendência do que o grau 2 (figura 2.3). Entretanto, os polinômios de grau 2 e 3 geram valores negativos nas bordas do corpo quando removidos do efeito gravimétrico resultante como pode ser visualizado nas figuras de 2.4 a 2.6.

Com o aumento do grau houve um aumento da área dos valores negativos em torno das anomalias estudadas (figuras 2.4 a 2.6). Comparando o campo observado com a representação do polinômio em uma análise qualitativa, conclui-se que o polinômio de grau 1 é melhor para representar o regional por não gerar valores negativos nas bordas, pois do ponto de vista geológico não há justificativa para a presença destes valores negativos.

O mapa de anomalia Bouguer residual da figura 2.7 foi obtido subtraindo-se do mapa de anomalia Bouguer original (figura 2.2) a superfície polinomial de primeiro grau (figura 
2.3). Este mapa residual gravimétrico é utilizado na inversão 3D e os correspondentes residuais dos perfis AA' e BB', obtidos diretamente do mapa residual, serviram para o modelamento direto $2,5 \mathrm{D}$ e inverso $2 \mathrm{D}$ e $3 \mathrm{D}$.

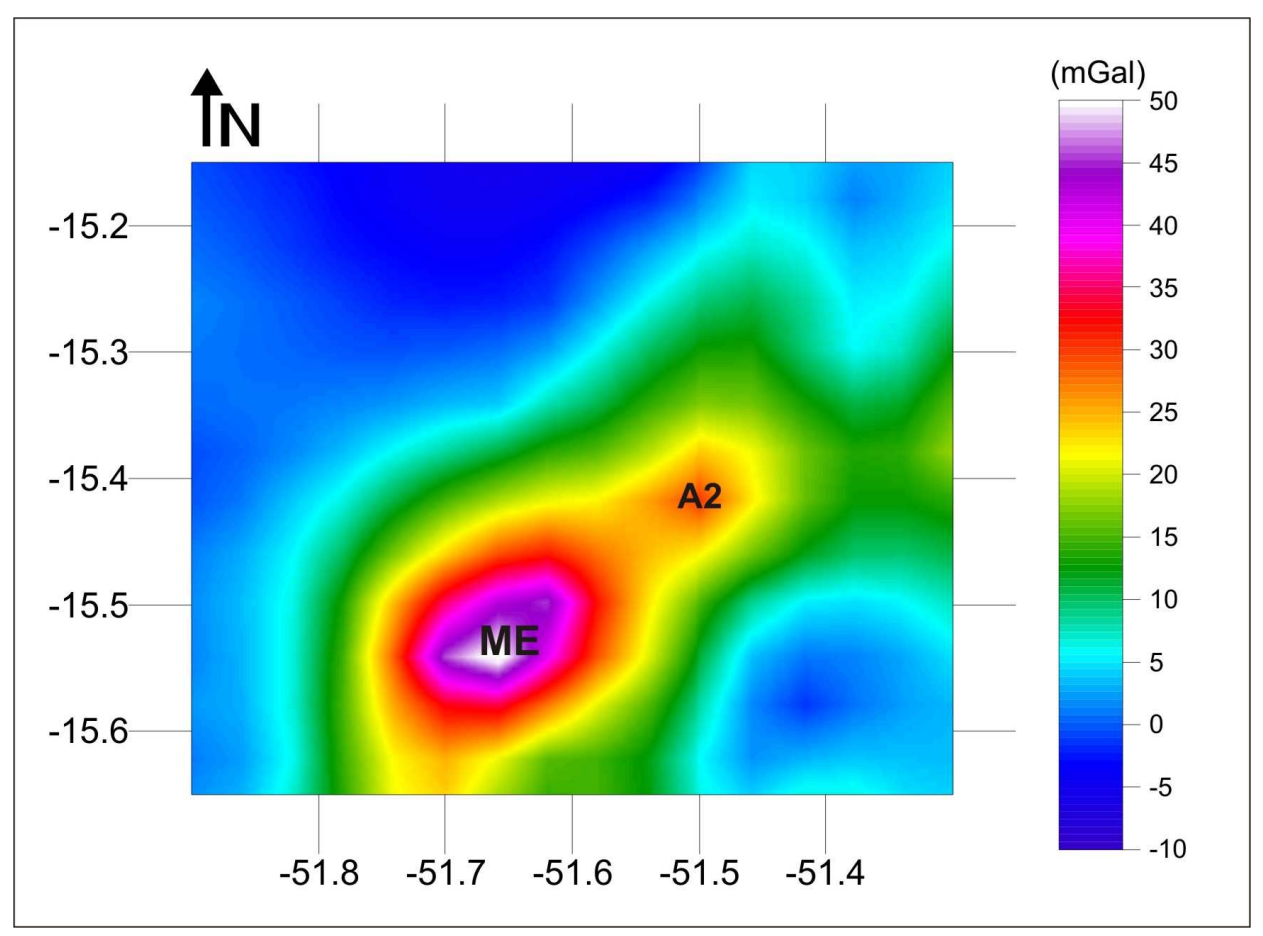

Figura 2.7: Mapa de anomlia Bouguer residual obtido pela remoção de um polinômio de grau 1. 


\subsection{Dados magnéticos}

Nos mapas aeromagnéticos de campo total disponíveis na área há informação da remoção de um valor constante de $17.000 \mathrm{nT}$ (Brasil, 1974). Os mapas em papel foram digitalizados em uma rede regular de $1 \mathrm{x} 1 \mathrm{~km}$ e na execução dos mapas de contorno manteve-se o mesmo espaçamento (figura 2.8). As fitas com os dados originais não estão disponíveis.

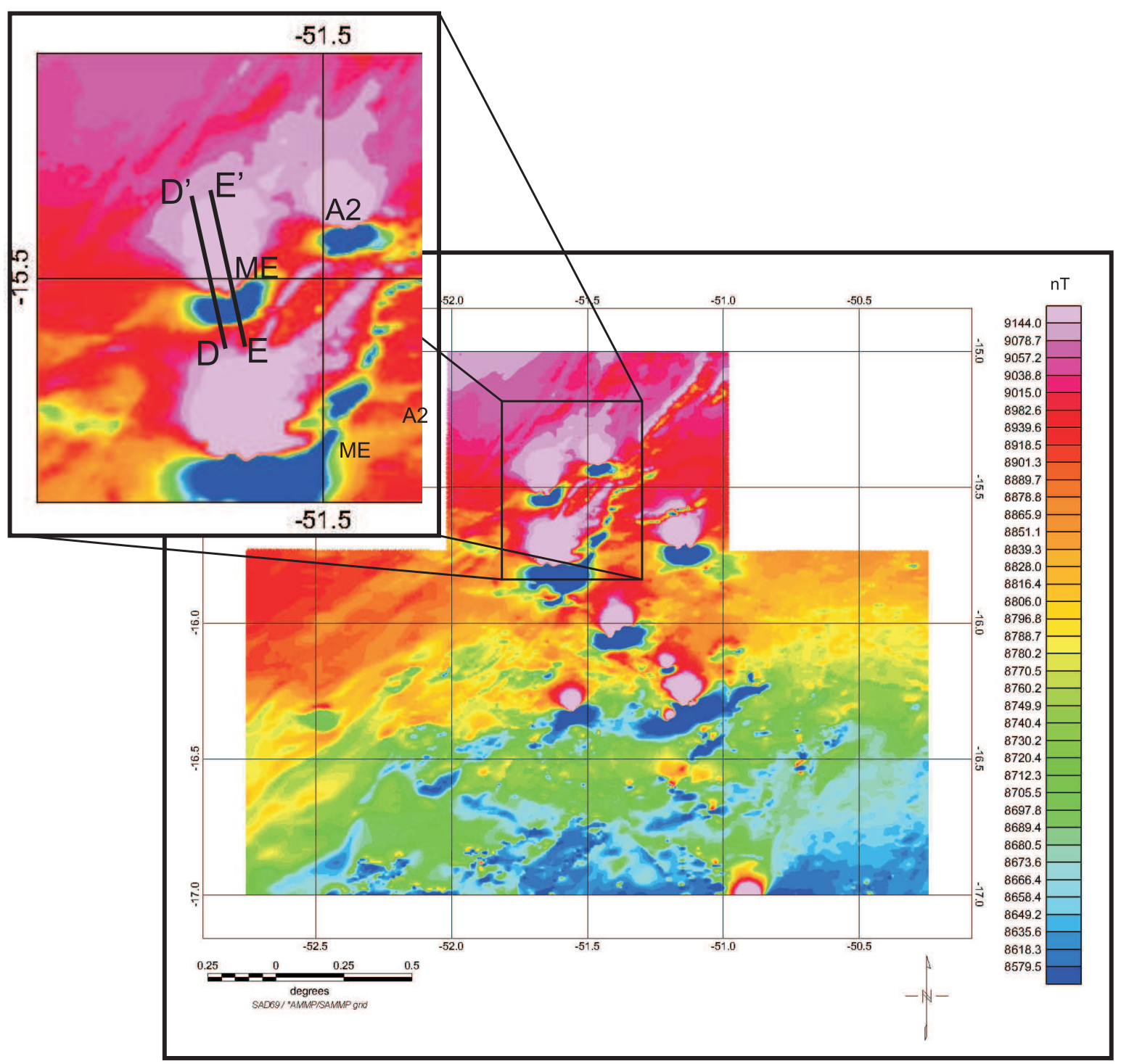

Figura 2.8: Mapa de campo magnético total. 
Desses dados removeu-se o IGRF - International Geomagnetic Reference Field para o ano de 1973. Após a remoção do IGRF verificou-se que os valores ainda permaneciam positivos, sendo necessária a remoção de um valor próximo à mediana. Isso foi feito para toda a área do projeto Iporá, e o resultado na área de interesse está na figura 2.9.

O mapa aeromagnético residual foi elaborado para permitir que as anomalias positivas e negativas fossem ressaltadas. Eles foram elaborados usando o programa Oasis Montaj 5.1 (Geosoft, 1994).

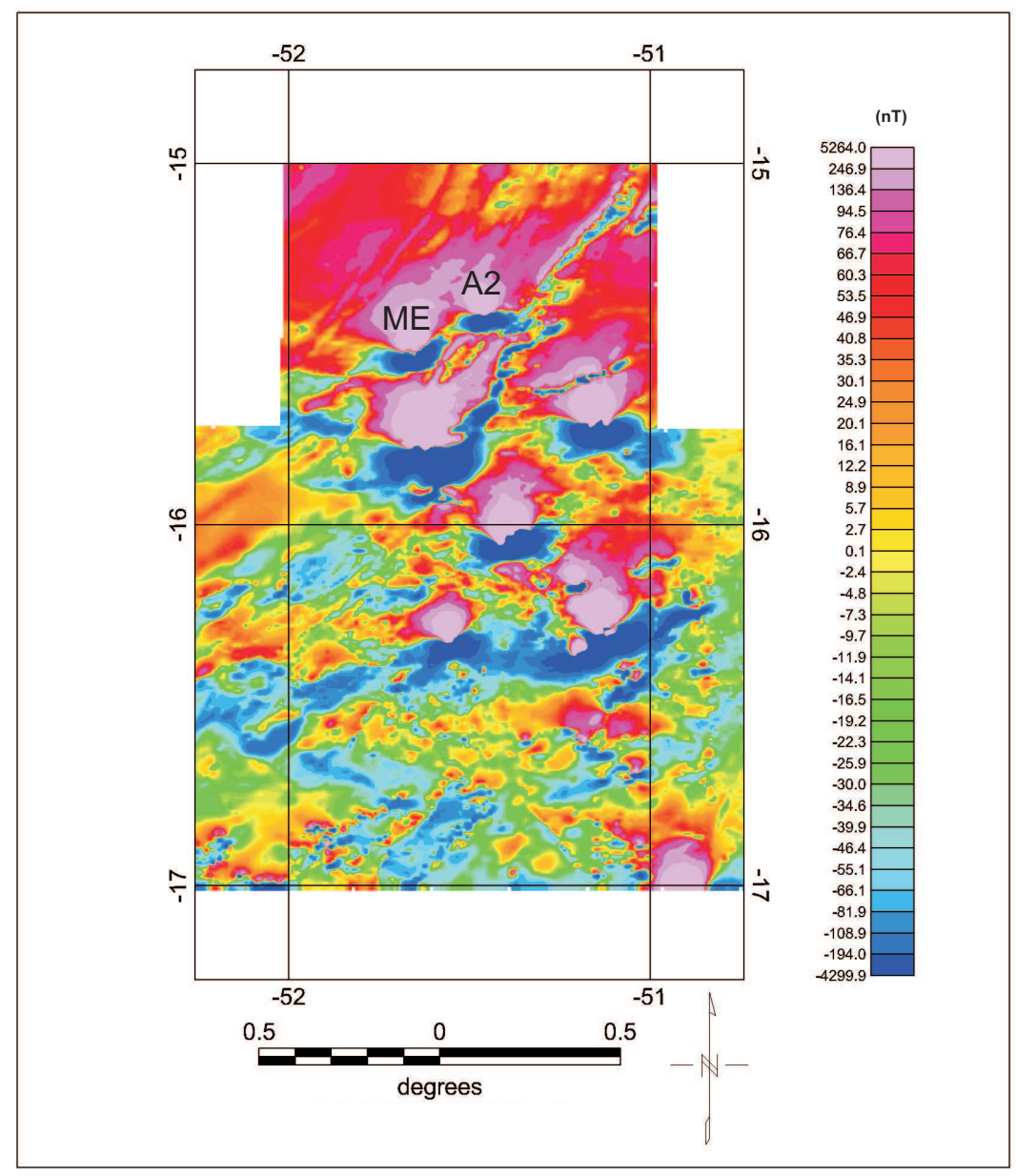

Figura 2.9: Mapa de campo magnético residual. 


\subsubsection{Tratamento dos dados}

Algumas transformações lineares (filtros) foram aplicadas aos dados para processar mudanças na amplitude e/ou fase relacionada ao conjunto de ondas seno que constituem todo o grid dos dados. Essas transformações podem ser realizadas no domínio do número de ondas através da seguinte multiplicação

$$
G(w) \cdot F(w)
$$

em que $\mathrm{G}(\mathrm{w})$ é a a anomalia gravimétrica ou magnética no domínio do número de ondas e F(w) é um filtro específico também no domínio do número de ondas.

A representação espectral generalizada dos campos magnéticos está presente em muitas das transformações possíveis. A multiplicação do espectro do campo pelo fator $F_{a}=$ $e^{-h\left(u^{2}+v^{2}\right)^{1 / 2}}$ converte-o no espectro do campo hipoteticamente medido a uma distância $h$ sobre o plano de observação do campo original, onde $u$ e $v$ são definidos como o número de ondas na direção x e y, respectivamente. A transformada inversa de Fourier volta ao domínio do espaço e dá o campo atual ao nível superior. Isto é equivalente a convoluir o campo no domínio do espaço por um operador (ou filtro). Todas as transformações do campo magnético trabalham neste caminho (Gunn, 1975);(Milligan and Gunn, 1997).

O cálculo do campo a níveis superiores é chamado de continuação para cima e o processo tem uma resposta da freqüência de $e^{-h\left(u^{2}+v^{2}\right)^{1 / 2}}$. Isto propõe que a continuação para cima remove anomalias de alta freqüência relativamente a anomalias de baixa freqüência. O processo pode ser usado para suprimir o efeito de anomalias mais rasas quando se pretende detalhar as anomalias mais profundas. 
O efeito da amplitude do sinal analítico é o de realçar as bordas das fontes das anomalias e é muito útil no caso de dados magnéticos que contenham influência de magnetização remanescente ou tomado a baixas latitudes magnéticas. Matematicamente ele é o módulo de gradiente 3D do campo cuja equação é:

$$
|A(x, y)|=\left[\left(\Delta T_{x}\right)^{2}+\left(\Delta T_{y}\right)^{2}+\left(\Delta T_{z}\right)^{2}\right]^{\frac{1}{2}}
$$

onde $\Delta T_{z}=d \Delta T / d z$ é a primeira derivada vertical da anomalia $\Delta T$ do campo magnético e $\Delta T_{x}=d \Delta T / d x, \Delta T_{y}=d \Delta T / d y$ são derivadas horizontais da anomalia $\Delta T$ do campo magnético (Nabighian, 1972).

A amplitude do sinal analítico é uma função simétrica em formato seno com máximo exatamente sobre o topo de cada contato e largura relacionada diretamente com a profundidade do corpo.

Para os processamentos de filtros utilizou-se o software Magmap (Geosoft, 1994). Na figura 2.10 tem-se o mapa de amplitude do sinal analítico onde as anomalias demarcam exatamente a posição das estruturas. A importância da função do sinal analítico reside no contexto de interpretação, pois a mesma é completamente independente da direção de magnetização e da direção do campo da Terra. Os picos da função do sinal analítico são simétricos e ocorrem diretamente sobre toda extensão das bordas dos corpos e centro do limite dos mesmos. Interpretações de mapas do sinal analítico podem fornecer indicações da geometria das fontes magnéticas e o contato dos corpos ficam localizadas nas bordas da anomalia, sendo possível inferir o tamanho do corpo. Se as fontes dos picos são contatos magnéticos verticais, a largura das anomalias é proporcional a sua profundidade.

Pode-se observar na figura 2.10 a sobreposição de sinais de largura variada dificultando 


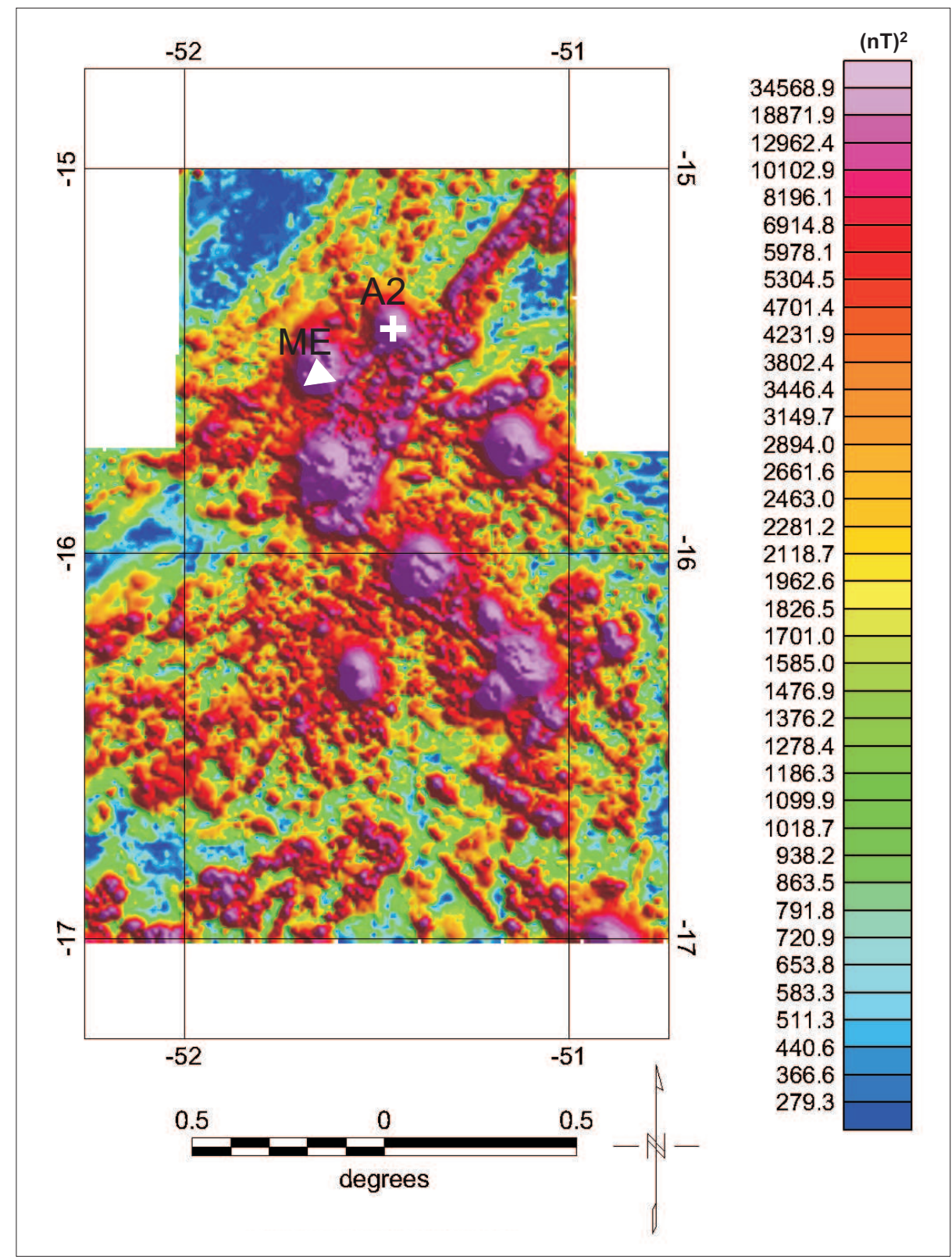

Figura 2.10: Mapa de amplitude do sinal analítico dos dados aeromagnético. O símbolo $\triangle$ representa o local onde $\mathrm{ME}$ aflora e + a localização inferida para A2.

a interpretação desse mapa. A técnica amplitude do sinal analítico foi aplicada ao nível de 2000m como mostrado na figura 2.11, esta técnica foi utilizada para obter melhor definição na localização e delimitação do corpo. O processo de continuação para cima elimina o efeito de anomalias rasas no estudo sobre as fontes mais profundas.

Considerando as fontes como cilindros verticais o pico da função sinal analítico, que 


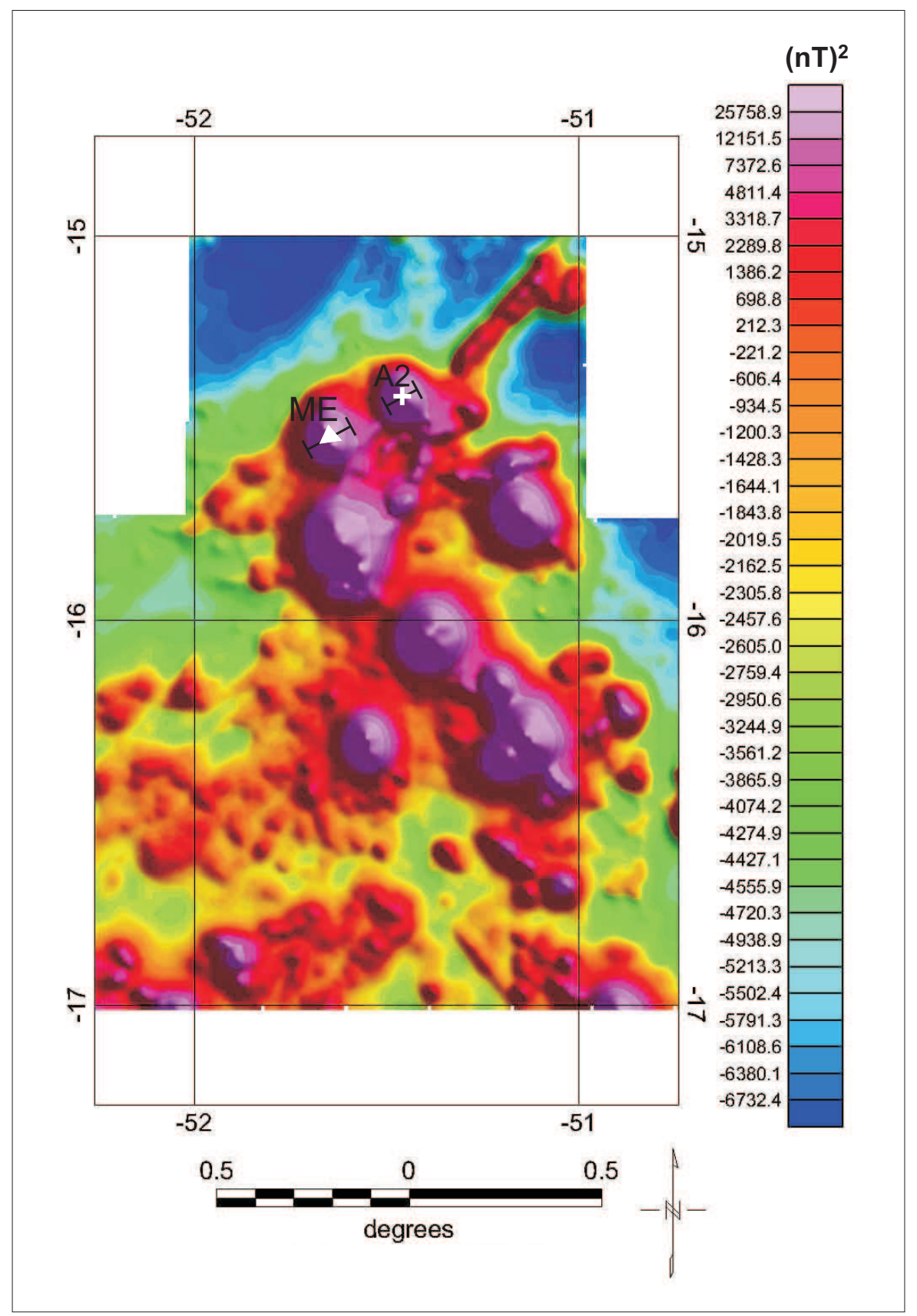

Figura 2.11: Mapa aeromagnético de amplitude do sinal analítico continuado a $2000 \mathrm{~m}$. O símbolo $\triangle$ representa o local onde $\mathrm{ME}$ aflora e $+\mathrm{a}$ localização inferida para A2.

limita as bordas do corpo, nota-se na superfície de dados da amplitude do sinal analítico um diâmetro em ME de $10 \mathrm{~km}$ e para A2 de $8 \mathrm{~km}$ aproximadamente. 


\subsubsection{Estimativa da profundidade}

Existem alguns métodos gráficos para determinação da profundidade do topo do corpo. Um deles é o modelo de meia largura derivado da fórmula do sinal do monopolo e dipolo em campo vertical e horizontal Gunn (1997). É aplicado às fontes anômalas de forma geométrica simples onde a profundidade do seu topo (h) está relacionada com a meia largura da anomalia.

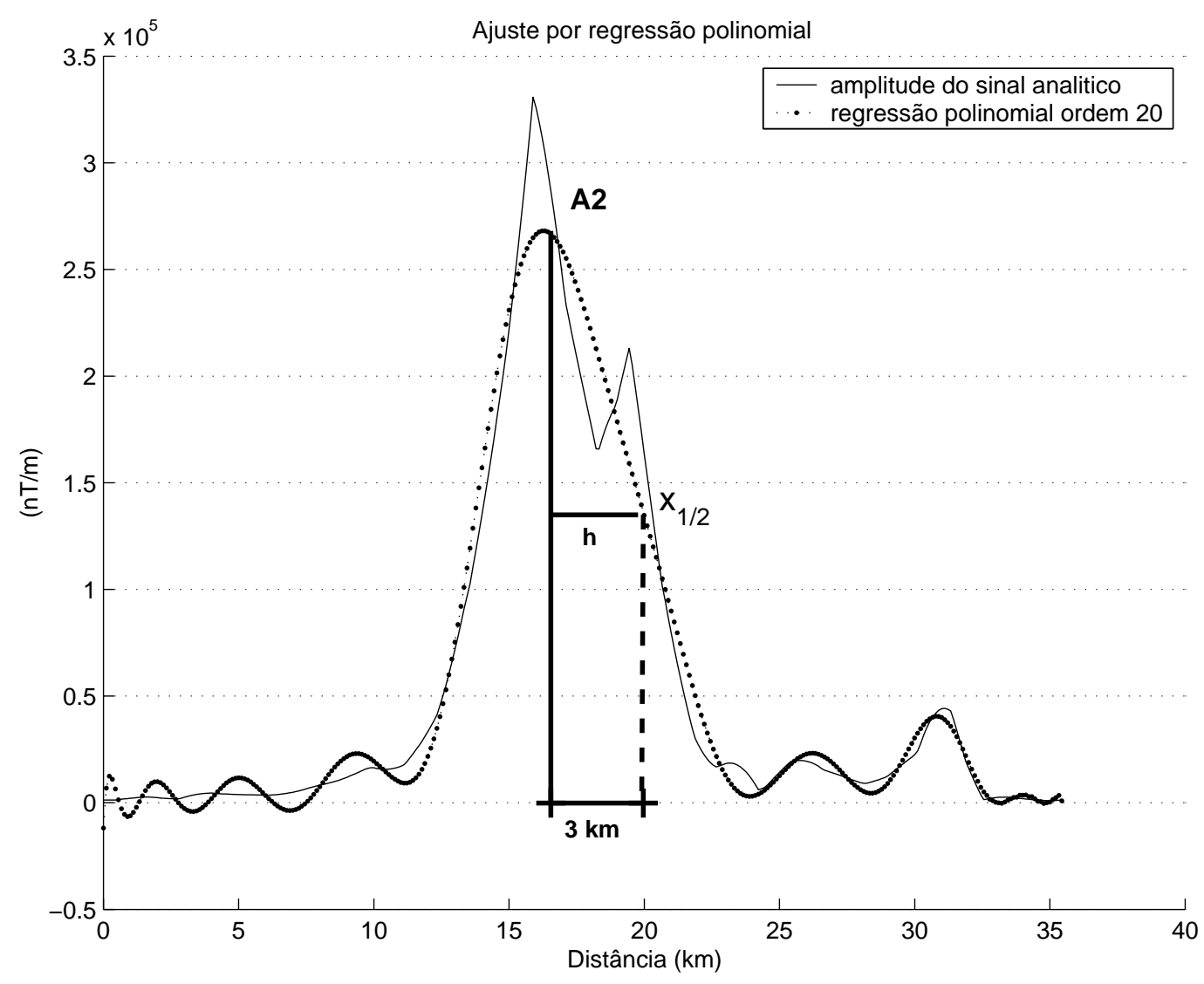

Figura 2.12: Curva de amplitude do sinal analítico para A2.

A meia largura é a distância horizontal $\left(x_{1 / 2}\right)$ entre o máximo principal da anomalia (assumindo estar sobre o centro da fonte) e o ponto onde o valor é exatamente a metade do valor máximo (Nabighian, 1972). Este método é válido apenas para formas simples ajustadas como uma esfera (dipolo), cilindro vertical (monopolo) e outras. 
Este método foi aplicado para estimativa do topo h da fonte. A curva para amplitude do sinal analítico foi ajustada pelo método dos mínimos quadrados (curva pontilhada na 2.12). A distância entre valor máximo obtido e a meia largura tirada do gráfico da sugere h em torno de $3 \mathrm{~km}$ para A2, como mostrado na figura 2.12. Dados de casos históricos sugerem que a determinação da profundidade por este método tem acurácia de \pm 15 por cento (Gunn, 1997).

Outra formulação para estimar a profundidade é assumir que a fonte é um cilindro vertical e a sua profundidade $z_{0}$ pode ser estimada utilizando um caso especial da expressão geral conhecida como expressão de Euler para equações homogêneas (Reid et al., 1990); (Thompson, 1982):

$$
\left(x-x_{0}\right) \frac{\partial T(x, y, z)}{\partial x}+\left(y-y_{0}\right) \frac{\partial T(x, y, z)}{\partial y}+\left(z-z_{0}\right) \frac{\partial T(x, y, z)}{\partial z}=-\eta T(x, y, z)
$$

em que $(\mathrm{x}, \mathrm{y}, \mathrm{z})$ são os pontos de observações, $\left(x_{0}, y_{0}, z_{0}\right)$ são as localizaçoes da fonte magnética e $\eta$ é um fator relacionado ao decaimento da anomlia magnética $(\eta=3$ para um dipolo, $\eta=2$ para um monopolo). Quando $x=x_{0}, y=y_{0}, z=z$ ero e $\eta=2$ que corresponde a uma fonte do tipo monopolos (cilindro vertical ou horizontal) a equação acima é simplificada como

$$
z_{0}=-2 T(x, y, z) / \frac{d T(x, y, z)}{d z}
$$

A estimativa da profundidade máxima do corpo estimada através do método do gradiente vertical, calculada pela relação (2.5) considerando um cilindro vertical com $\eta=2$. Sob as fontes das anomalias foram passadas janelas e calculado qual seria a profundidade máxima. Os resultados foram mostrados nos histogramas das figuras 2.13 e 2.14. Os valores negativos correspondem a $Z$ acima da superfície (aflorantes) e os valores positivos 
para subsuperfície. Os valores próximos de zero correspondem às regiões sem anomalia.

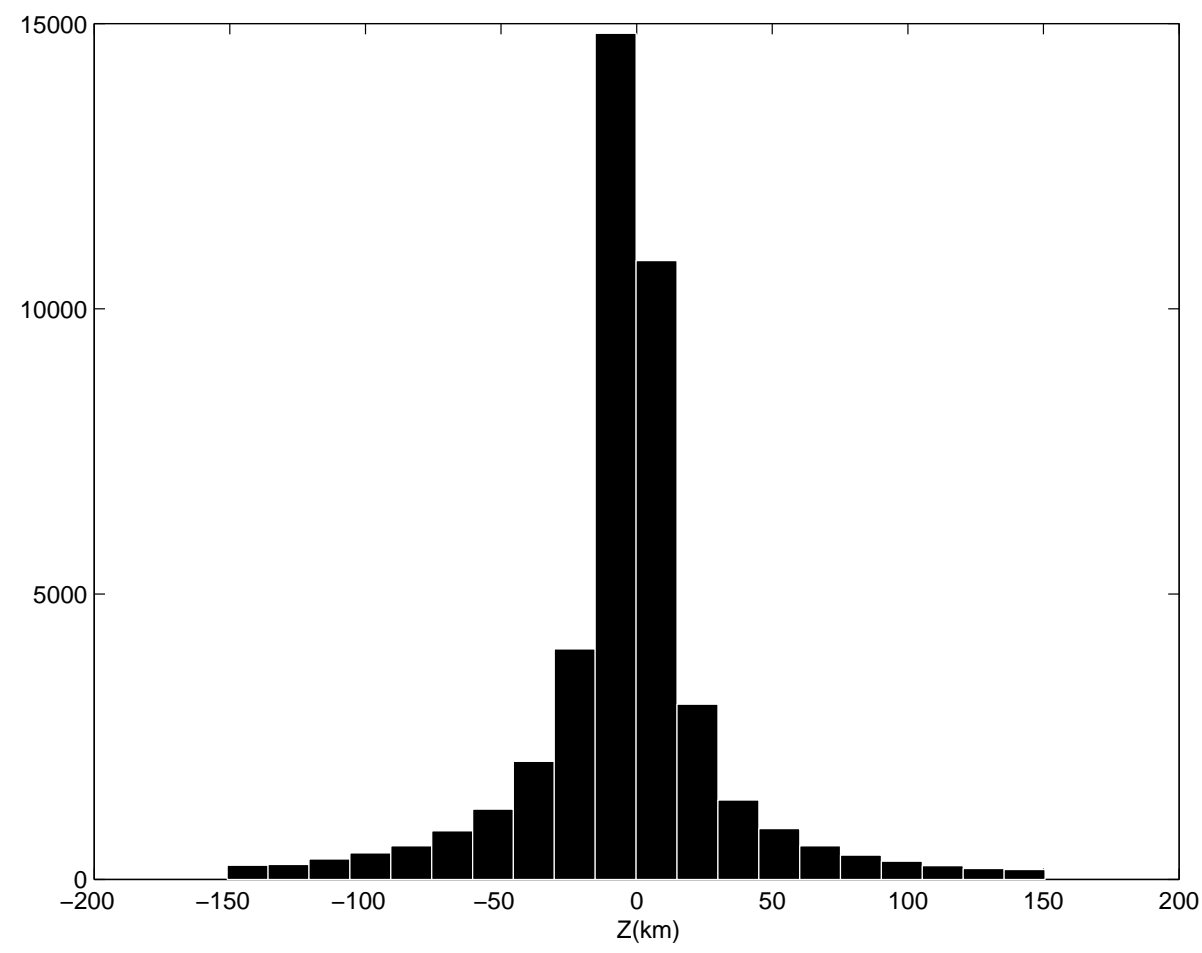

Figura 2.13: Histograma das soluções de profundidade para toda a região de Iporá.

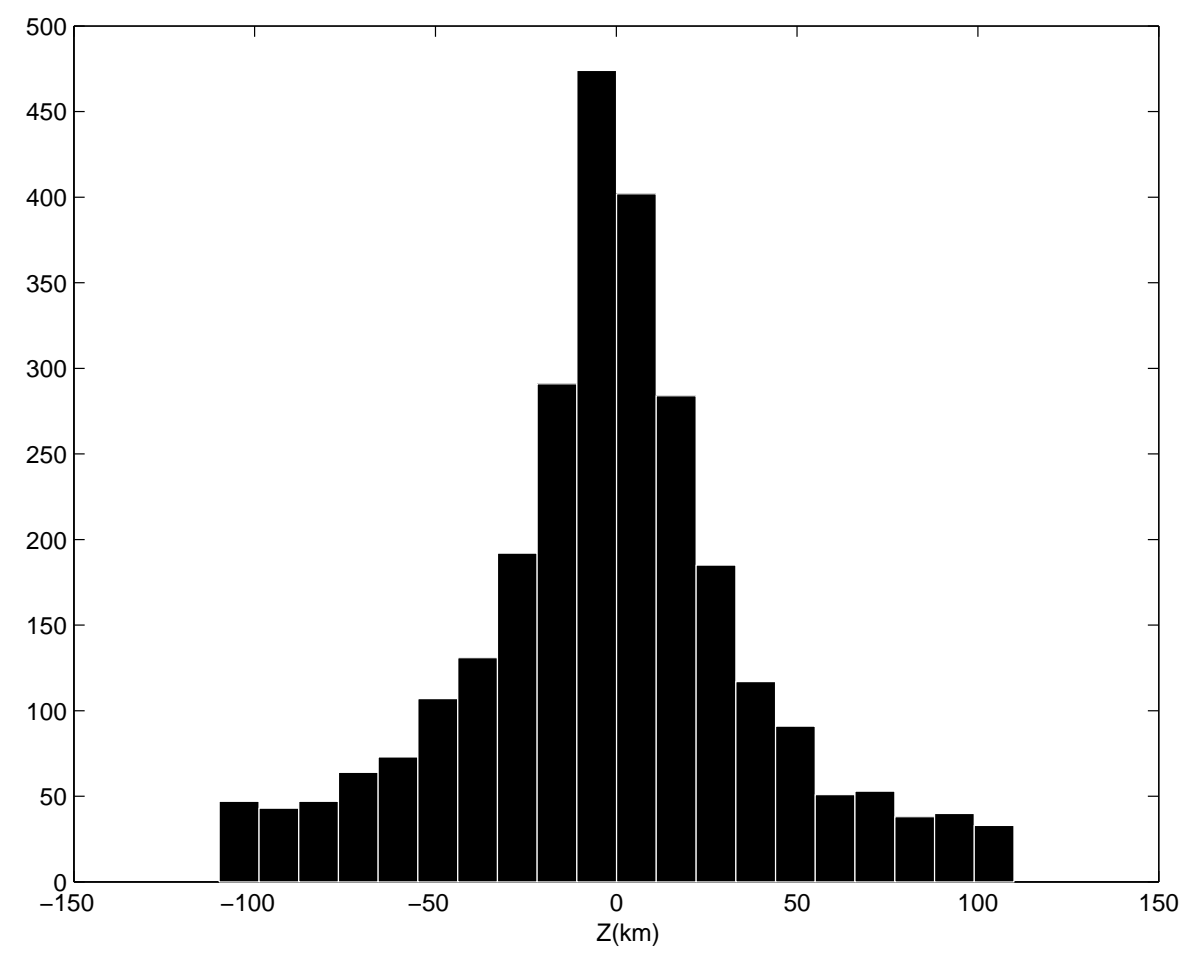

Figura 2.14: Histograma das soluções de profundidade para região de ME e A2. 


\subsection{Propriedades físicas das amostras}

As amostras foram coletadas em afloramento cuja localização e descrição encontram-se apresentadas na tabela 2.1. A observação da continuidade dos tipos litológicos em campo é dificultada devido à serpentinização e alteração intempérica impostas ao material, o que leva ao pequeno número de amostras coletadas, sendo algumas encontradas próximas à zonas de cisalhamento.

Tabela 2.1: Localização das amostras e descrição litológica.

\begin{tabular}{lllcc}
\hline $\mathrm{N}^{\circ}$ & Longitude & Latitude & Tipo & prof. do poço $(\mathrm{m})$ \\
\hline 1 & $-51,3848$ & $-15,2946$ & Dunito & - \\
2 & $-51,407$ & $-13,029$ & Piroxênito & - \\
3 & $-51,3907$ & $-16,0454$ & Dunito bastante alterado & - \\
4 & $-51,3901$ & $-16,0453$ & Diorito & - \\
5 & $-51,1413$ & $-15,752$ & Piroxênito alterado & - \\
6 & $-51,07$ & $-16,1454$ & Veio de Quartzo & - \\
7 & $-51,3906$ & $-16,281$ & Veio de Quartzo & - \\
8 & $-51,1413$ & $-15,7401$ & Dunito bastante alterado & - \\
9 & $-51,1413$ & $-15,7401$ & Granito & - \\
10 & $-51,1413$ & $-15,7401$ & Dunito alterado & - \\
11 & $-51,1133$ & $-15,7549$ & Dunito alterado & - \\
12 & $-51,682$ & $-15,542$ & Dunito alterado & 14,35 \\
13 & $-51,1232$ & $-15,7329$ & Piroxênito & 10,35 \\
14 & $-51,1232$ & $-15,7329$ & Dunito alterado & 25,9 \\
15 & $-51,1648$ & $-15,7365$ & Dunito alterado & 38,4 \\
16 & $-51,1657$ & $-15,7365$ & Dunito alterado & 45,2 \\
17 & $-51,1666$ & $-15,7365$ & Dunito alterado & 22,55 \\
18 & $-51,1676$ & $-15,7365$ & Olivina-Piroxenito & 20,15 \\
19 & $-51,1647$ & $-15,7347$ & Piroxênito & 39,68 \\
20 & $-51,1657$ & $-15,7347$ & Dunito alterado & \\
\hline
\end{tabular}

As amostras foram cedidas pela empresa Teckcominco Brasil S.A. onde as de número 13 a 20 são partes de testemunhos de poços perfurados pela mesma empresa. Cada uma delas foi analisada em microscópio óptico para se obter a desrição da mineralogia de 
cada litotipo encontrado, com o auxílio do professor Ricardo Trindade (grupo de Paleomagnetismo - IAG/USP). Não foi possível analisar as amostras 13 e 18 pois as mesmas encontram-se bastante alteradas não havendo possibilidade de confeccionar as lâminas. Nas amostras restantes foram observados os principais minerais desse tipo de rocha e uma breve descrição de cada amostra será feita a seguir.

As amostras 2, 5 e 19 foram classificadas como piroxenitos, onde a 2 é rica em enstatita. Piroxênio é o grupo mais importante das rochas formadas por silicatos ferromagnesianos e ocorre como fase estável em muitos tipos de rochas ígneas. A caracterísitica de pleocroismo do verde para o rosa é uma boa indicação da presença de ortopiroxênio (MacKenzie and Guilford, 1980); (Deer et al., 1992). Os outros minerais nas amostras são quartzo, feldspato alcalino, plagioclásio e cristais de biotita. As amostras 5 e 19 estão bem alteradas, mas preservam o mineral no centro (ortopiroxênio). A magnetita é encontrada em grande quantidade.

As amostras 3, 8, 10, 11, 12, 14, 15, 16, 17 e 20 foram classificadas como dunitos que se encontram de forma bastante alterada. O dunito é constituído de olivina magnesiana, que se apresentou pouquíssimo preservada nestas amostras. Na amostra 8 não se observa a olivina. Na amostra 10 a olivina encontra-se um pouco mais preservada que nas outras sendo que também foram encontrados serpentina e talco. A alteração da olivina leva à formação da magnetita, observada em grande quantidade em todas as amostras, que é adicionada ao opaco original da rocha.

A amostra 6 é composta por quartzo e a amostra 7 por quartzo e muscovita, as duas foram classificadas como veios de quartzo. A amostra 9 é um granito com biotita e magnetita associada a biotita na maioria das vezes. A biotita é invariavelmente marrom 
ou verde em cores (Deer et al., 1992). A amostra 4 foi classificada como um tonalito, apresentando biotita, quartzo, plagioclásio.

Como a maior parte dos minerais máficos nas amostras encontram-se bastante alterados se torna muito arriscado utilizar os valores de densidade destas amostras como o valor para a rocha total. Não há problema algum em se utilizar os valores de susceptibilidade encontrados pois a quantidade de magnetita das amostras apresentou-se bastante representativa.

Os dados de densidades foram obtidos com medidas do peso da amostra no ar e do peso da amostra submersa em água. A figura 2.15 apresenta os resultados dessas medidas.

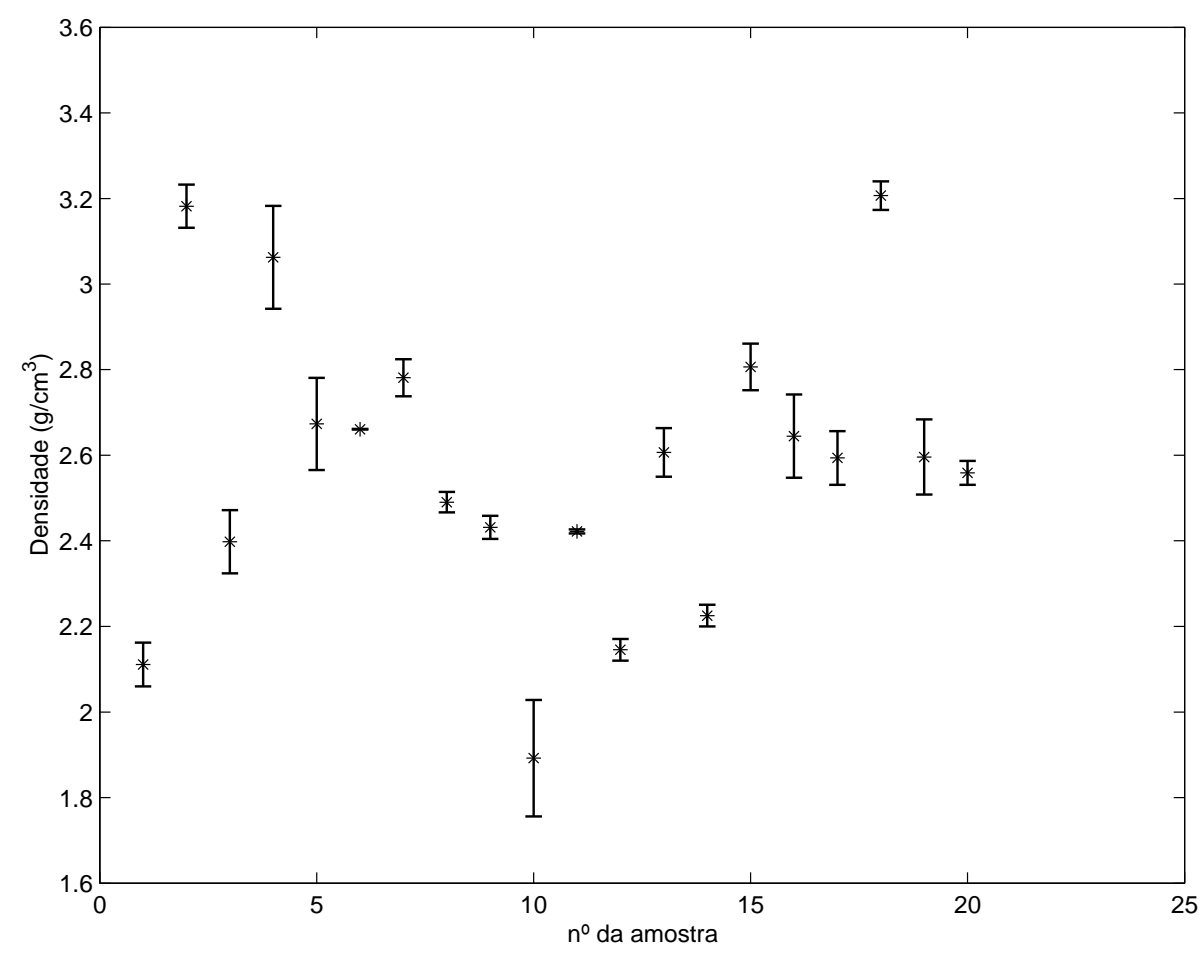

Figura 2.15: Densidade média * e desvio padrão (barra vertical) de cada amostra.

As medidas de susceptibilidade magnética foram determinadas no local usando o susceptibilímetro do Depto. de Geofísica e também no Laboratório de Paleomagnetismo - IAG/USP. Não foi possível obter medidas desse parâmetro em todas as amostras, pois 


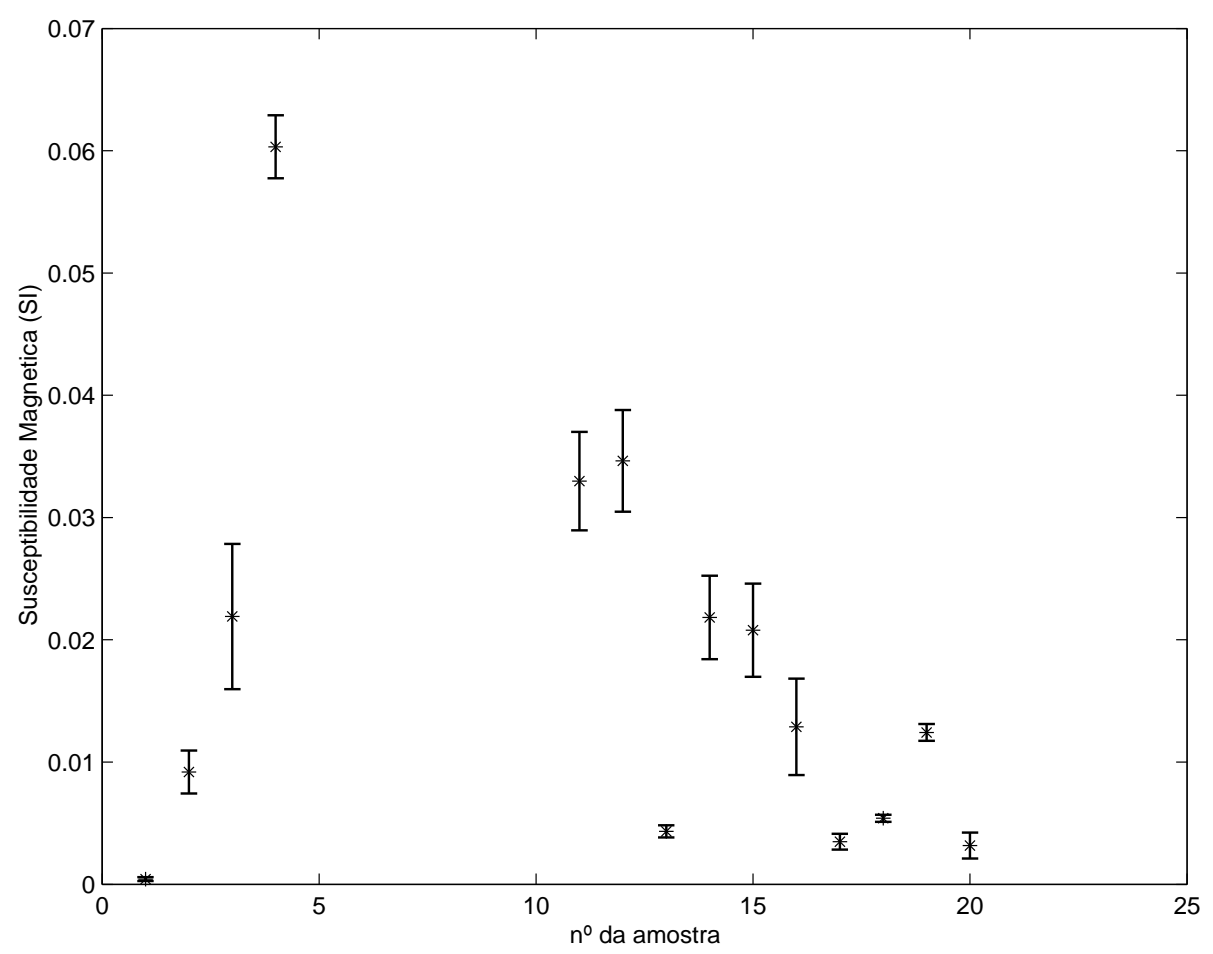

Figura 2.16: Susceptibilidade média * e desvio padrão (barra vertical) de cada amostra.

algumas delas encontram-se em estado bastante alterado tendo sido coletadas em zonas de afloramento perto de rochas bastante cisalhadas. É provável que a alteração tenha afetado os minerais magnéticos presentes o que invalidaria os resultados das medidas. Estes estão mostrados na figura 2.16. A tabela 2.2 apresenta os resultados dos valores medidos em laboratório para verificar a existência de magnetização remanescente. Alguns desses valores de susceptibilidade puderam ser utilizados no modelamento dos corpos estudados.

\subsubsection{Magnetização remanescente}

Pode-se descrever o que ocorre no interior dos materiais magnéticos fazendo intervir explicitamente dois campos magnéticos, um que é representado por $\vec{B}$ - designado por indução magnética - e outro representado por $\vec{H}$ - designado por campo magnético (Telford 
et al., 1976). A relação entre esses dois campos é dada por:

$$
\vec{B}=\mu_{0}\left(\vec{H}+\vec{J}^{M}\right)
$$

em que $\vec{J}^{M}$ representa a parte de excitação magnética que é gerada pela presença da matéria e é, ao mesmo tempo, a soma dos momentos elementares por unidade de volume. O movimento de uma bússola na superfície da Terra mostra que o Campo Magnético da Terra (CMT) exerce sobre um determinado tipo de material, um momento cuja magnitude é proporcional ao momento magnético total do material $\vec{M}$. Este momento magnético pode ser considerado do ponto de vista macroscópico como o valor integrado da magnetização volumétrica por $\vec{J}^{M}$, ou seja:

$$
\vec{M}=\int_{V} \vec{J}^{M} d v
$$

Deste modo, sempre que for discutido o CMT tem-se a presença de dois campos $\vec{B}$ e $\vec{H}$. O primeiro é considerado sempre que forem analisadas as observações experimentais do CMT à superfície; o segundo será considerado sempre que for analisada a interação com os materiais terrestres.

A magnetização volumétrica é função da história magnética da rocha, que determina a magnetização remanescente do material, e do campo magnético ambiente, que determina a magnetização induzida. Em uma primeira aproximação quando a susceptibilidade é muito pequena, como é mais freqüente no caso de material encontrado em exploração mineral, a magnetização $\vec{M}$ é proporcional à susceptibilidade e é dada pelo produto da susceptibildade $(\chi)$ com o campo magnético $\vec{H}_{0}$,

$$
\vec{M}=\chi \vec{H}_{0}
$$

onde $\vec{H}_{0}=\vec{B}_{0} / \mu_{0}$, o valor de $B_{0}$ adotado foi de $25000 \mathrm{nT}$ correspondente ao CMT próximo ao equador magnético. 
Tabela 2.2: Medidas de magnetização remanescente e razão de Konigsberger.

\begin{tabular}{lccccc}
\hline \multicolumn{1}{c}{$\chi$} & $M_{R}$ & & $\mathrm{Q}$ \\
$\mathrm{N}^{\mathrm{o}}$ & $(\mathrm{SI})$ & média & $(\mathrm{SI})$ & média & \\
\hline 1 & $0,0003-0,0007$ & 0,0004 & $0,0937-0,2689$ & 0,1568 & 10,5529 \\
2 & $0,0073-0,0114$ & 0,0092 & $1,2995-1,7653$ & 1,5803 & 6,9474 \\
3 & $0,0141-0,0284$ & 0,0219 & $1,1126-1,6838$ & 1,3635 & 2,7570 \\
4 & $0,0288-0,0822$ & 0,0603 & $2,7138-5,3897$ & 3,9227 & 2,9844 \\
11 & $0,0277-0,0379$ & 0,0330 & $1,3238-2,3915$ & 1,8457 & 2,2624 \\
12 & $0,0274-0,0380$ & 0,0346 & $6,6236-8,3423$ & 7,6455 & 9,0756 \\
13 & $0,0038-0,0050$ & 0,0043 & $3,9732-6,6285$ & 2,1203 & 19,6837 \\
14 & $0,0170-0,0247$ & 0,0218 & $5,3518-9,9158$ & 5,5808 & 10,5976 \\
15 & $0,0163-0,0255$ & 0,0208 & $14,3420-25,4191$ & 1,8728 & 40,5418 \\
16 & $0,0072-0,0156$ & 0,0129 & $15,3434-25,4191$ & 1,5849 & 45,3367 \\
17 & $0,0028-0,0039$ & 0,0035 & $2,7388-8,8263$ & 5,9884 & 65,3156 \\
18 & $0,0051-0,0057$ & 0,0054 & $0,5646-1,1270$ & 8,4586 & 6,1659 \\
19 & $0,0120-0,0132$ & 0,0124 & $3,6074-7,6899$ & 6,0916 & 19,5830 \\
20 & $0,0024-0,0039$ & 0,0032 & $1,8077-4,6119$ & 3,2098 & 38,0585 \\
\hline \multicolumn{6}{c}{$\chi$ é a susceptibilidade magnética } \\
$M^{R}$ é a magnétização remanescente & \\
\hline \multicolumn{6}{c}{ Q é a razão de Konigsberger } \\
\hline
\end{tabular}

A magnetização volumétrica é gerada pelo CMP, pelo que se torna necessário conhecer de que maneira e por que processos essa influência é realizada. De uma forma simplificada, pode-se partir de uma expressão do tipo:

$$
\vec{M}=\chi \vec{H}+\vec{M}^{R}
$$

em que o termo $\vec{H}$ corresponde à componente induzida - que existe apenas na presença de um campo magnético ambiente - e o termo $\vec{M}^{R}$ à componente remanescente da magnetização, que corresponde à componente permanente da magnetização.

As medidas da magnetização remanescente das amostras na tabela 2.2 foram utilizadas no cálculo da medida da importância relativa da magnetização remanescente em relação à magnetização induzida, dada pela razão de Konigsberger:

$$
Q=\frac{\vec{M}^{R}}{\chi \vec{H}}
$$


A equação 2.10 aplicada aos valores das amostras mostrou uma importância muito maior para magnetização remanescente do que para magnetização induzida.

As amostras não foram coletadas de forma orientada, de modo que a inclinação $\left(\mathrm{I}_{R}\right)$ e a declinação $\left(D_{R}\right)$ remanescente não puderam ser determinadas. Para contornar esse problema foi usada a posição do pólo paleomagnético de idade Cretácea para determinar a posição da amostra na época da extrusão desse material e obter a $\mathrm{I}_{R}$ usando a relação 2.11 entre latitude e inclinação do campo magnético, mantendo $\mathrm{D}_{R}$ próximo ao valor do campo atual, pois as informações encontradas na literatura não sugerem variação.

$$
\tan I_{R}=2 * \tan \lambda
$$

Com muitos dados paleomagnéticos é possível reconstruir o movimento das placas no passado. Ernesto (1996) realizou a reconstrução do movimento da placa Sul Americana de acordo com as rotações indicadas pelos pólos magnéticos médios obtidos a partir de amostras de diferentes idades. As rotações embora pequenas são melhor avaliadas pela comparação da rotação do eixo da placa para cada idade. Dentre as idades estudadas inclui-se o período Cretáceo Superior que está relacionado à formação das rochas alcalinas aqui estudadas. Segundo o trabalho de Ernesto (1996) quando a rocha foi magnetizada ela se encontrava na latitude de $25^{\circ} \mathrm{S}$. O valor de $I_{R}$ calculado é $-43^{\circ} \pm 5^{\circ}$. 


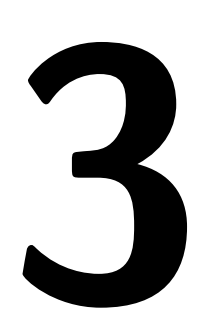

\section{METODOLOGIA}

As anomalias gravimétricas e magnéticas da área estudada foram interpretadas baseando-se no método de modelamento direto 2,5D e inversão 2D e 3D. Os fundamentos teóricos do modelamento direto 2,5D e das técnicas inversão utilizadas estão apresentados neste capítulo.

Foram aplicadas duas técnicas de inversão: 2D e 3D, com o objetivo de recuperar o modelo para distribuição de densidade em subsuperfície. Para o modelo de susceptibilidade magnética foi utilizada apenas a técnica de inversão 3D.

As técnicas de inversão empregadas aos dados observados foram baseadas em informações de perfis gravimétricos para obter o modelo 2D e grades regulares dos dados gravimétricos ou magnéticos para o modelo 3D. A inversão 3D foi utilizada para que o modelo obtido ficasse mais próximo da geometria real dos corpos.

O desenvolvimento das rotinas para inversão pode ser tratado como uma progressão lógica do modelamento direto. Ambas rotinas produzem um modelo geológico em subsuperfície a partir das observações em superfície do campo gravimétrico ou magnético. A 
principal diferença é que o modelamento direto é realizado interativamente (tentativa e erro) e apresenta a possibilidade de se utilizar os sinais gravimétrico e magnético de forma conjunta, enquanto que a inversão é realizada de forma automática e ambos sinais são tratados separadamente.

\subsection{Modelamento direto 2,5D}

O modelamento direto é uma técnica geralmente empregada em corpos de estruturas 2D com extensão 2,5D (correção da borda do corpo), não sendo a mais aproriada para as intrusões alcalinas estudadas que são estruturas 3D. O programa disponível permite a interpretação conjunta dos sinais gravimétricos e magnéticos e optou-se por utilizar na anomalia cujo corpo aflora (ME) aumentando o vínculo no modelamento. O objetivo foi investigar o comportamento conjunto dos dois sinais, tomando-se o cuidado de reproduzir um corpo 3D com a melhor aproximação possível na análise dos resultados obtidos.

O modelamento conjunto foi realizado com perfil residual de anomalia Bouguer obtido com ajuste polinomial de grau 1 da figura 2.3a. Os perfis magnéticos foram retirados diretamente dos mapas aeromagnéticos de campo total na escala de 1:50.000, suas localizações encontram-se na figura 2.8 e os valores do campo magnético total e residual estão na figura 3.1.

As informações dos parâmetros geométricos como a localização, limites e profundidades dos corpos discutidos nas seções 3.2.2 e 3.2.3 foram utilizadas no modelamento conjunto dos sinais gravimétrico e magnetométrico.

O Departamento de Geofísica do IAG dispõe do programa GravMag (Pedley et al., 1993) que realiza o modelamento conjunto usando uma geometria 2,5D baseado no método 

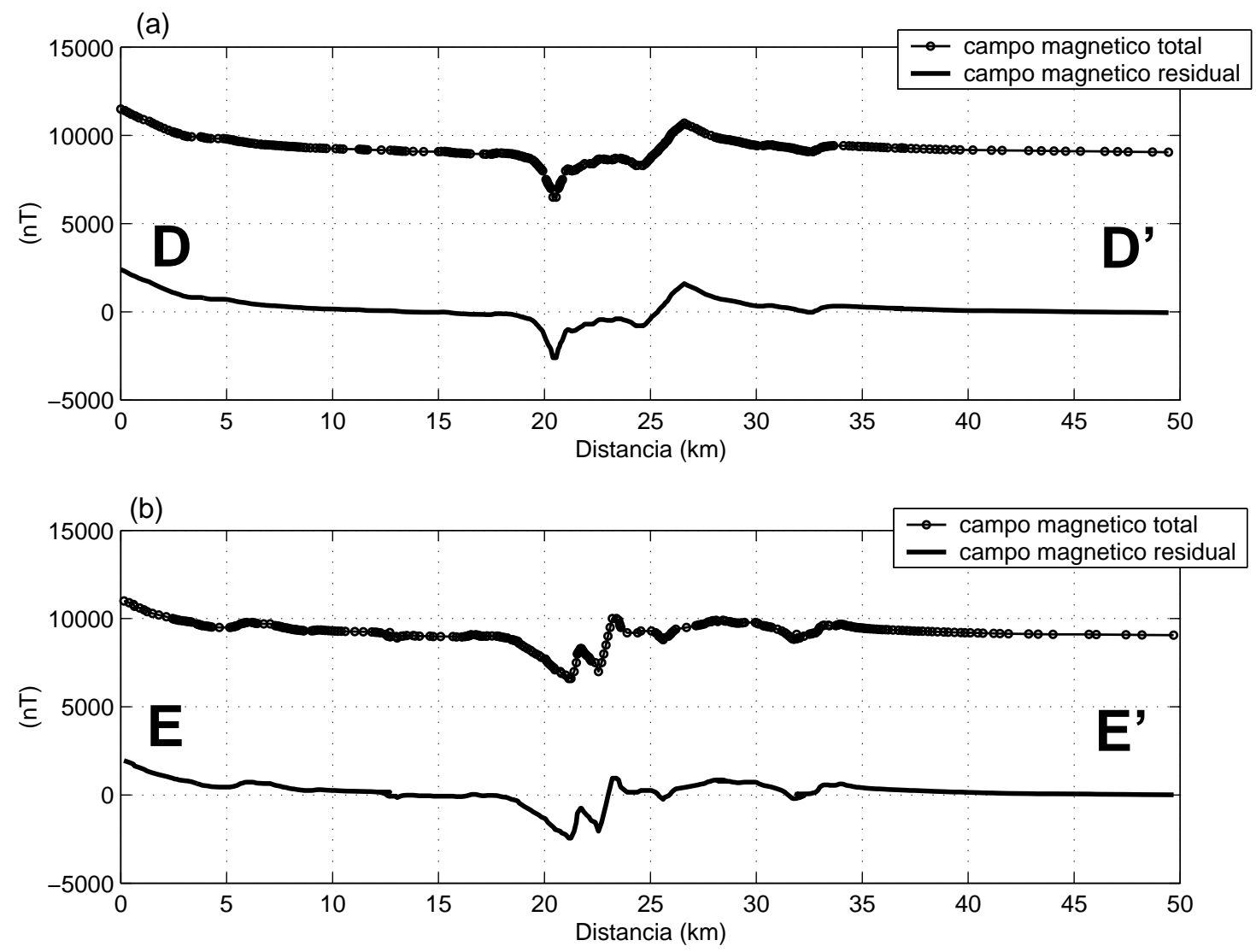

Figura 3.1: Perfis do campo magnético total e anomalia magnética residual: (a) Perfil magnético $D^{\prime} D$ e (b) Perfil magnético $E^{\prime} E$.

de Talwani et al. (1959).

Segundo o trabalho de Talwani et al. (1959) muitos corpos e estruturas geológicas podem ser simplificados usando-se estruturas lineares. As seções dessas feições são aproximadas por um conjunto de polígonos fechados de $n$ vértices, onde é possível calcular, por meio de expressões algébricas, as componentes horizontal e vertical da atração gravitacional em um ponto qualquer, como mostrado na figura 3.2. Adota-se um sistema de coordenadas cartesianas com origem no ponto $\mathrm{P}$ do plano $x z$ e o eixo- $z$ positivo apontando verticalmente para baixo. Nessa geometria consideram-se os ângulos $\theta_{i}$ entre o plano xz e a reta ligando o ponto $\mathrm{P}$ ao ponto médio de cada lado do polígono e o ângulo $\vartheta_{i}$ entre o vértice $i$ e o plano xz (figura 3.2). 


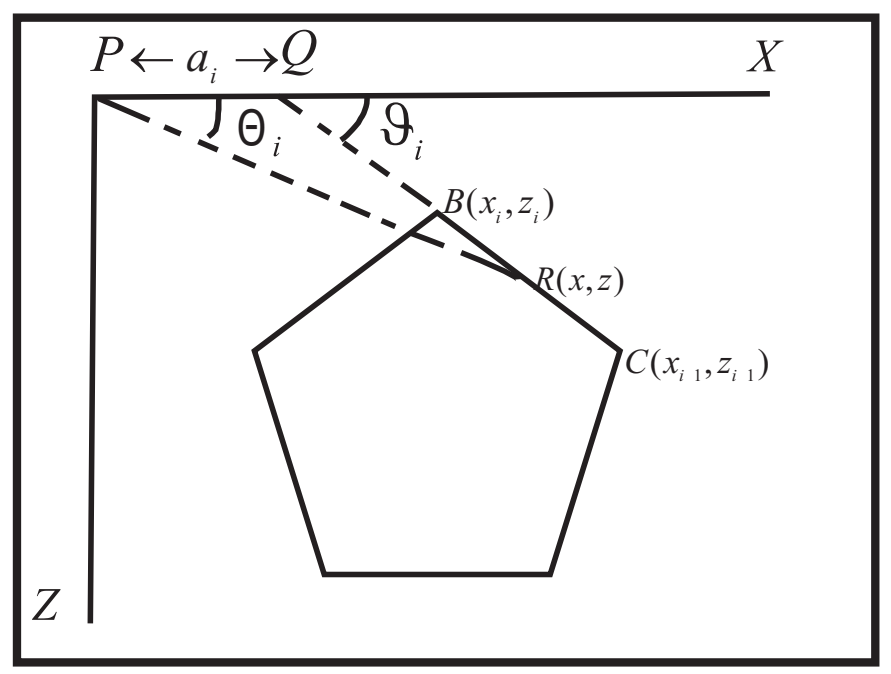

Figura 3.2: Elemento geométrico envolvido na atração gravitacional de um polígono de $n$ lados (modificado de Talwani et al., 1959).

A componente vertical da atração gravitacional (V) de um polígono de $n$ lados e de densidade $\rho$ é calculada pela equação:

$$
V=2 G \rho \sum_{i=1}^{n} Z_{i}
$$

onde $G$ é a constante de gravitação universal e $Z_{i}$ é dada pela relação:

$$
Z_{i}=a_{i} \operatorname{sen} \vartheta_{i} \cdot \cos \vartheta_{i}\left[-\theta_{i}-\theta_{i+1}+\tan \vartheta_{i} \ln \frac{\cos \theta_{i}\left(\tan \theta_{i}-\tan \vartheta_{i}\right)}{\cos \theta_{i+1}\left(\tan \theta_{i+1}-\tan \vartheta_{i}\right)}\right]
$$

onde

$$
\begin{gathered}
\theta_{i}=\tan ^{-1} \frac{z_{i}}{x_{i}} \\
\vartheta_{i}=\tan ^{-1} \frac{z_{i+1}-z_{i}}{x_{i+1}-x_{i}}, \\
\theta_{i+1}=\tan ^{-1} \frac{z_{i+1}}{x_{i+1}}, \\
a_{i}=x_{i+1}+z_{i+1} \frac{x_{i+1}-x_{i}}{z_{i}-z_{i+1}} .
\end{gathered}
$$


A formulação apresentada no trabalho citado considera que o polígono é infinito ao longo do plano xz. Existem formulações algébricas que permitem considerar esse comprimento infinito em um tamanho finito (figura 3.3), mantendo a mesma seção transversal do corpo. A formulação empregada pelo programa GravMag foi desenvolvida por Rasmussem and Pederson (1979).

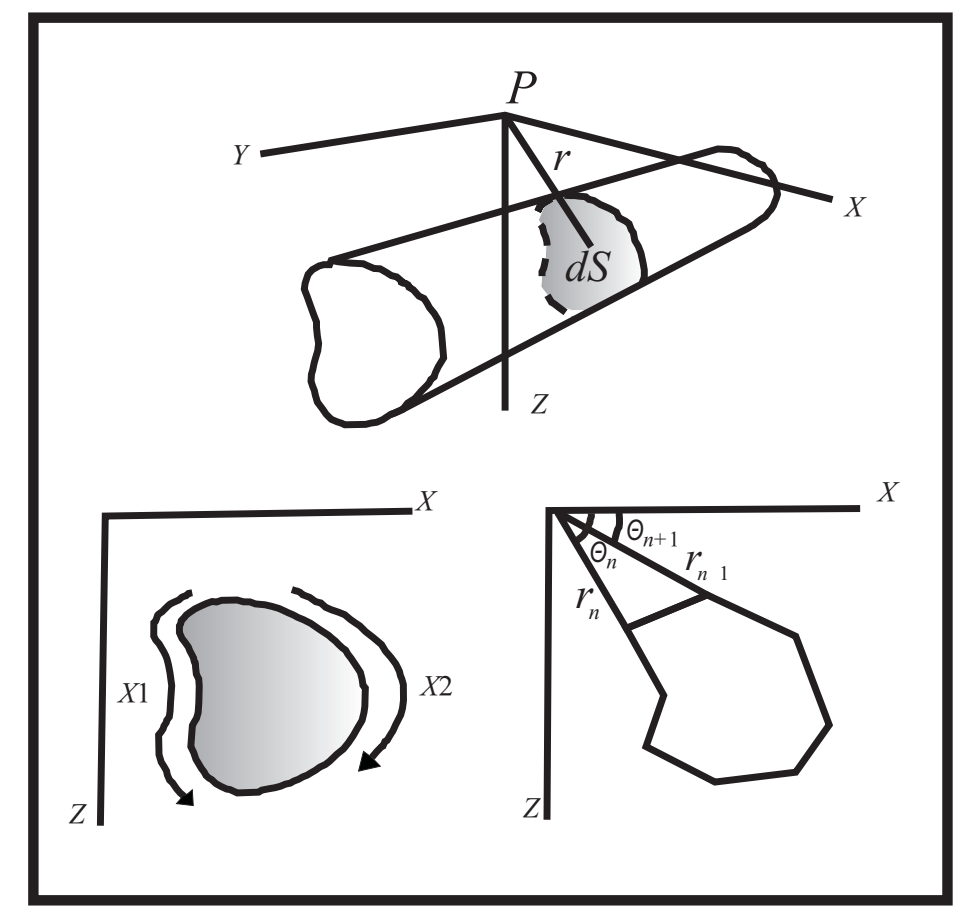

Figura 3.3: Elemento geométrico representando a aproximação de um corpo bidimensional por um polígono de $n$ lados (modificado de Blakely, 1996).

As bordas de um corpo bi-dimensional podem ser representadas por um polígono fechado fazendo o número de lados suficientemente grande. A anomalia magnética causada pelo mesmo polígono também pode ser determinada analiticamente em relação ao mesmo ponto externo. Vários programas usam essa rotina de cálculo no modelamento direto. Um modelo inicial para o corpo é construído, baseando-se em informações geológicas e geofísicas. A anomalia do modelo é calculada e comparada com a anomalia observada. Os parâmetros geométricos específicos e físicos (densidade e susceptibilidade) são 
modificados até obter-se o melhor ajuste entre o valor calculdado e o observado. Ao fazer as modificações nos parâmetros buscou-se tomar cuidado para manter a consistência geológica.

\subsection{Inversão dos dados gravimétricos e magnéticos}

Neste trabalho temos um conjunto de observações geofísicas $\mathbf{d}$ produzidas por fontes arbitrárias, adotando-se o sistema de coordenadas cartesianas. Geralmente assume-se que as fontes são corpos bi ou tri-dimensionais, dependendo do algoritimo utilizado. Inclue-se a fonte em uma região que é discretizada em M células. Dentro de cada célula assume-se que a propriedade física seja constante. As observações $\mathbf{d}$ são aproximadas por um funcional contínuo $f(x, \mathbf{q}, \mathbf{p})$ expressando a relação entre a propriedade física e as observações geofísicas correspondentes; q é um conjunto de parâmetros associados a geometria e a posição de cada célula e p é um vetor dimensão $M$ das propriedades física.

A anomalia gravimétrica ou magnética em uma dada localização sobre a superfície está relacionada às propriedades físicas da subsuperfície (densidade ou susceptibilidade, conforme o tipo de problema) por uma relação linear

$$
\mathbf{d}=\mathrm{Gp}
$$

onde $d=\left(d_{1}, \ldots, d_{N}\right)^{T}$ é o vetor de dados e $p=\left(p_{1}, \ldots, p_{M}\right)^{T}$ a propriedade física em cada célula da subsuperfície discretizada. A matriz $G$ tem como elementos $g_{i j}$ que quantificam a contribuição do i-ésimo dado para a propriedade física na j-ésima célula. O objetivo é recuperar a propriedade física $p$ diretamente dos dados observados.

A componente vertical do campo gravitacional $F_{z}\left(r_{i}\right)$ na localização da i-ésima ob- 
servação $r_{i}$ é dada por (Telford et al., 1976).

$$
F_{z}\left(r_{i}\right)=\gamma \int_{V} \rho(\vec{r}) \frac{z-z_{i}}{\left(\left|\vec{r}-\overrightarrow{r_{i}}\right|\right)^{3}} d v
$$

onde $\rho(r)$ é a distribuição de massa anômala, e $\gamma$ é a constante gravitacional de Newton, $\mathrm{z}$ e $\mathrm{z}_{i}$ são pontos no eixo- $z$, onde $\mathrm{z}_{i}$ depende da altitude da observação dos dados e $\mathrm{z}$ do comprimento da célula. O sistema de coordenadas cartesianas tem sua origem na superfície da Terra e o eixo- $z$ aponta verticalmente para baixo.

Para o campo magnético anômalo $B_{a}\left(\overrightarrow{r_{0}}\right)$ produzido pela distribuição de magnetização $\vec{M}$ tem-se a seguinte equação (Telford et al., 1976):

$$
\overrightarrow{B_{a}}\left(r_{0}\right)=\frac{\mu_{0}}{4 \pi} \int_{V} \nabla \nabla \frac{1}{\left|r^{\prime}-r^{\prime \prime}\right|} \cdot \vec{M} d v
$$

onde $\overrightarrow{r_{0}}$ é a posição do ponto observado, V representa o volume da magnetização e $\vec{M}$ é magnetização induzida. A equação acima é válida para observações localizadas acima da superfície da Terra. É válida também no vácuo, assumindo que permeabilidade magnética é $\mu_{0}$.

Para o caso de dados magnéticos a inversão assume que não há magnetização remanescente considerando apenas a magnetização induzida. Esta magnetização é uniforme em cada célula e é dada pelo produto da susceptibilidade magnética e do campo geomagnético induzido relação (2.8).

A estimativa da distribuição de densidade ou de susceptibilidade magnética é um problema inverso linear caracterizado pela não unicidade e instabilidades de suas soluções - Para encontrar um modelo particular único e estável, o caso estudado acima é transformado em um problema de otimização (Parker, 1991). A função objetivo particular é dependente do problema, mas geralmente requer que o modelo esteja próximo a um modelo 
de referência e que seja suave. A solução é obtida usando o método dos multiplicadores de Lagrange que consiste em uma técnica de cálculo destinada a incorporar uma restrição a uma função objetivo.

Para obter uma solução numérica do problema inverso é necessário discretizar a região da fonte, admitindo que seja dividida em células por uma malha ortogonal e assumindo um valor constante para a propriedade física em cada célula.

\subsubsection{Aplicação da teoria de inversão $2 \mathrm{D}$ aos dados gravimétricos}

Na inversão gravimétrica 2D foi utilizado o programa Multi (Silva and Barbosa, 2006) para interpretar anomalias gravimétricas produzidas por fontes múltiplas e complexas, que sejam separadas de outras por curtas distâncias (verticalmente e/ou lateralmente). O modelo interpretativo assumido é um grid 2D de prismas justa-postos cujos contrastes de densidades são os parâmetros a serem determinados. O interprete especifica o esboço das fontes gravimétricas em termos de elementos geométricos (segmento de linha ou ponto) e o contraste de densidade associado com o elemento geométrico que define a estrutura de cada fonte gravimétrica. O método em seguida estima a distribuição do contraste de densidade que ajuste a anomalia observada dentro de um erro experimental e represente fontes gravimétricas compactas para os elementos geométricos especificados. O usuário pode aceitar a interpretação ou modificar a estrutura da fonte gravimétrica, mudando a posição dos elementos geométricos e/ou o contraste de densidade associado a cada um destes elementos geométricos e reinicia-se a inversão.

O vínculo denominado mínimo momento de inércia é empregado para incorporar informação a priori sobre as principais direções ao longo das quais as massas anômalas estão supostamente centradas. Este método é empregado para caracterizar a dispersão 
das fontes interpretativas, existindo a possibilidade de incorporar informações pontuais sobre as propriedades físicas e a forma dos corpos (Barbosa and Silva, 1994).

A fundamentação usada pelo programa é encontrada em Last and Kubic 1983; Guillen and Menichetti 1984; Barbosa and Silva 1994; Silva and Barbosa 2006. As soluções serão direcionadas a concentrar excesso ou deficiência de massa nas proximidades dos elementos geométricos introduzidos pelo analista. Desta forma o algoritmo empregado usa valores iniciais para cada parâmetro do corpo a ser modelado, os quais podem ser modificados, de modo a incorporar dados reais. A qualidade do ajuste é medida pela relação da soma ponderada dos desvios quadráticos entre valores observados e calculados.

\subsubsection{Aplicação da teoria de inversão 3D aos dados gravimétricos e magnéticos}

A técnica de inversão 3D utilizada neste trabalho foi desenvolvida por Li and Oldenburg (1996, 1998, 2003) nos programas GRAV3D (2002) e MAG3D (2002). A inversão da superfície de dados gravimétricos ou magnéticos foi desenvolvida com o objetivo de se obter um modelo 3D para distribuição de densidade ou susceptibilidade magnética, assumindo que a região da fonte seja representada por um conjunto de células retangulares de uma malha ortogonal 3D e densidade $(\rho)$ ou susceptibilidade magnética $(\chi)$ de valor constante em cada célula.

Para inversão gravimétrica ou magnética, a primeira questão é a que concerne a origem da definição do 'modelo', em geral prefere-se que o modelo para $p$ seja diretamente proporcional a anomalia do campo e que varie em uma escala linear. A função objetivo do modelo usada nos algoritmos GRAV3D (2002) e MAG3D (2002) tem a forma 


$$
\begin{gathered}
\phi_{m}(p)=\alpha_{s} \int_{V} w_{s}\left[w(z)\left(p(r)-p_{0}\right)\right]^{2} d v+\alpha_{x} \int_{V} w_{x}\left[\frac{\partial w(z)\left[p(r)-p_{0}\right]}{\partial x}\right]^{2} d v+ \\
\alpha_{y} \int_{V} w_{y}\left[\frac{\partial w(z)\left[p(r)-p_{0}\right]}{\partial y}\right]^{2} d v+\alpha_{z} \int_{V} w_{z}\left[\frac{\partial w(z)\left[p(r)-p_{0}\right]}{\partial z}\right]^{2} d v
\end{gathered}
$$

Na função objetivo do modelo $w_{s}, w_{x}, w_{y}$ e $w_{z}$ são funções peso espacialmente dependentes e $\alpha_{s}, \alpha_{x}, \alpha_{y}$ e $\alpha_{z}$ são coeficientes que afetam a importância relativa dos diferentes componentes na função objetivo. Aqui $w(z)$ é a função peso da profundidade. É conveniente escrever a equação 3.7 como $\phi_{m}(p)=\phi_{m s}+\phi_{m v}$ onde $\phi_{m s}$ refere-se ao primeiro termo na equação 3.7 e $\phi_{m v}$ coletivamente aos três termos restantes que envolvem a variação do modelo em três direções espaciais. O modelo de referência pode ser incluído em $\phi_{m s}$ e se necessário, remover algum outro termo restante.

A equação 3.7 pode ser escrita de forma simplificada da seguinte maneira

$$
\phi_{m}=\left\|W_{m} L\left(p(\vec{r})-p_{0}(\vec{r})\right)\right\|^{2}
$$

onde L é um operador aproximado de primeira derivada ponderado por uma matrix $W_{m}$.

Os valores de $g_{i j}$ para dados magnéticos de superfície decaem com a profundidade. Para se contrapor ao decaimento geométrico de $\left.g_{(} i j\right)$ e a distribuição da propriedade física com a profundidade é introduzido no algoritmo de Li and Oldenburg (1996) um peso da forma $w(z)=\left(z-z_{0}\right)^{-\beta / 2}$ dentro de $\phi_{m s}$, e opcionalmente em $\phi_{m v}$, onde $\beta$ é geralmente igual a 3 e $z_{0}$ depende do comprimento da célula da discretização do modelo e da altitude da observação dos dados.

A próxima etapa do problema consiste em encontrar um modelo que além de minimizar $\phi_{m}$ explique os dados dentro de uma precisão experimental $(\delta)$. Para tanto miniiza- 
se a norma L2 definida pelo funcional

$$
\phi_{d}=\left\|W_{d}\left(d^{o b s}-d\right)\right\|^{2}
$$

e assume-se que o resíduo contaminante nos dados seja independente e Gaussiano com média zero. $W_{d}$ é uma matriz diagonal cujo i-ésimo elemento é $1 / \sigma_{i}$, onde $\sigma_{i}$ é o desvio padrão do i-ésimo dado, e $\phi_{d}$ uma variável quadrática distribuída com $\mathrm{N}$ graus de liberdade.

O melhor modelo será um que miniminize a função objetivo do modelo, $\phi_{m}$, e que melhor ajuste os dados em uma intervalo aceitável da dirença entre o resultado obtido e resultado verdadeiro. Isto é acompanhado pela minimização de $\phi=\phi_{d}+\mu \phi_{m}$, onde $\phi$ é a função objetivo global e $\mu$ é o multiplicador de Lagrange. Os passos para discretização do modelo e utilização do vínculo de positividade estão descritos em Li and Oldenburg (1996).

A inversão tridimensional pode ser utilizada com sucesso em muitas interpretações de dados magnéticos (Li and Oldenburg, 1996). Contudo, um parâmetro crucial neste processo é a direção de magnetização. A magnetização total é o vetor soma de duas componentes. A magnetização induzida é aproximada pela direção do campo induzido e a magnetização remanescente é geralmente desconhecida. Esta muitas vezes tem direção muito diferente da direção do campo atual ou uma intensidade grande o suficiente para que altere a direção da magnetização total.

O algoritmo de inversão desenvolvido por Li and Oldenburg (1996) inverte dados de anomalia de campo total assumindo que apenas exista no corpo a magnetização induzida, ignorando a magnetização remanescente. Em Li et al. (2004) e Shearer and Li (2004) foram apresentados dois caminhos para que seja possível a aplicação do método de inversão de 
dados magnéticos na presença de forte magnetização remanescente. O primeiro caminho consiste em conhecer com boa aproximação a direção da magnetização total, e os dados são invertidos com o algoritmo. O segundo caminho dispensa o conhecimento seguro da direção da magnetização e inverte diretamente a amplitude do campo anômalo ou o gradiente total dos dados observados usando o algoritmo de Shearer and Li (2004), não disponível ao Departamento de Geofísica do IAG.

Em Li et al. (2004) são utilizados métodos para estimativa da direção da magnetização e em seguida a aplicação do método de inversão de dados. Contudo a maioria dos métodos apresentados encontra dificuldades em baixas latitudes magnéticas.

As amostras da região da província alcalina Rio Verde - Iporá apresentaram uma importância muito maior para magnetização remanescente em relação à magnetização induzida, como foi visto na tabela 2.2, seção 3.3 e encontram-se em região de baixa latitude magnética. Apesar da restrição imposta pelo algoritimo de inversão quanto a existência de magnetização remanescente procurou-se estratégias para usar os dados magnéticos e realizar a inversão.

A magnetização determinada é de fato de uma amostra paleomagnética, então assumese que a magnetização é primeiramente remanescente e foi registrada no tempo em que o corpo foi formado, podendo representar a contribuição para campo magnético anômalo no período de sua formação. Os corpos aqui estudados são do Cretáceo Superior podendo-se utilizar a latitude do corpo no período de formação para obter a $I_{R}$ como foi discutido na subseção 3.3.1. Esta informação foi utilizada na construção do modelo da susceptibilidade para calcular o campo magnético produzido pela soma da magnetização remanescente com a magnetização induzida. Usualmente $\vec{B}, \vec{M}$ e $\vec{H}$ são paralelos dentro de um material, 
especialmente nos materiais anisotrópicos. Quando a rocha possui uma magnetização remanescente esta pode ter direção diferente da magnetização induzida atual.

A segunda tentativa foi realizar a inversão dos dados magnéticos considerando a hipótese de que só existe no corpo a magnetização induzida, o valor de $B_{0}$ adotado foi de 25000 nT e a partir desta consideração inicial obtêm-se um modelo de distribuição de susceptibilidade em subsuperfície. 


\section{4}

\section{RESULTADOS}

Este capítulo apresenta os resultados do emprego do modelamento direto 2,5D e das técnicas de inversão aos dados magnéticos e gravimétricos. Os modelos obtidos referem-se aos corpos ME e A2 obtendo uma estimativa da profundidade e do modelo de distribuição das propriedades físicas em subsuperfície.

O desenvolvimento das rotinas para inversão pode ser tratado como uma progressão lógica do modelamento direto. Ambas rotinas produzem um modelo geológico em subsuperfície a partir das observações em superfície do campo gravimétrico ou magnético. A principal diferença é que o modelamento direto é realizado interativamente e apresenta a possibilidade de se utilizar os sinais gravimétrico e magnético de forma conjunta, enquanto que a inversão é realizada de forma automática e ambos sinais são tratados por programas diferentes e separadamente.

O modelamento conjunto foi realizado com perfil magnético E'E mostrado na figura 3.1 (b) e a localização deste perfil foi utilizada para obter o perfil correspondente a anomalia Bouguer residual do Complexo ME retirado diretamente do mapa da figura 2.3a. 
As técnicas de inversão empregadas aos dados observados foram baseadas em informações de perfis gravimétricos AA' e BB' da figura 2.2 para obter o modelo $2 \mathrm{D}$ e grades regulares dos dados gravimétricos (figura 2.7) ou magnéticos (figura 2.9) para o modelo 3D.

\subsection{Modelamento direto 2,5D para dados gravimétricos e magnéticos}

A construção dos modelos bidimensionais para os corpos alcalinos baseou-se em informações geológicas (figura 4.1) e informações provenientes da interpretação de dados aeromagnéticos. Este tipo de procedimento procura reduzir o caráter ambíguo dos modelos baseados apenas em dados de campos potenciais.

As convenções adotadas para realização da modelagem 2,5D foi a adoção de valores de densidade e susceptibilidade constantes para cada polígono, geometria 2D, mas impondo uma largura finita no plano yz.

O programa GravMag (Talwani et al., 1959) usa um processo interativo para a modelagem conjunta dos perfis residuais gravimétricos e magnéticos. Nessa modelagem procurou-se atingir um melhor ajuste entre as anomalias observadas e calculadas a partir do modelo.

O modelamento conjunto foi realizado com perfil residual de anomalia Bouguer e o perfil magnético escolhido para o modelamento do Complexo ME foi o E'E, mostrado na figura 3.1.

O valor médio para susceptibilidade magnética retirado das amostras correspondente ao Complexo ME foi usado no modelamento. Para o modelo representado na figura 4.2 


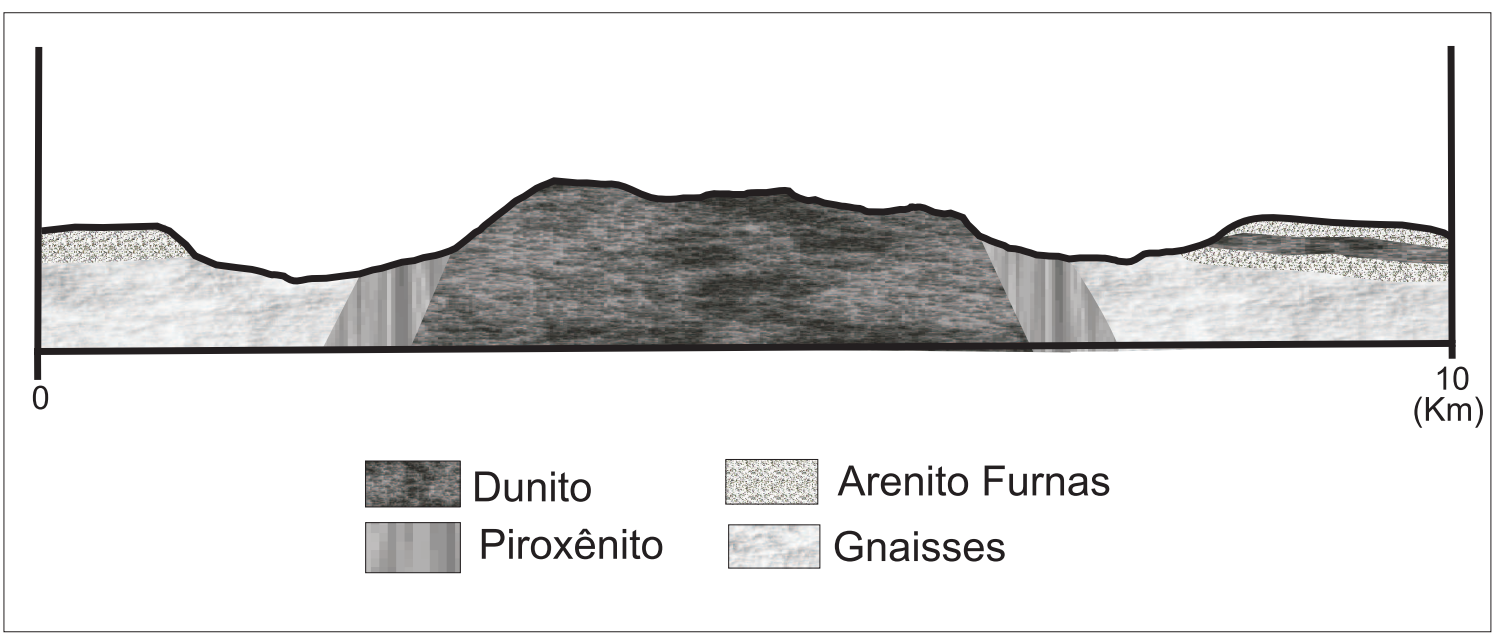

Figura 4.1: Esquema do modelo geológico para ME.

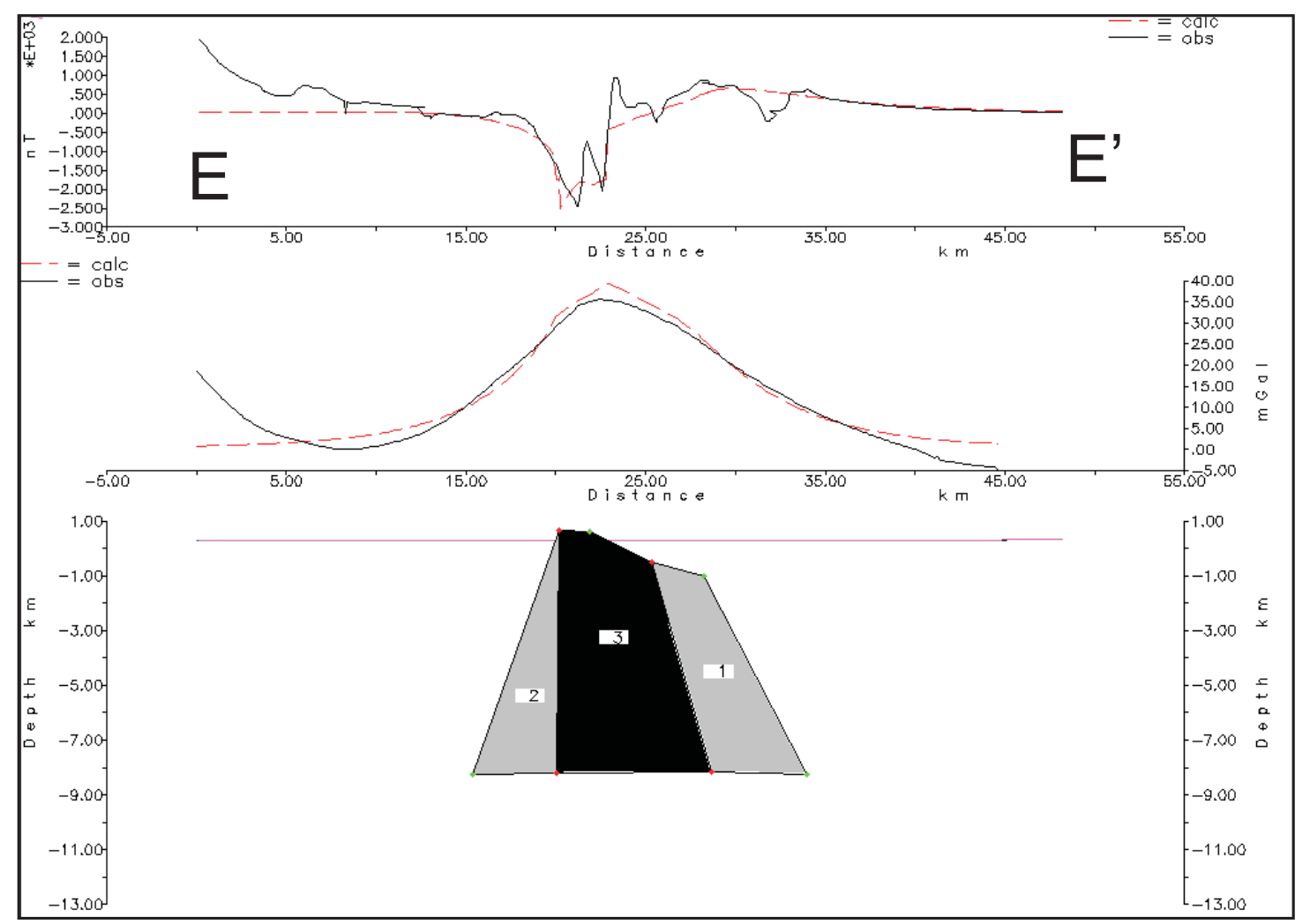

Figura 4.2: Modelo dos sinais gravimétricos e magnéticos para o perfil E’E do complexo ME.

foi proposto um corpo interno com susceptibilidade de 0,035 (SI) (corpo 3) circundado por material de susceptibilidade menor 0,0035 (SI) (corpos 1 e 2), como descrito por Radaelli (2000), em que o Complexo Alcalino de Morro do Engenho constitui uma intrusão 
circular composta por núcleo de dunito circundado por piroxenito, como mostra o esquema da figura 4.1. Para o modelamento direto do corpo ME foi utilizado o valor médio da magnetização remanescente encontrada nas amostras, $I_{R}=-43^{\circ}, D_{R}=-14^{\circ}$ e $M_{R}=$ $6,3 \mathrm{~A} / \mathrm{m}$ que é o valor médio das medidas feitas com as amostras coletadas em campo.

No modelamento da figura 4.2considera-se que o Complexo ME tem densidade média de $3,0 \mathrm{~g} / \mathrm{cm}^{3}$ e a densidade da rocha encaixante $2,7 \mathrm{~g} / \mathrm{cm}^{3}$, utilizando-se o valor do contraste de densidade de $0,3 \mathrm{~g} / \mathrm{cm}^{3}$. O valor de densidade atribuído a ME corresponde em média aos valores de densidade do gabro alcalino $2,7-3,5 \mathrm{~g} / \mathrm{cm}^{3}$, peridotito $2,78-$ $3,37 \mathrm{~g} / \mathrm{cm}^{3}$, piroxenito $2,93-3,34 \mathrm{~g} / \mathrm{cm}^{3}$ (Telford et al., 1976).

Como pode ser visto no modelo da figura 4.2, o corpo apresenta-se em forma de um tronco de cone, na profundidade de $8 \mathrm{~km}$ tem cerca de $18 \mathrm{~km}$ de diâmetro, e $8 \mathrm{~km}$ à profundidade de $1 \mathrm{~km}$. Apenas uma pequena parte, cerca de $4 \mathrm{~km}$, aflora. Este valor está bem próximo dos $5 \mathrm{~km}$ proposto por Radaelli (2000). O volume do corpo anômalo é da ordem de $980 \mathrm{~km}^{3}$.

Na tentativa de refinar os resultados alcançados em relação a distribuição das propriedades físicas dos corpos aplicou-se a técnica de inversão aos dados gravimétricos.

\subsection{Inversão dos dados gravimétricos e magnéticos}

As técnicas de inversão empregadas aos dados observados foram baseadas em informações de perfis gravimétricos para obter o modelo 2D e grades regulares dos dados gravimétricos ou magnéticos para o modelo 3D. A inversão 3D foi utilizada para que o modelo obtido ficasse mais próximo da geometria real dos corpos. 


\subsubsection{Inversão 2D: dados gravimétricos das alcalinas ME e A2}

A inversão 2D foi realizada com o programa Multi (Silva and Barbosa, 2006) onde foram utilizados vínculos de compacidade e mínimo momento de inércia. Para inversão foram utilizadas observações gravimétricas contaminadas por ruído Gaussiano com média zero e desvio padrão igual a $0.5 \mathrm{mGal}$, maior que o erro obtido pela propagação de erros na anomalia Bouguer. O valor maior pode incorporar fatores aleatórios desprezados anteriormente.

Alguns resultados significantes das inversões dos dados de ME são mostrados nas figuras 4.3, 4.44 .5 e 4.6. Estas mostram os resultados da inversão com informação a priori do ponto onde o corpo ME aflora, ponto azul na figura. Os limites inferiores do contraste de densidade mínimo $\left(\Delta \rho_{\min }=0.0\right)$ são os mesmos para cada prisma e limita a anomalia gravimétrica a apenas um sinal positivo, como é esperado do mapa de anomalia Bouguer residual.

A inversão foi aplicada aos dados gravimétricos variando-se os valores atribuídos aos contrastes de densidade máximo $\left(\Delta \rho_{\max }\right)$. O valor máximo obtido na figura 4.3 foi de $\Delta \rho_{\max }=0,27 \mathrm{~g} / \mathrm{cm}^{3}$ e na figura 4.4 o valor máximo atingido foi $\Delta \rho_{\max }=0,31 \mathrm{~g} / \mathrm{cm}^{3}$ para o corpo de ME. A recuperação das massas anômalas distribuídas ao longo das difrentes direções de concentração depende da qualidade da informação a prioiri introduzida, embora não necessite ser ideal.

As inversões realizadas e mostradas nas figuras 4.3 e 4.4 ajustaram melhor os dados para valores baixos de contrastes de densidade $0,27 \mathrm{~g} / \mathrm{cm}^{3}$, que pode ser justificado pelos tipos litológicos encontrados na região. A maioria das fácies estudadas por Danni (1994), na região de Iporá, possui minerais de alteração, tais como: serpentina, magnetita, na- 

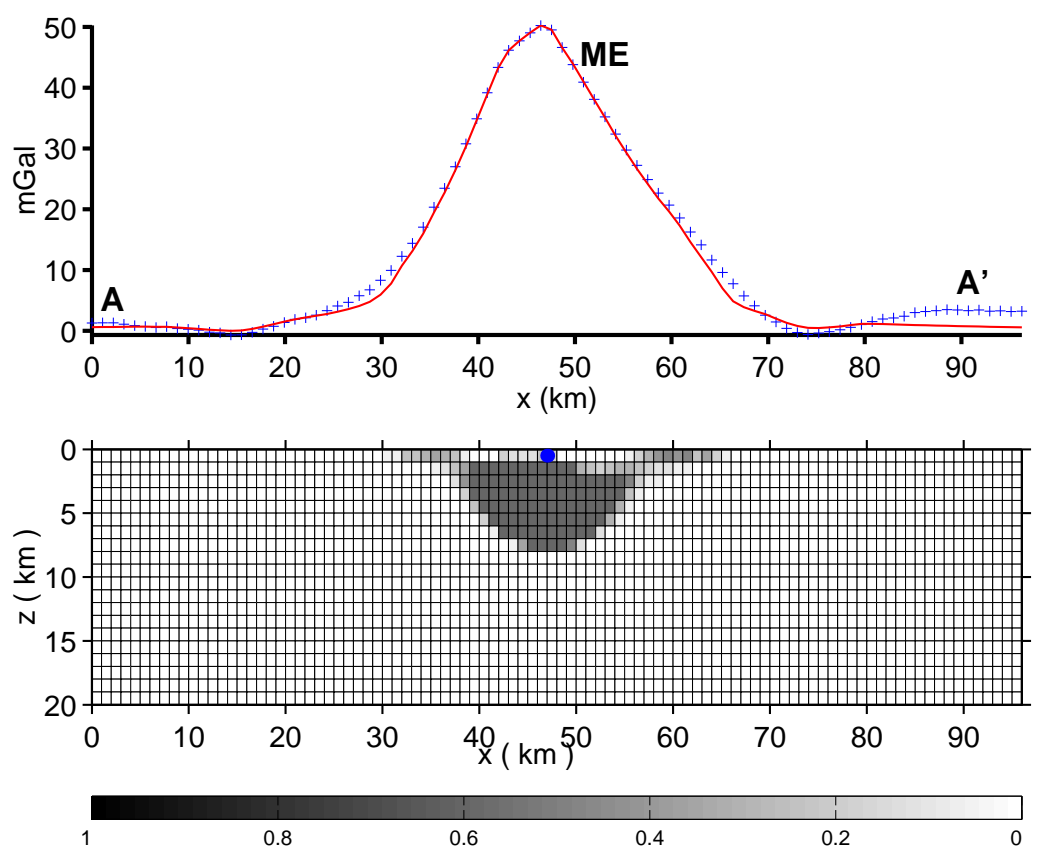

Figura 4.3: Perfil AA' da figura 2.2. Inversão com vínculo de compacidade e informação geológica do corpo. Limites do contraste de densidade em cada prisma: $\Delta \rho_{\min }=0,0 \mathrm{~g} / \mathrm{cm}^{3}$ e $\Delta \rho_{\max }=0,27 \mathrm{~g} / \mathrm{cm}^{3}$. A legenda indica o valor percentual do limite máximo que foi atingido em cada célula.

trolita, analcita, calcedônia e calcita. As análises das lâminas confirmaram uma forte alteração para as amostras da região de estudo.

As rochas ultramáficas apresentam uma mineralogia original essencialmente anidra muito pouco estável sob quaisquer condições de metamorfismo e sua composição química é muito contrastante com a composição química das rochas com as quais estão em contato. A primeira característica faz com que a mineralogia original seja transformada numa série de minerais hidratados (serpentina, brucita, talco), cuja formação pode ser unicamente explicada pela introdução de $\mathrm{OH}$ - nas rochas ultramáficas; os minerais que comumente predominam como resultado deste processo de transformação metamórfica são as serpentinas, daí a denominação de serpentinização para tal processo Strieder (1992).

As transformações em rochas ultramáficas podem se dar pelo método isoquímico. 

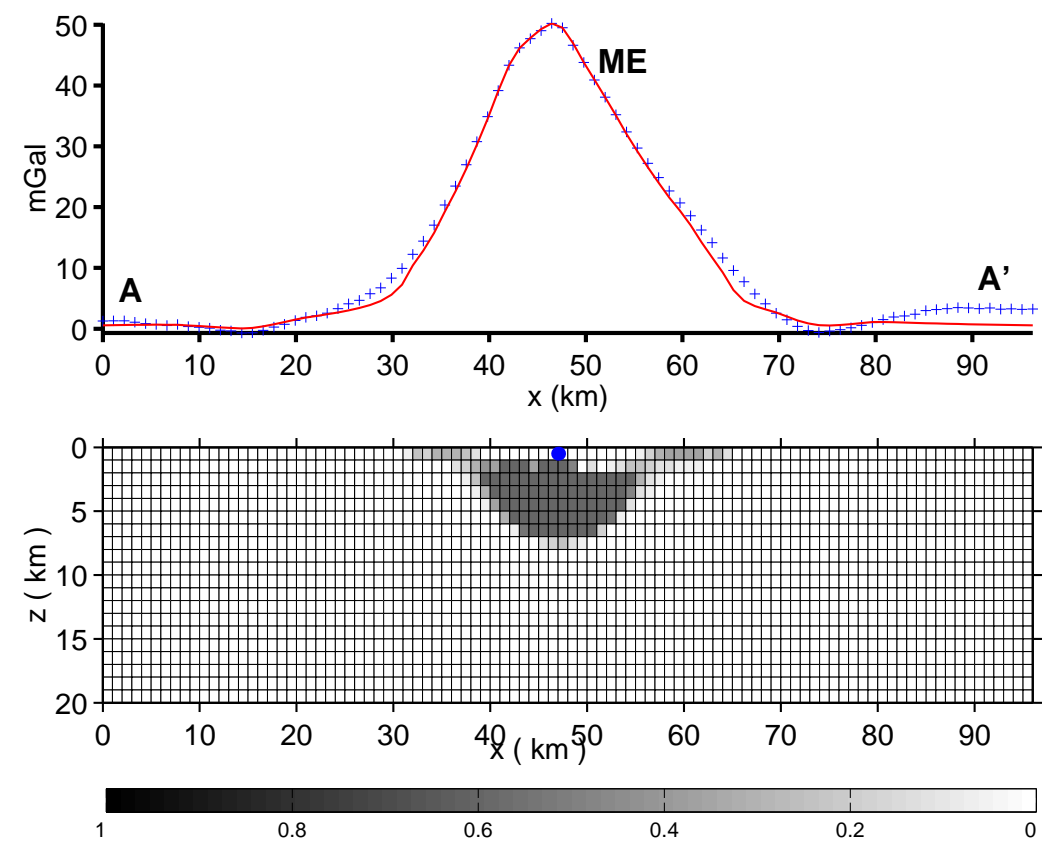

Figura 4.4: Perfil AA' da figura 2.2. Inversão com vínculo de compacidade e informação geológica do corpo. Limites do contraste de densidade (\%) em cada prisma: $\Delta \rho_{\min }=0,0 \mathrm{~g} / \mathrm{cm}^{3}$ e $\Delta \rho_{\max }=0,31 \mathrm{~g} / \mathrm{cm}^{3}$. A legenda indica o valor percentual do limite máximo que foi atingido em cada célula.

Neste método se reconhece a possibilidade de se preservar texturas pseudomórficas e há modificação de volume (aumento) e os fraturamentos são importantes na delimitação de um maior espaço aos corpos ultramáficos. Essa modificação de volume provoca, consequentemente, variação no contraste de densidade entre o corpo ultramáfico e a rocha encaixante. Isso justificaria o baixo contraste de densidade encontrado na inversão dos dados gravimétricos, havendo aumento do volume nas transformações e diminuição no valor de densidade do corpo. Segundo Telford et al. (1976) o valor de densidade da rocha metamórfica serpentinito varia de $2,4-3,1 \mathrm{~g} / \mathrm{cm}^{3}$ com valor médio de $2,74 \mathrm{~g} / \mathrm{cm}^{3}$.

Para inversão do perfil $B B^{\prime}$, que corta as três anomalias, foi admitido valores diferentes para o contraste de densidade em cada corpo (figuras 4.5 e 4.6). Em um furo de sondagem de 50 m próximo a região de Britânia foi encontrado um granito recorberto por sedimentos, o que acarreta num contraste de densidade positivo de valor de $\Delta \rho_{\text {Max }}=0,1$ admitindo- 

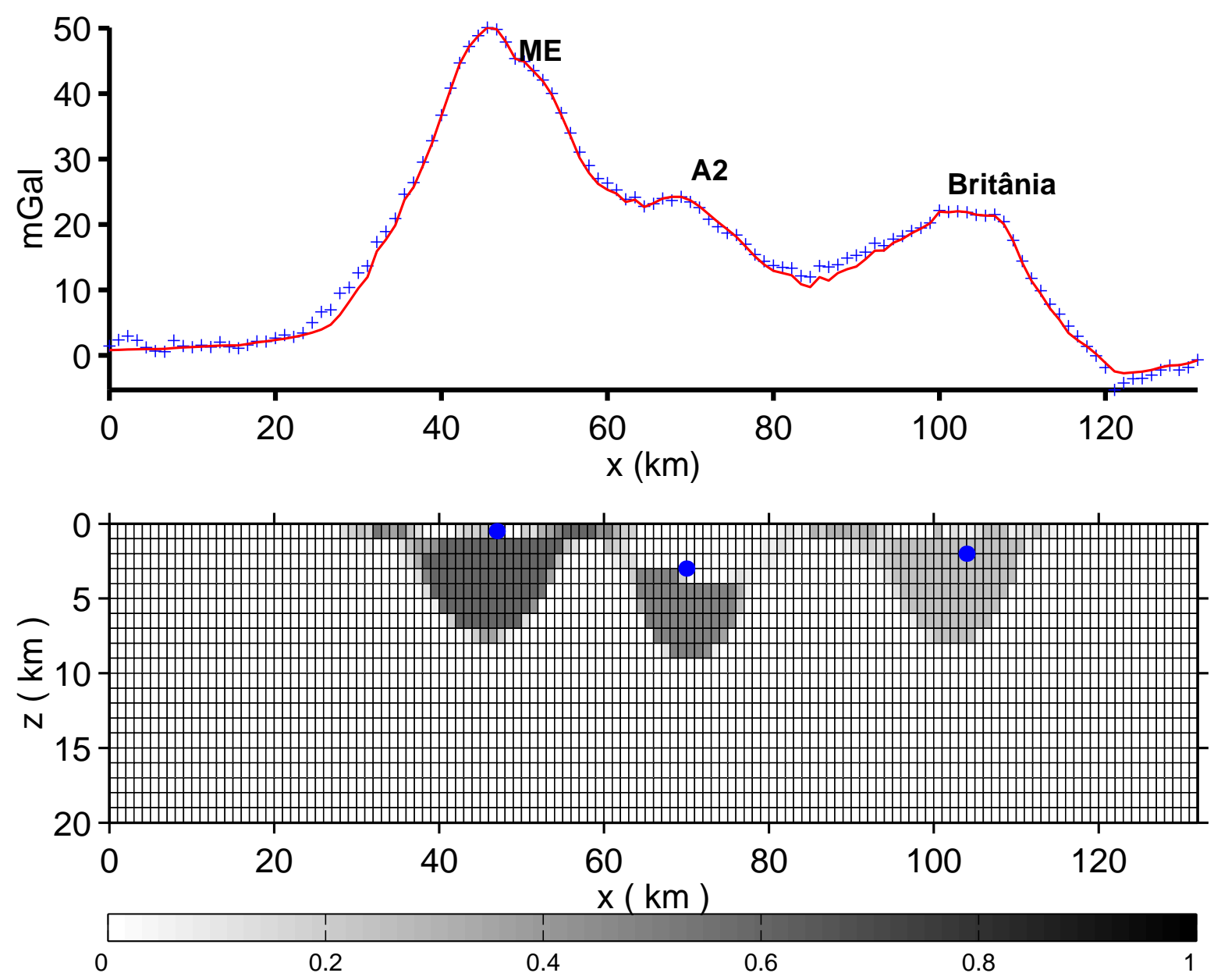

Figura 4.5: Perfil BB' da figura 2.2. Inversão com vínculo de compacidade e informação geológica do corpo. Limites do contraste de densidade (\%) em cada prisma: $\Delta \rho_{\text {min }}=0,0 \mathrm{~g} / \mathrm{cm}^{3}$ e $\Delta \rho_{\max }=0,26 \mathrm{~g} / \mathrm{cm}^{3}$ para ME; $\Delta \rho_{\max }=0,2 \mathrm{~g} / \mathrm{cm}^{3}$ para A2 e $\Delta \rho_{\max }=0,1 \mathrm{~g} / \mathrm{cm}^{3}$ em Britânia. A legenda indica o valor percentual do limite máximo que foi atingido em cada célula.

se $2,7 \mathrm{~g} / \mathrm{cm}^{3}$ para a densidade do granito e $2,6 \mathrm{~g} / \mathrm{cm}^{3}$ para a densidade dos sedimentos (Telford et al., 1976). Esta informação associada à ausência de anomalia magnética impõe o abandono da hipótese de corpo alcalino para anomalia no extremo leste do perfil BB'.

O corpo A2 não é aflorante e está recoberto por arenitos da Formação Furnas. O vínculo de mínimo momento de inércia foi utilizado para representar. O topo da fonte é representado pelo ponto em azul sob A2 nas figuras 4.5 e 4.6. A profundiade do topo para A2 foi o valor estimado a partir do gráfico da figura 2.12 em aproximadamentte 3 

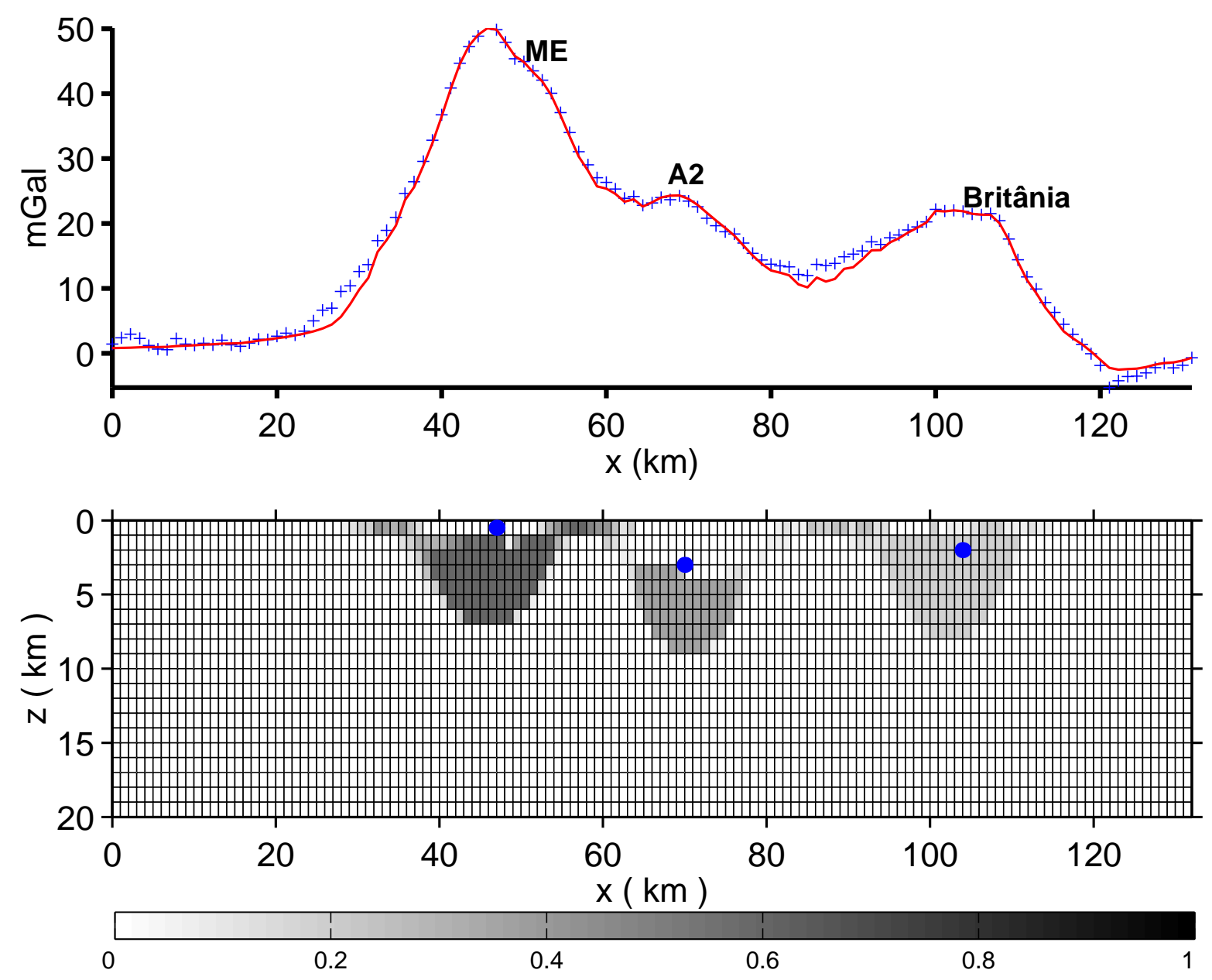

Figura 4.6: Perfil BB' da figura 2.2. Inversão com vínculo de compacidade e informação geológica do corpo. Limites do contraste de densidade (\%) em cada prisma: $\Delta \rho_{\min }=0,0 \mathrm{~g} / \mathrm{cm}^{3}$ e $\Delta \rho_{\max }=0,31 \mathrm{~g} / \mathrm{cm}^{3}$ para ME; $\Delta \rho_{\max }=0,2 \mathrm{~g} / \mathrm{cm}^{3}$ para A2 e $\Delta \rho_{\max }=0,1 \mathrm{~g} / \mathrm{cm}^{3}$ em Britânia. A legenda indica o valor percentual do limite máximo que foi atingido em cada célula.

$\mathrm{km}$.

A inversão aplicada a este perfil com a varição dos valores atribuídos aos contrastes de densidade obteve valores máximos de $\Delta \rho_{\max }=0,27 \mathrm{~g} / \mathrm{cm}^{3}$ (figura 4.3 ) e $\Delta \rho_{\max }=$ $0,31 \mathrm{~g} / \mathrm{cm}^{3}$ (figura 4.4) para o corpo de ME, a anomalia A2 com o valor de $\Delta \rho_{\max }=$ $0,2 \mathrm{~g} / \mathrm{cm}^{3}$ e Britânia com $\Delta \rho_{\max }=0,1 \mathrm{~g} / \mathrm{cm}^{3}$.

As soluções apresentaram um menor número possível de prismas elementares com contrastes de densidades diferentes de zero, o que implica em fontes com maior compacidade, 
compatíveis com as observações. A técnica de inversão empregada recuperou satisfatoriamente todas as fontes e permitiu o cálculo de parâmetros tais como largura e espessura para o corpo de ME que possui geometria simples e topo conhecido. Os resultados da inversão indicam um corpo gravimétrico com diâmetro de 10 a 12 km e espessura entre 6 e $8 \mathrm{~km}$ para ME. O corpo A2 tem $12 \mathrm{~km}$ de diâmetro $6 \mathrm{~km}$ de espessura.

\subsubsection{Inversão 3D: dados gravimétricos e magnéticos das alcali- nas ME e A2}

A inversão 3D trabalha com dados em superfície, usando mapas de anomalias residuais apresentadas nas figuras 2.7 e 2.9, passando pelas anomalias de ME e A2.

O programa GRAV3D (2002) Version 2.0 , discretiza a região do modelo em um conjunto de células retangulares, onde cada uma delas tem densidade constante. Para inverter os dados gravimétricos, foi utilizada uma malha com células de $1 \mathrm{~km}$ nas direções $x, y$ e $z$.

O algoritmo pode incorporar informações a priori dentro de um modelo pelo uso de um ou mais vínculos apropriados. Neste trabalho foi adotado como modelo de referência um corpo de geometria cilíndrica vertical para região onde ME aflora e A2 (não aflorante). Também foi usado o vínculo de positividade. Os limites de contraste de densidade são $\rho_{\text {min }}=0,0 \mathrm{~g} / \mathrm{cm}^{3}$ e $\rho_{\text {Max }}=0,3 \mathrm{~g} / \mathrm{cm}^{3}$.

A inversão da anomalia residual gravimétrica da figura 2.7 produziu o modelo de distribuição de densidade 3D mostrado nas figuras 4.7 e 4.8. A aplicação desta técnica de inversão aos dados gravimétricos produziu modelos de densidade representativos ao das estruturas, mostrando que a inversão destes dados produz um modelo consistente com a geologia, recuperando o local onde ME aflora. A profundidade máxima atingida pela 
distribuição de densidade do modelo foi de $10 \mathrm{~km}$ para ME e $6 \mathrm{~km}$ para A2.

Os valores do campo gravimétrico anômalo observado (figura 4.9 (a)) foram comparados aos dados calculados (figura 4.9 (b)), como pode ser visto os valores se ajustaram. O mapa da figura 4.9 (b) representa a contribuição do campo gravimétrico produzido pelos corpos ME e A2 do modelo de distribuição de contraste de densidade, obtidos com inversão 3D.

Além da utilização dos dados gravimétricos, torna-se interessante a utilização no processo de inversão o uso dos dados magnéticos das alcalinas estudadas. As respostas obtidas pelas duas inversões podem ser analisadas com o objetivo de dimiuir ambiguidades do modelo.

Para realizar a inversão de dados magnéticos foi utilizado o programa MAG3D (2002) Version 2.0 , onde a região do modelo é discretizada em um conjunto de células retangulares e cada uma delas têm susceptibilidade constante. Foi utilizada na inversão a grade regular de dados magnéticos da figura 4.10 e uma malha com células de $1 \mathrm{~km}$ na direção de $x, y$ e $z$. Os resultados da inversão de dados magnéticos são mostrados nas figuras 4.11 e 4.12 .

Foi realizada a inversão dos dados magnéticos da figura 4.10 considerando a hipótese de que só existe no corpo a magnetização induzida determinada pelo CMT. O valor de $B_{0}$ adotado foi de $25000 \mathrm{nT}$. A partir desta consideração inicial foi obtido um modelo de distribuição de susceptibilidade em subsuperfície apresentado na figura 4.11(a).

Usando este modelo obtido com a inversão foi calculado o campo magnético por modelamento direto (figura 4.13 (a)). Os valores obtidos com o modelamento direto resultaram em intensidades inferiores aos dados utilizados e representam a contribuição 

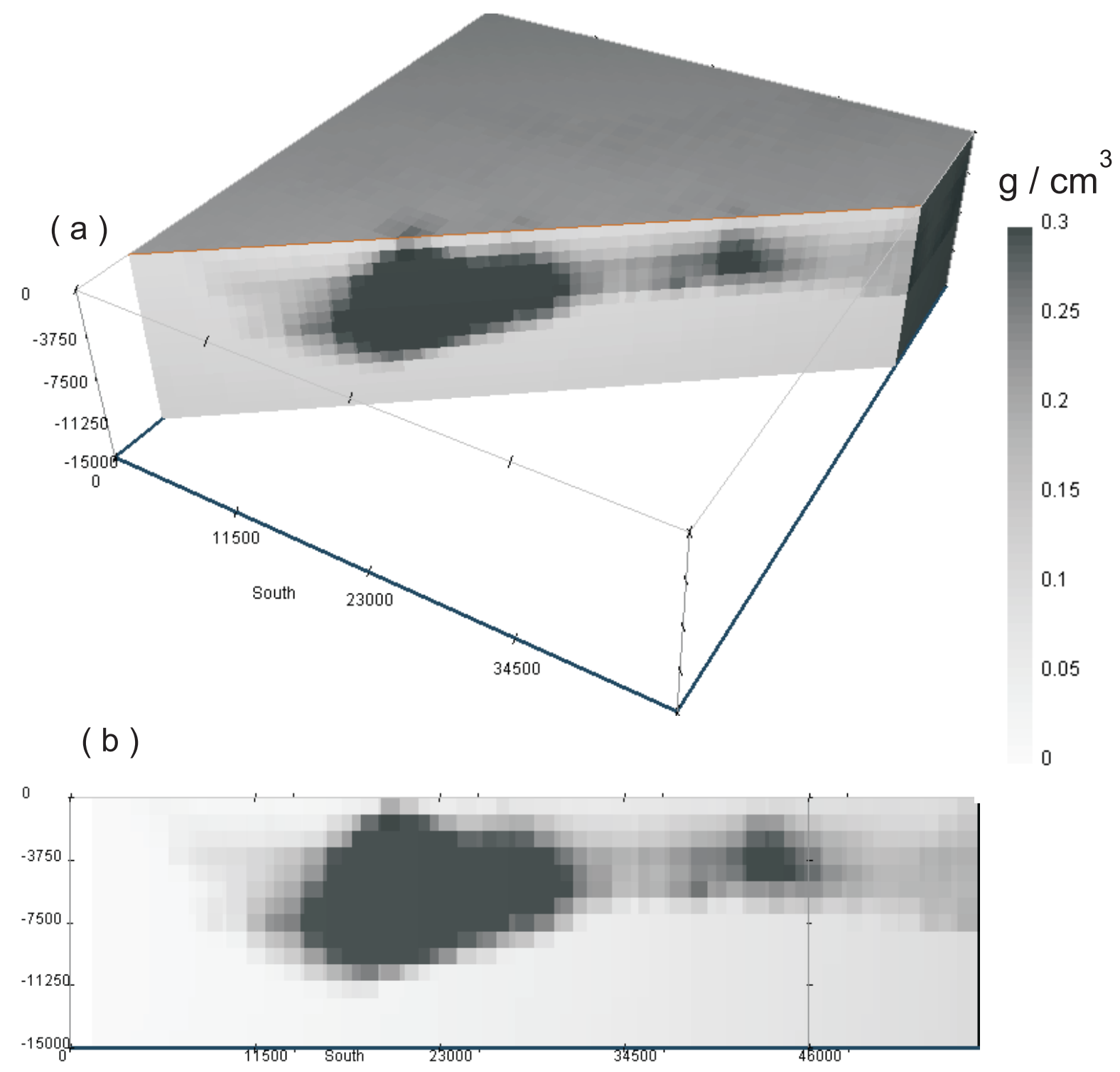

Figura 4.7: Modelo da distribuição de contraste de densidade em subsuperfície obtido pela inversão de dados gravimétricos com $\Delta \rho_{\text {min }}=0,0 \mathrm{~g} / \mathrm{cm}^{3}$ e $\Delta \rho_{\max }=0,3 \mathrm{~g} / \mathrm{cm}^{3}$. O corte feito em (a) serve para mostrar como os dois corpos estão disposto em profundidade, melhor apresentado em (b).

do campo magnético produzido pela magnetização induzida.

Os programas de inversão de dados magnéticos em geral assumem que não há magnetização remanescente $\left(M_{R}\right)$ e que os dados magnéticos são produzidos unicamente pela magnetização induzida $\left(M_{i}\right)$. Apesar da restrinção imposta pelo algoritmo de inversão quanto à existência de magnetização remanescente procurou-se estratégias para aproveitar 


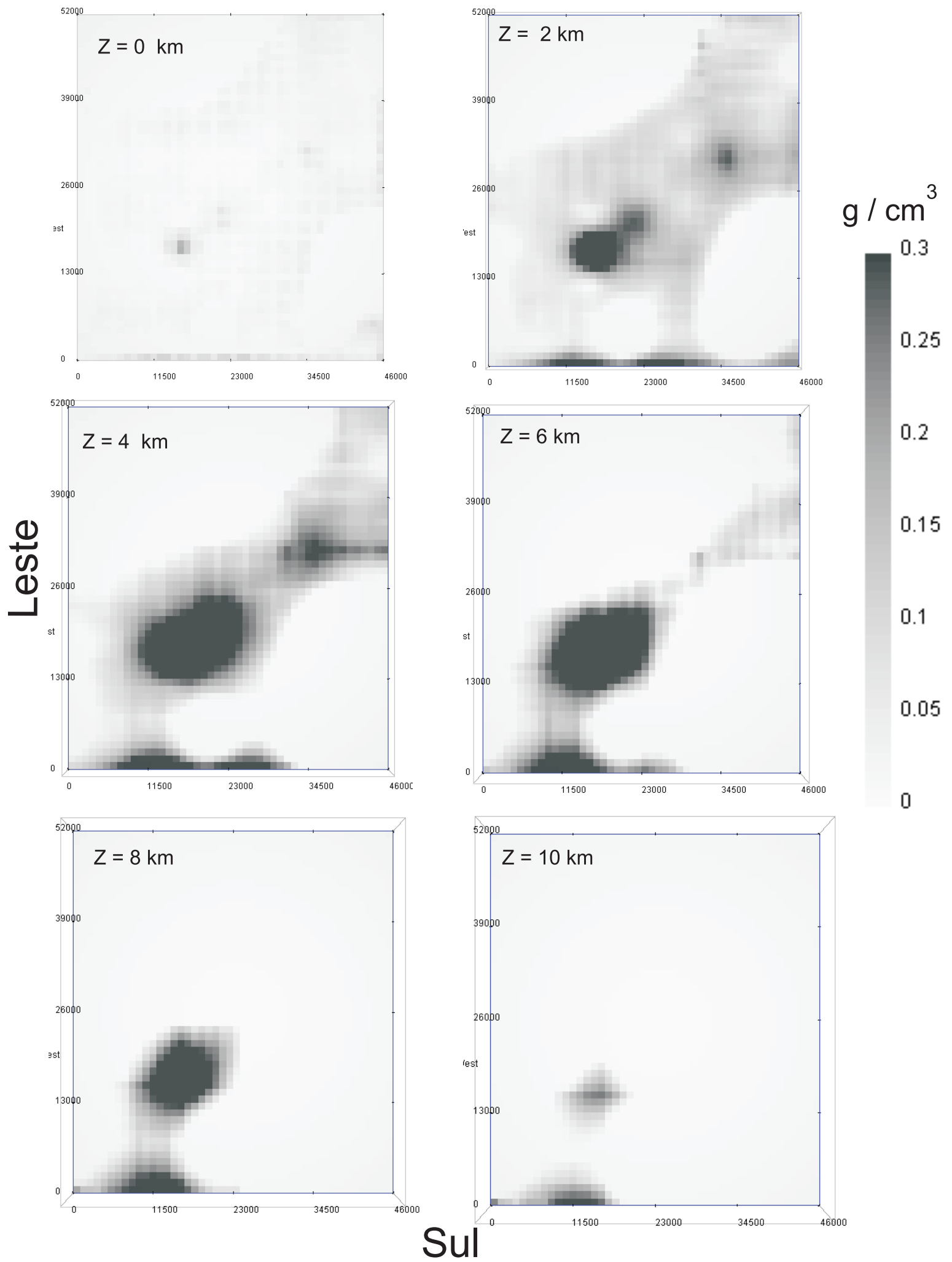

Figura 4.8: Modelo de contraste de densidade obtido pela inversão de dados gravimétricos, com a profundidade de cada seção. 

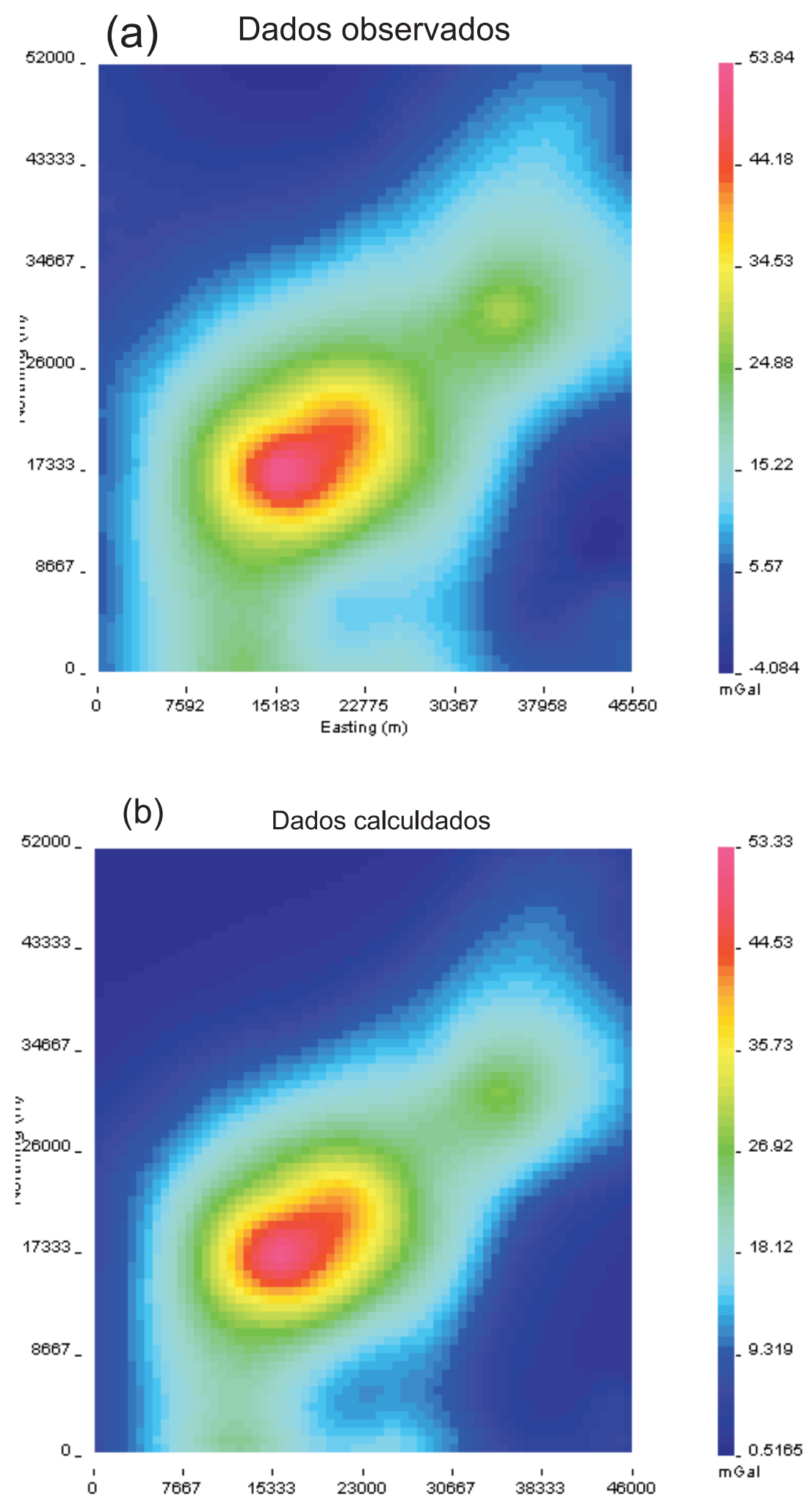

Figura 4.9: Valores do (a) campo gravimétrico anômalo observado comparados aos (b) dados calculdados de forma direta a partir do modelo de distribuição de contraste de densidade obtido. 


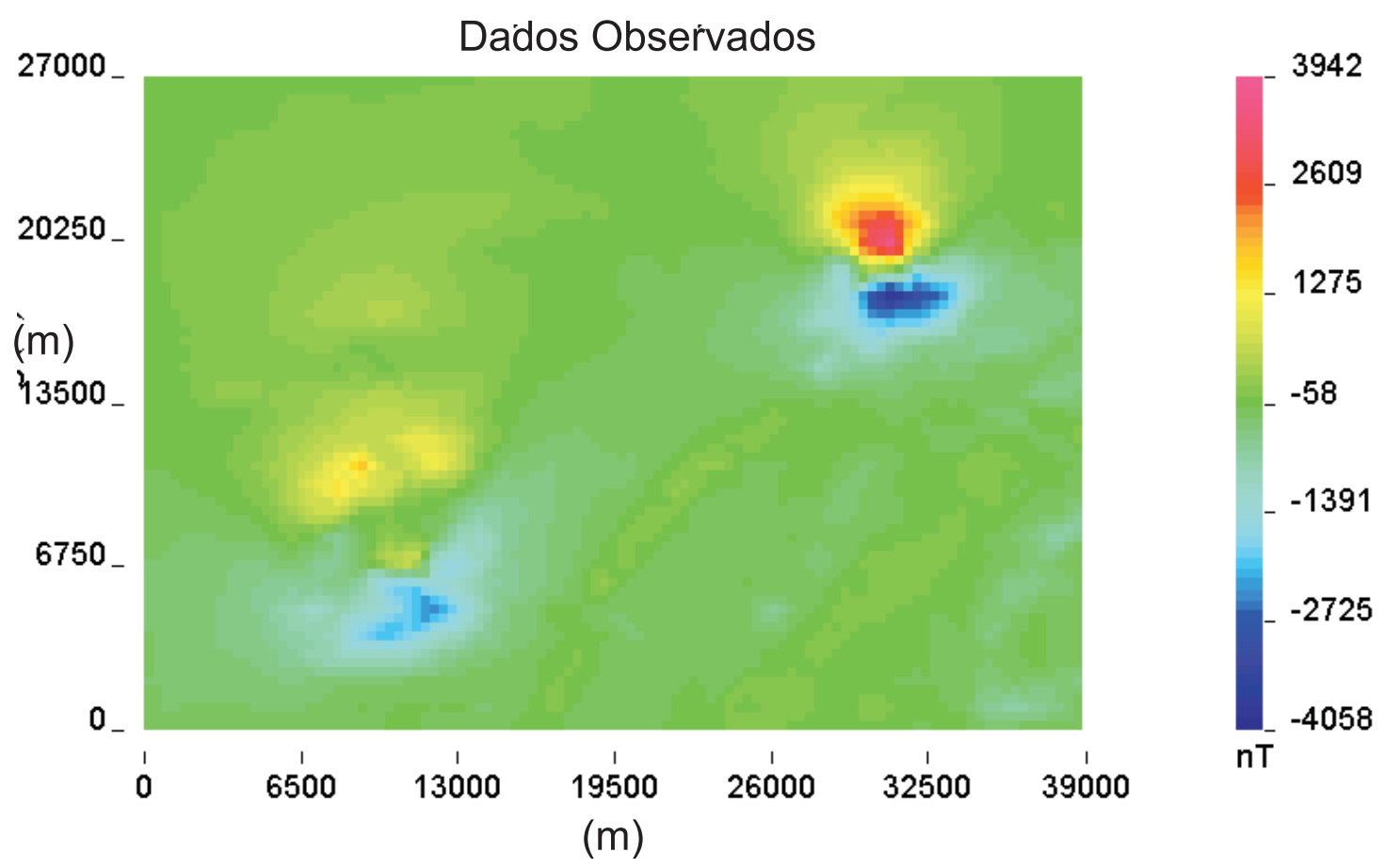

Figura 4.10: Campo magnético residual observado.

os dados magnéticos e realizar a inversão.

Para obter a distribuição de susceptibilidade através da inversão de dados do campo magnético anômalo foi considerado a magnetização induzida ( $\mathrm{I}=-9.5^{\circ}$ e $\left.\mathrm{D}=-13^{\circ}\right)$ somada a magnetização remanescente $\left(I_{R}=-43^{\circ}\right.$ e $\left.D_{R}=-14^{\circ}\right)$, o valor de $\vec{B}$ utilizado como campo induzido foi obtido a partir da relação 2.6. O modelo de distribuição de susceptibilidade em subsuperfície obtido nesta segunda inversão está apresentado na figura 4.11(b).

A partir do modelo obtido com a segunda inversão também foi calculado o campo magnético (figura 4.13 (b)). Os valores do campo magnético anômalo calculados comparados aos dados observados ficam próximos aos dados reais, representando a contribuição do campo magnético produzido pela magnetização remanescente mais magnetização induzida.

A aplicação desta técnica de inversão aos dados magnéticos produziu modelos de sus- 

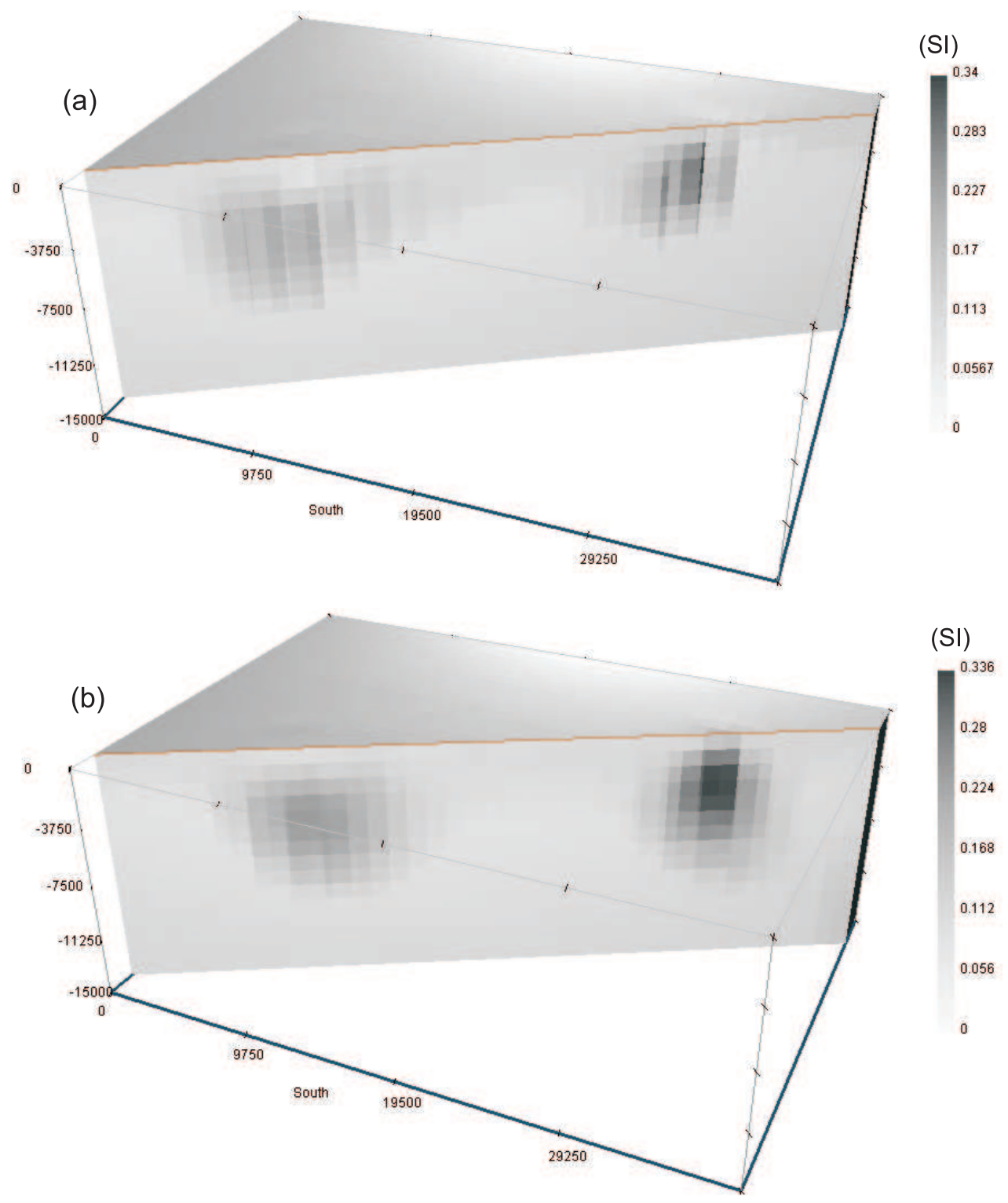

Figura 4.11: Susceptibilidade recuperada pela inversão da anomalia magnética de campo total: (a) adotando apenas a magnetização induzida e (b) magnetização induzida mais remanescente

ceptibilidade magnética representativos das estruturas do modelo inicial. A profundidade máxima atingida pela distribuição de susceptibilidade do modelo ficou entre 8 e $9 \mathrm{~km}$ para ME e a espessura para A2 de aproximadamente $7 \mathrm{~km}$, como pode ser viso na figura 4.12. A forte magnetização remanescente influencia a forma da anomalia magnética e faz com que os dados do campo anômalo tenham valores elevados. 


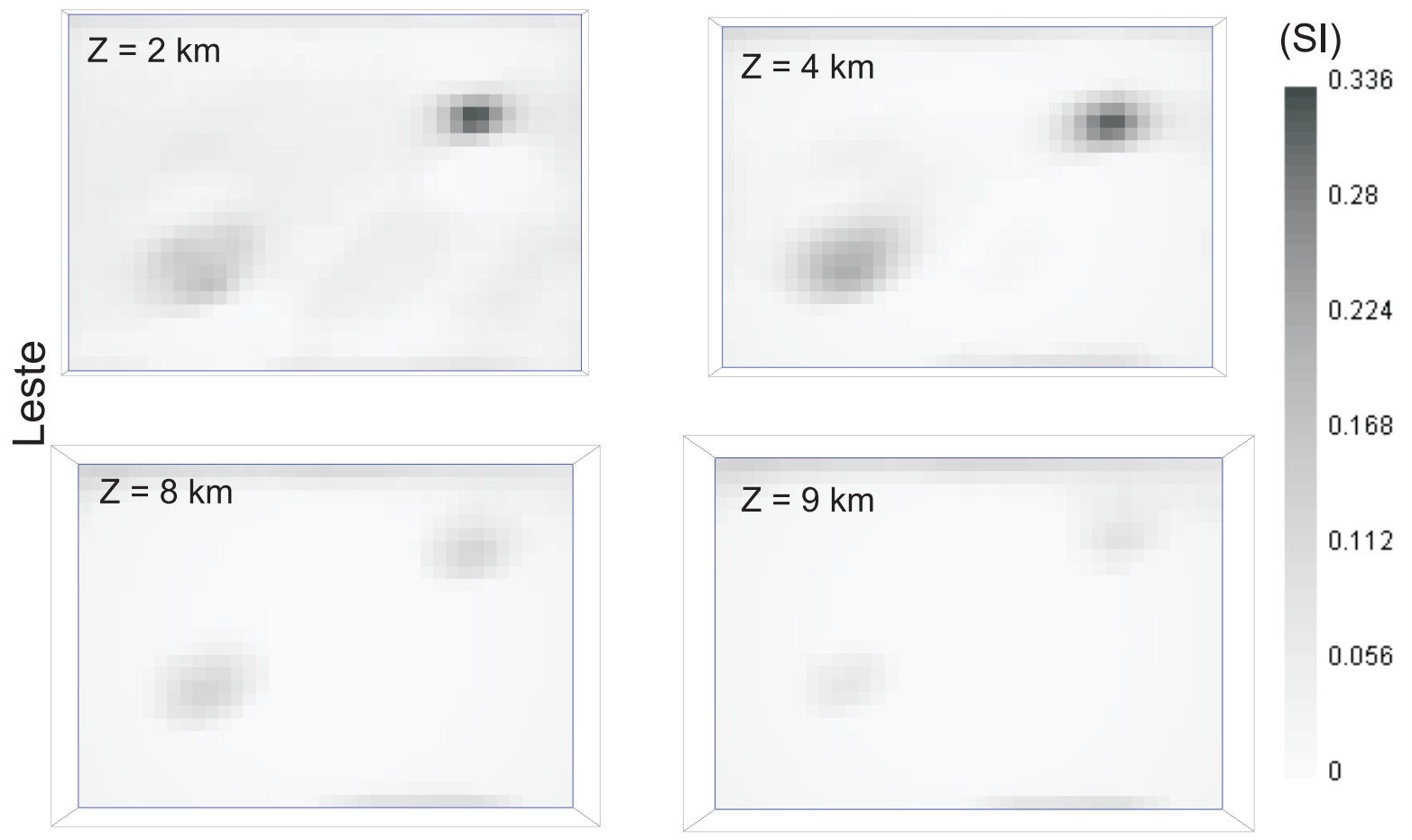

Sul

Figura 4.12: Modelo de susceptibilidade obtido pela inversão de dados magnéticos considerando a magnetização remanescente mais induzida, com a profundidade de cada seção.

Os valores de susceptibilidade obtidos pelas duas inversões é uma ordem de grandeza maior que os medidos e usados no modelamento direto. As amostras mostraram ser fortemente alteradas o que pode ter influenciado as medidas dos parâmetros físicos. Resultados de inversão apresentados por Li and Oldenburg (1996); Li et al. (2004) com valores mais baixos de susceptibilidade da ordem de 0,05 (SI) resultam em anomalias da ordem de 500 nT, sete a oito vezes menores do que as anomalias encontradas na região. O modelamento direto pode usar este valor mais baixo de susceptibilidade em função da introdução da intensidade da magnetização remanescente. 


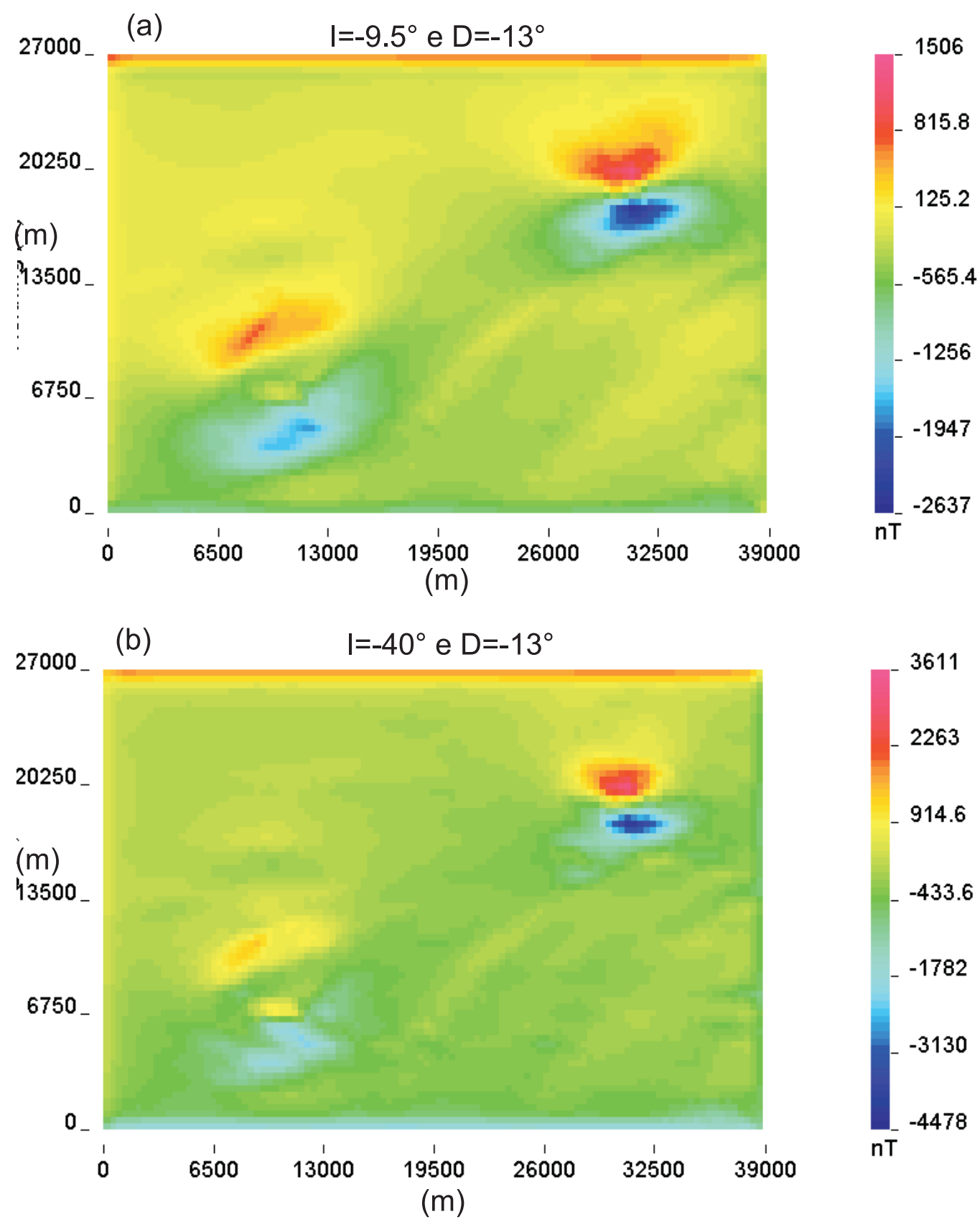

Figura 4.13: Campo magnético calculado para o modelo de distribuição de susceptibilidade obtido pela inversão dos dados magnéticos: (a) adotando apenas a magnetização induzida e (b) magnetização induzida mais remanescente. 


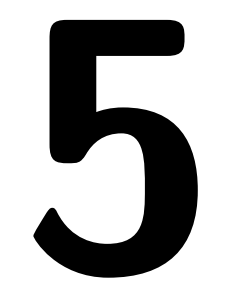

\section{CONCLUSÕES}

Os resultados da presente pesquisa mostram que a integração dos dados aeromagnéticos e gravimétricos e sua análise em conjunto com a geologia de superfície promoveu um conhecimento consistente da estrutura da região da alcalina Morro do Engenho e da intrusão com característica alcalina que produz a anomalia magnética A2, localizadas no norte da Província Rio Verde - Iporá, situada no sudoeste de Goiás próximo à cidade de Britânia.

O sinal aeromagnético parece ser gerado por corpos de geometria cilíndrica vertical e o pico da função sinal analítico que limita as bordas do corpo sugere um diâmetro em ME de $10 \mathrm{~km}$ e para A2 de $8 \mathrm{~km}$, aproximadamente. O método de meia largura foi aplicado para definição do topo da fonte, estimando-a em torno de $3 \mathrm{~km}$ para A2. Para a estimativa da profundidade das fontes obteve-se o valor de $10 \mathrm{~km}$. Estes valores puderam ser usados no modelamento direto. O modelo obtido com o modelamento direto é consistente com a descrição geológica encontrada na literatura. No modelamento conjunto 2,5D de ME, o corpo geométrico apresenta-se com distribuição de densidade homogênea e uma mudança do centro para as bordas em sua distribuição de susceptibilidade magnética. 
A técnica de inversão 2D empregada permitiu o cálculo de parâmetros tais como largura e espessura para o corpo de ME que possui geometria simples e topo conhecido. Os resultados da inversão indicaram corpos gravimétricos com diâmetro de 10 a 12 km, e espessura entre 8 e $10 \mathrm{~km}$ para ME e $6 \mathrm{~km}$ para A2 em função da variação do contraste de densidade.

A aplicação da técnica de inversão 3D aos dados gravimétricos produziu um modelo de contraste de densidade representativo consistente com a geologia, recuperando o local onde ME aflora.

As amostras da região da província alcalina Rio Verde - Iporá contêm forte magnetização remanescente e a inversão de dados magnéticos necessita do conhecimento preciso da direção da magnetização remanescente que altera a direção da magnetização total. Aplicando o algoritimo de inversão 3D aos dados magnéticos utilizando a direção da magnetização total foi possível obter um modelo para distribuição de susceptibilidade em subsuperfície.

A recuperação das fontes interpretativas é satisfatória e ambos resultados das inversões apresentaram profundidade máxima atingida em torno de $10 \mathrm{~km}$ para ME e espessura de 6 a 7 km para A2, em função da distribuição do contraste de densidade ou susceptibilidade magnética dos modelos. O topo de A2 ficou entre 2 e $3 \mathrm{~km}$.

A aplicação dos métodos geofísicos a área pesquisada contribuiu para definir a forma geométrica das intrusões alcalinas ME e A2. A caracterização geofísica desses corpos assume importância em função da possibilidade de exploração de níquel na área. 


\section{6}

\section{REFERÊNCIAS BIBLIOGRÁFICAS}

Almeida, F., 1983. Relações tectônicas das rochas alcalinas mesozóicas da região meridional da plataforma sul-americana. Rev.Bras.Geoc. 13 (3), 139-158.

Barbosa, V. C. F., Silva, J. B. C., 1994. Generalized compact gravity inversion. Geophysics $59,57-68$.

Barbour, A. P., 1976. Geologia do maciço ultramáfico de Santa Fé, Goiás. Tese de livre docência, IG-USP, São Paulo.

Brasil, 1974. Mapa de interpretação magnética, Projeto Iporá, escala 1:250.000, prospec s.a. Tech. rep., Depto. Nac. Prod. Min.

Camargo, E., 1997. Desenvolvimento, implementação e teste de procedimentos geoestatísticos (krigagem) no sistema de processamento de informações georreferenciadas spring. Dissertação de mestrado, INPE-São José dos Campo.

Danni, J. C. M., 1994. Os picritos alcalinos da região de Iporá: implicações na gênese dos complexos do tipo central do sul de Goiás. Rev. Bras. Geoc. 24 (2), 112-119.

Deer, W. A., Howie, R. A., Zussman, J., 1992. An introduction to the rock-forming minerals, 2nd Edition. Logman Scientific \& Technical.

Ernesto, M., 1996. Determinação da curva de deriva polar aparente para o Mesozóico da América do Sul. Tese de livre docência, Instituto Astronômico e Geofísico, Universidade de São Paulo.

Fitton, J. G., Upton, B. G. J., 1987. Alkaline igneous rocks. Geological Society Special Publication (30), 29-52.

Geosoft, 1994. GEOSOFT- Magmap: 2D frequency domain processing. Geosoft Inc. Toron. 
Gibson, S., Thonson, R. N., Leonardos, O. H., Dickin, A. P., Mitchell, J. G., 1995. The late Cretaceous impact of the Trinidad mantle plume: evidence from large-volume, mafic, potassic magmatism in SE Brazil. J.Petrol. 36 (1), 189-229.

Gomes, C. B., Ruberti, E., Morbidelli, L., 1990. Carbonatite complexes from Brazil: a review. J. South Am. Earth Sci. 3 (1), 51-63.

GRAV3D, 2002. A program library for forward modelling and inversion of gravity data over 3D structures, version 2.0, 2002. Developed under the consortium research project Joint/Cooperative Inversion of Geophysical and Geological Data, UBC-Geophysical Inversion Facility, Department of Earth and Ocean Sciences, University of British Columbia, Vancouver, British Columbia.

Guillen, A., Menichetti, V., 1984. Gravity and magnetic inversion with minimization of a specific functional. Geophysics 49, 1354-1360.

Gunn, P. J., 1975. Linear transformation of gravity and magnetic fields. Geophys. Prosp. $23,300-312$.

Gunn, P. J., 1997. Qantitative methods for interpreting aeromagnetic data: a subjective review. Journal of Australian Geology and Geophysics 17 (2), 105-113.

Isaaks, E. H., Srivastava, R. M., 1989. An introduction to applied geostatistcs. New York: Oxford University Press, 561p.

Junqueira-Brod, T. C., Roig, H. L., Gaspar, J. C., Brod, J. A., Meneses, P. R., 2002. A província alcalina de Goiás e a extensão do seu vulcanismo kamafugítico. Rev. Bras. de Geoc. 32 (4), 559-566.

Last, B. J., Kubic, K., 1983. Compact gravity inversion. Geophysics 48, 713-721.

Li, Y., Oldenburg, D. W., 1996. 3d inversion of magnetic data. Geophys. 61, 394-408.

Li, Y., Oldenburg, D. W., 1998. 3d inversion of gravity data. Geophys. 63, 109-119.

Li, Y., Oldenburg, D. W., 2003. Fast inversion of large-scale magnetic data using wavelet transforms and a logarithmic barrier method. Geophysics 152, 251-265.

Li, Y., Shearer, S., Haney, M., Dannemiller, N., 2004. Comprehensive approaches to the inversion of magnetic data with stong remenent magnetization. $74^{\text {th }}$ Ann. Internat. Mtg., Soc. Expl. Gophys. Expanded Abstracts.

Lowrie, W., 1997. Fundamentals of Geophysics. Cambridge University Press, cap. 2.

MacKenzie, W. S., Guilford, C., 1980. Atlas of rock-forming minerals in thin section. London; New York : Longman.

MAG3D, 2002. A program library for forward modelling and inversion of magnetic data over 3D structures, version 3.1, 2002. Developed under the consortium research project Joint/Cooperative Inversion of Geophysical and Geological Data, UBC-Geophysical Inversion Facility, Department of Earth and Ocean Sciences, University of British Columbia, Vancouver, British Columbia. 
Milligan, P. R., Gunn, P. J., 1997. Enhancement and presentation of airborne geophysical data. Journal of Australian Geology and Geophysics 17 (2), 63-75.

Morbidelli, L., Gomes, C. B., Beccaluva, L., Brotzu, P., Conte, A. M., Ruberti, E., Traversa, G., 1995. Mineralogical, petrological and geochemical aspects of alkaline and alkaline-carbonatite associations from Brazil. Earth Sci. Rev. 39, 135-168.

Nabighian, M. N., 1972. The analitic signal of two dimensional magnetic bodies with poligonal cross-section: It's properties and use for automated anomaly interpretation. Geophysics 37, 507-517.

Parker, R. L., 1991. Geolphysical inverse theory. Princeton University Press, USA.

Pedley, R. C., Busby, J., Dabek, Z. K., 1993. Gravmag user manual - interactive 2.5d gravity \& magnetic modelling. Tecnical report wk/93/26/r, Britsh Geological Survey, 73.

Radaelli, V. A., 2000. Programa Levantamentos Geológicos Básicos do Brasil. Geologia e Recursos Minerais do Estado de Goiás e do Distrito Federal. informe de recursos minerais, níquel do Morro do Engenho - Estado de Goiás-Goiânia. Tech. rep., CPRM, $1 \mathrm{v} ; \mathrm{il} ;$, 10p.

Rasmussem, R. J., Pederson, L., 1979. End corrections in potencial field modeling. Geophysical Prospecting 27, 749-760.

Reid, A. B., Allsop, J. M., Granser, H., Millett, A. J., Somerton, I. W., 1990. Magnetic interpretation in three dimensions using Euler deconvolution. Geophysics 55, 80-91.

Rodrigues, B. J., Gioia, S. M. L. C., Pimentel, M. M., 1999. Geocronologia e geoquímica de ortognaisses da região norte entre iporá e firminópolis: Implicações para a evolução do arco magmático de Goiás. Rev. Bras. de Geoc. 29 (2), 207-216.

Sá, N. C., 2002. Redução de observações gravimétricas, teoria e prática. IAG/USP, Departamento de Geofísica, Universidade de São Paulo.

Shearer, S., Li, Y., 2004. 3d inversion of magnetic total gradiente data in the presence of remanent magnetization. $74^{\text {th }}$ Ann. Internat. Mtg., Soc. Expl. Gophys. Expanded Abstracts.

Silva, J. B. C., Barbosa, V. C. F., 2006. Interactive gravity inversion. Geophysics 71 (1), P.J1-J9.

Strieder, A. J., 1992. Serpentinização e metassomatismo em rochas ultramáficas: discussão das características e recomendações para o tratamento geoquímico. Rev. Bras. Geoc. $22(3), 329-337$.

Surfer, 1999. Golden Software Surfer version 7.00. Surface mapping system.

Talwani, M., Worzel, J. L., Landisman, M., 1959. Rapid gravity computations for two dimensional bodies with application to the Mendoncino submarine fracture zonel. J. Geophys. Res. 64, 49-59. 
Telford, W. M., Geldart, L. P., Sheriff, R. E., Keys, D. A., 1976. Applied geophysics, 2nd Edition. Cambridge University Press, USA.

Thompson, D. T., 1982. A new technique for making computer-assisted depth estimates from magnetic data. Geophysics 47, 31-37. 